\title{
Legitimation in corporate discourse: The case of Enbridge and the Northern Gateway Pipeline
}

by

Alicia Massie

A thesis submitted to the Faculty of Graduate and Postdoctoral Affairs in partial fulfillment of the requirements for the degree of

Master of Arts

in

Applied Linguistics and Discourse Studies

Carleton University

Ottawa, Ontario

(C) 2016, Alicia Massie 


\begin{abstract}
Despite interest in the genres of corporate discourse, and recognition of the role of corporations in shaping social knowledge and 'reality', critical discourse analysts have infrequently focused on investigating how corporate actors employ discursive strategies to represent and legitimate their activities. Widely studied in other disciplines such as political science, philosophy and law, legitimation is a necessary field of inquiry for critical discourse studies as it is through this discursive practice that corporations employ ideological arguments to influence and manipulate public knowledge and opinion. This thesis is a qualitative critical discourse and multimodal analysis of the oil corporation Enbridge's "Gateway Facts" website - an online discourse created to offer information to the public regarding their new Northern Gateway Pipeline project proposed in western Canada. An extremely controversial project among the Canadian public largely due to its potentially devastating environmental impacts, Enbridge, like other oil corporations worldwide, has been forced to devote large amounts of time and energy to justify and promote this pipeline. This results of this study argue that a close analysis of the website's discursive strategies reveals the appropriation of four discursive themes to rationalize, justify and legitimate the NGP: economic development, scientific and technical expertise, environmental stewardship, and industry leadership. These findings suggest that this type of corporate legitimation may be a reflection of the broader ideology of late capitalism's struggle to justify controversial practices at a time when environmental protection is a priority and public attitudes and understandings of corporate responsibility are shifting. This thesis underscores the importance of critical studies of corporate discourse, especially that offered online, as it has the potential to highlight the ideological underpinnings of corporations and their actions.
\end{abstract}




\section{Acknowledgements}

It is with the deepest of thanks that I extend my gratitude to all the lovely and inspiring people that helped me arrive at the final product of this project. I am indebted and forever grateful to Dr. Jaffer Sheyholislami and Dr. Graham Smart, my brilliant and devoted thesis supervisors. There is no way to adequately put into words the formative influence they have had on my academic life, and this project would certainly not have come to fruition without their guiding hands. I must also extend my greatest thank you to my partner and friend Lisa Armstrong for her kind words, commiseration, and emotional support. I simply could not have done this without you.

This experience would not have been possible without the support of the incredible staff and faculty in the School of Linguistics and Language studies at Carleton. A new student to Carleton, each and every experience helped to bring me to my full potential, and show me what a kind, compassionate school I am so lucky to have been a part of. Through this school and program, I have learned what it is to be critical, to be modest, to be thoughtful and to be driven. 


\section{Table of Contents}

Abstract........................................................................................................................ ii

Acknowledgements .........................................................................................................................iii

Table of Contents ............................................................................................................................. v

List of Figures................................................................................................................................ $\mathrm{x}$

List of Appendices......................................................................................................................... xi

1 Chapter: Introduction ...................................................................................................... 12

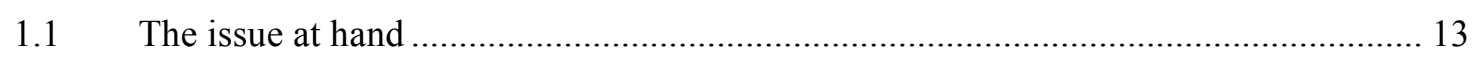

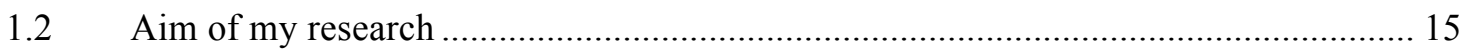

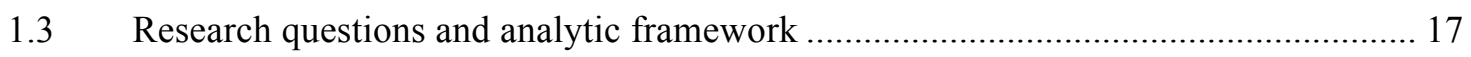

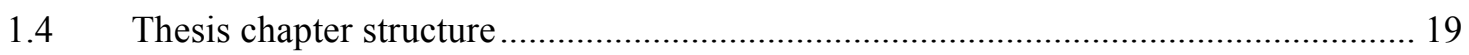

2 Chapter: Background on the Northern Gateway Pipeline ....................................... 22

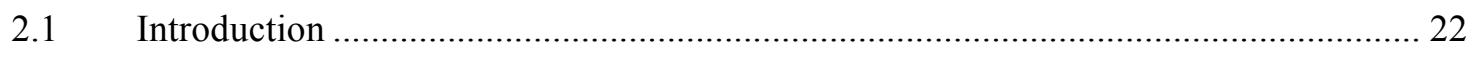



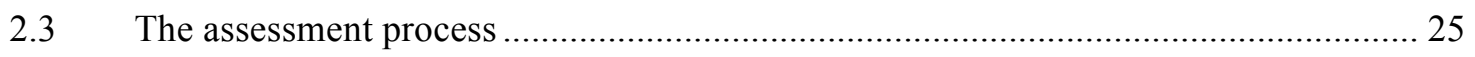

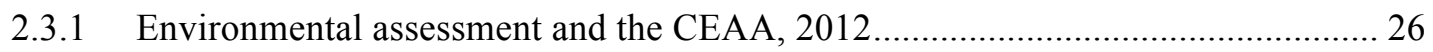



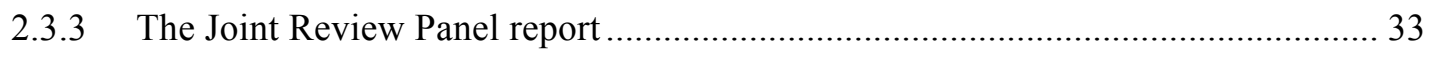

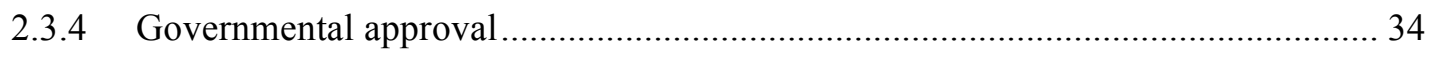

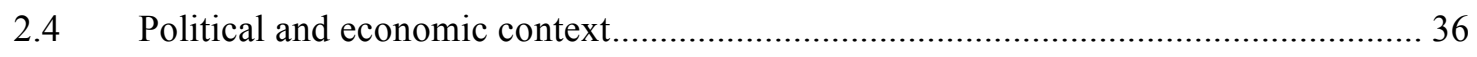

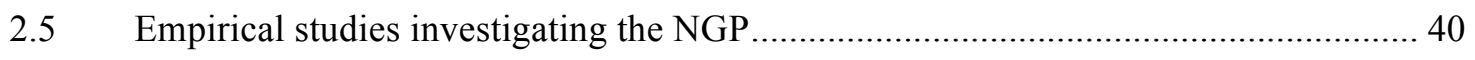

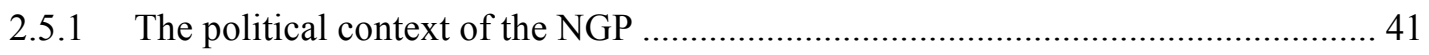

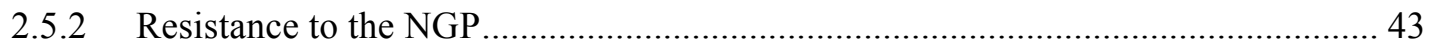

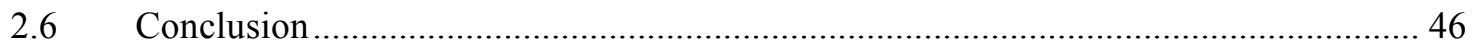

3 Chapter: Literature Review and Theoretical Framework....................................... 48 


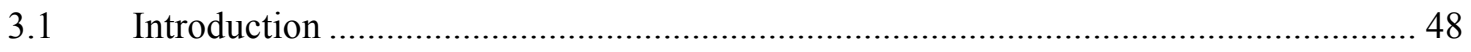

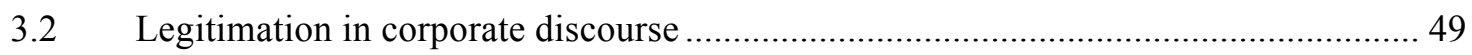

3.2.1 Legitimacy theory as an explanatory framework ............................................ 49

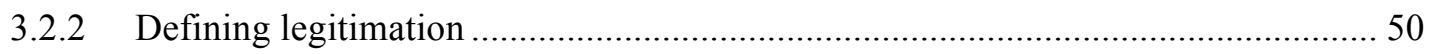



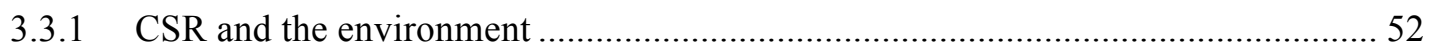

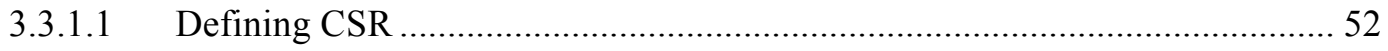

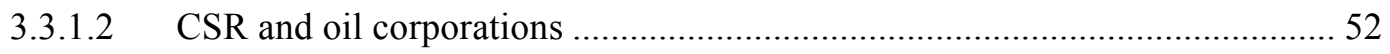

3.3.1.3 Oil corporations’ discursive CSR practices................................................ 53

Examples of legitimation in corporate discourse ................................................. 54

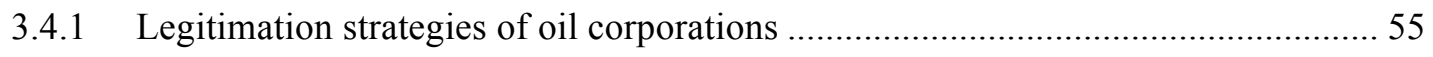

3.4.1.1 Eco-identities and the socially constructed nature of the environment........... 55

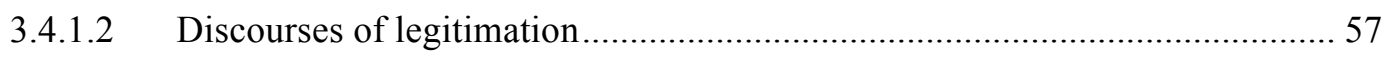

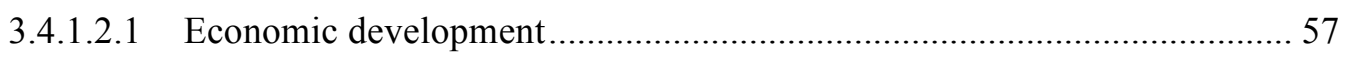

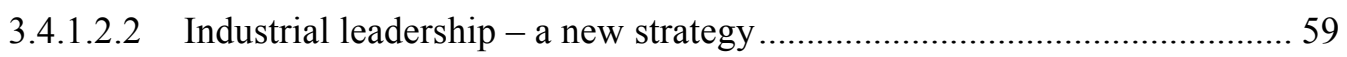

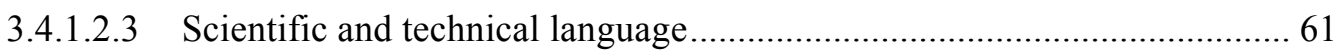

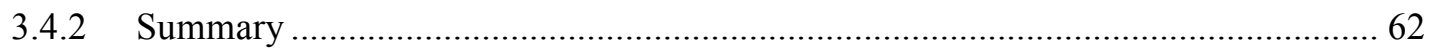

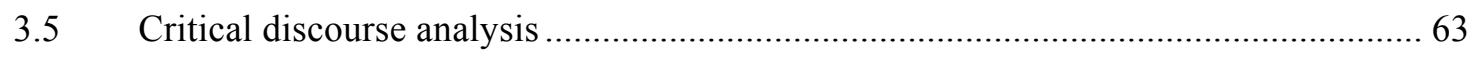

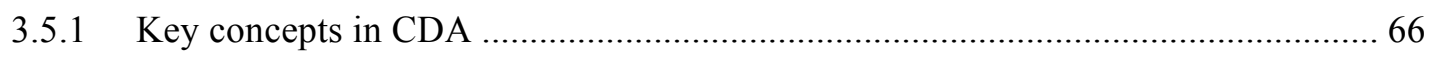

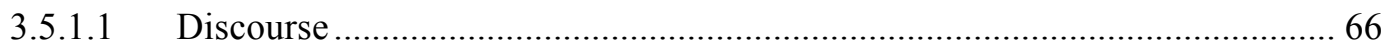

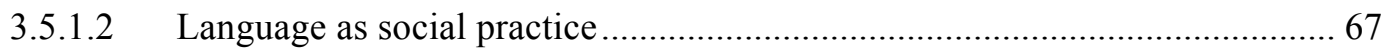

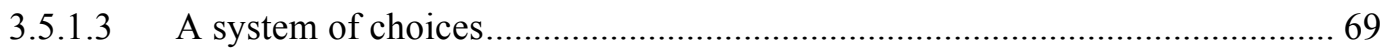

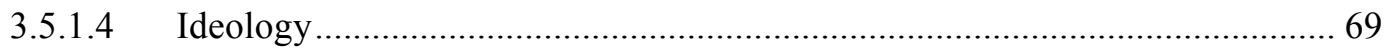

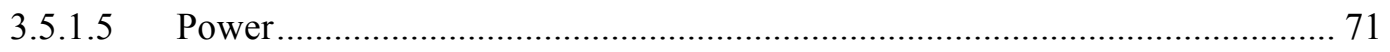

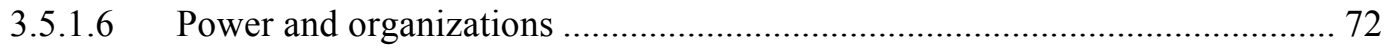

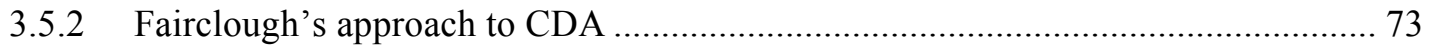




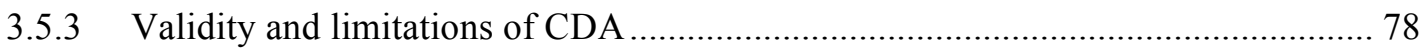

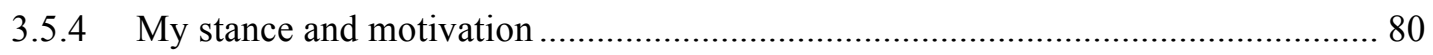

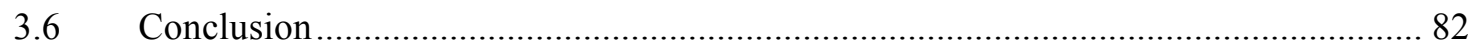

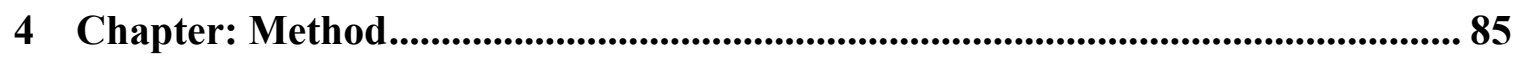

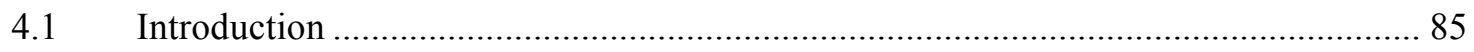

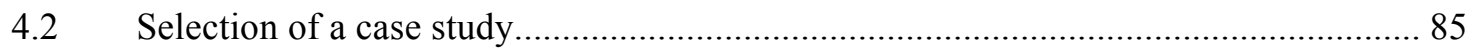

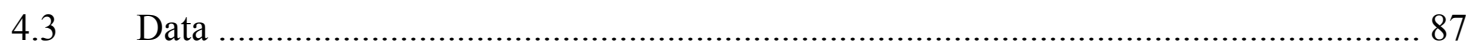

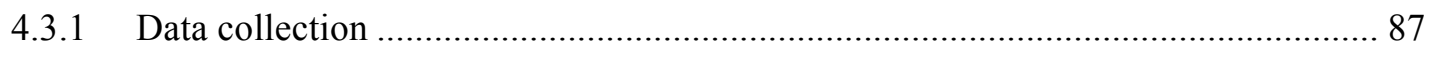

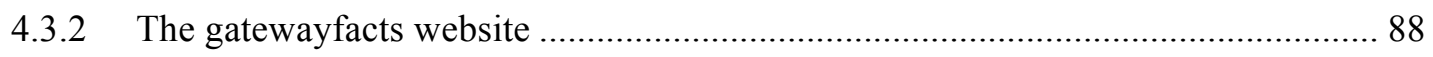

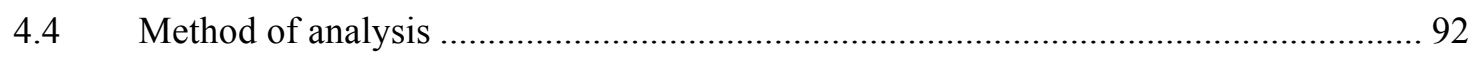

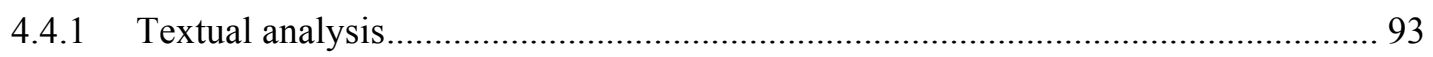

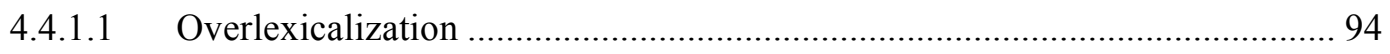

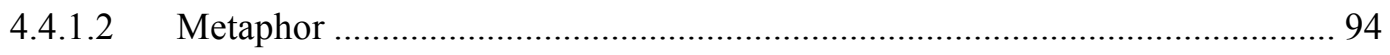

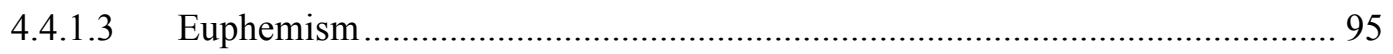

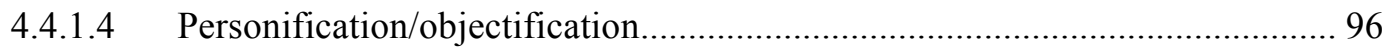

4.4.1.5 Lexical cohesion and structural opposition .............................................. 97

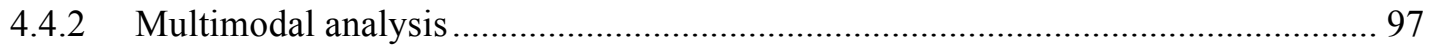

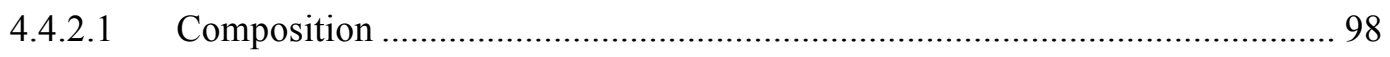

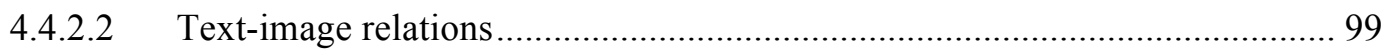

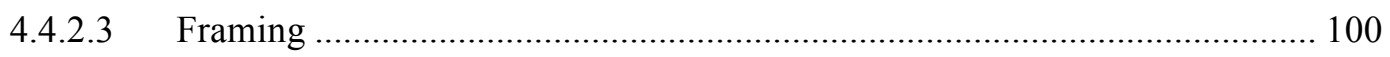

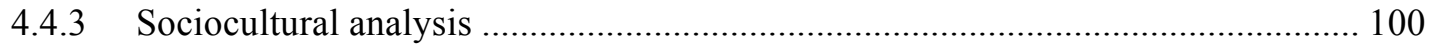

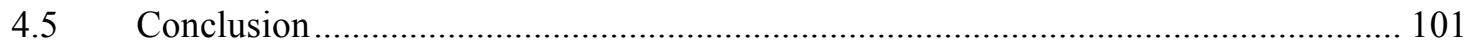

5 Chapter: Findings ................................................................................................ 102



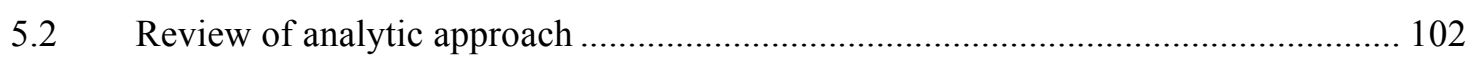

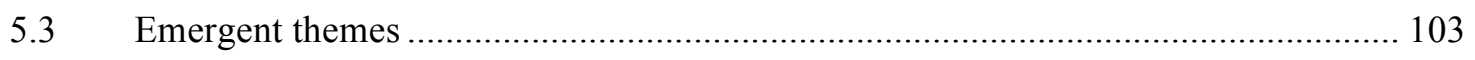

vii 


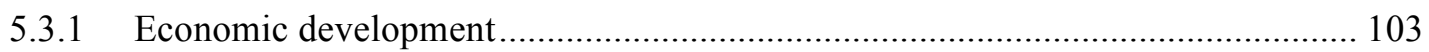

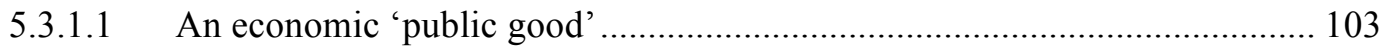





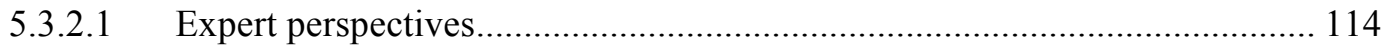



5.3.3.1 The design of the website - the use of greens and blues............................. 117

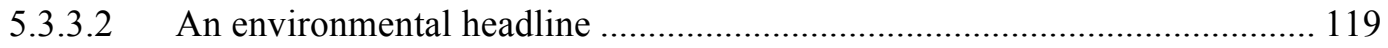

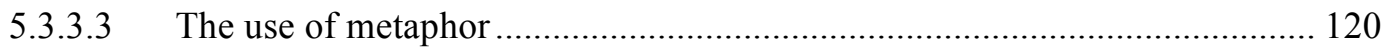

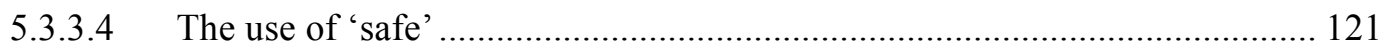

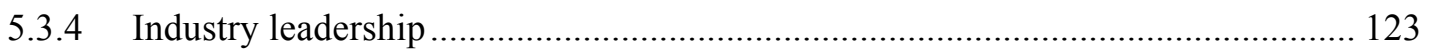

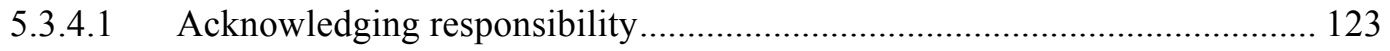

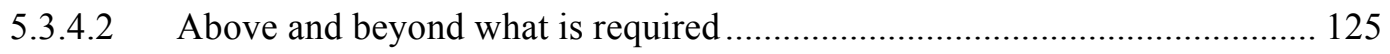

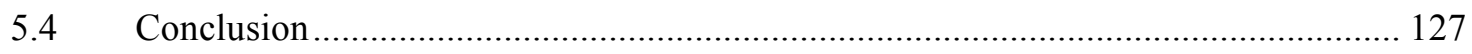

6 Chapter: Discussion ................................................................................................ 129

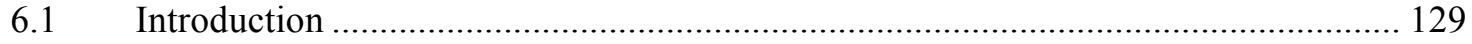



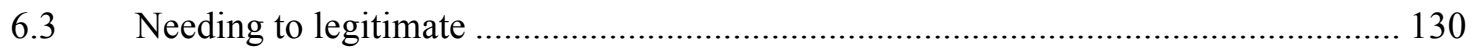

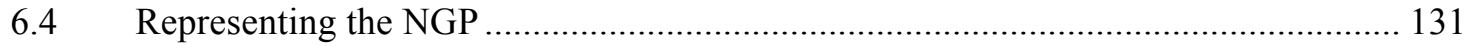

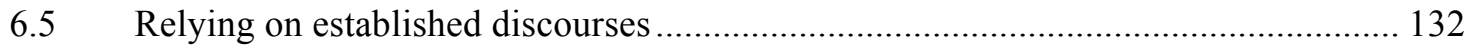

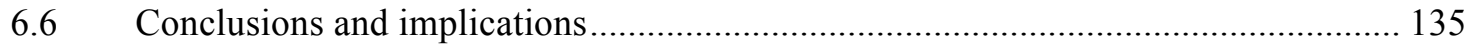

7 Chapter: Conclusion ........................................................................................................ 137

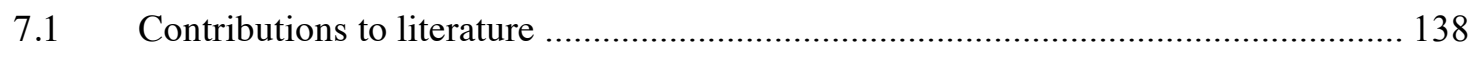

7.2 Limitations and directions for future research................................................. 140

Appendices.............................................................................................................................. 142 
Appendix A .



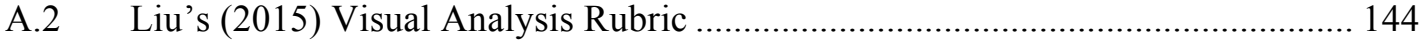

Appendix B

B.1 Expert Opinion Sections - Linked Texts …................................................... 145

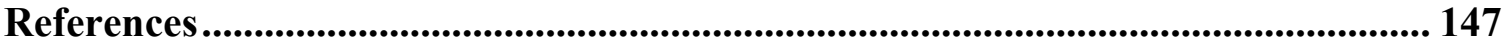




\section{List of Figures}

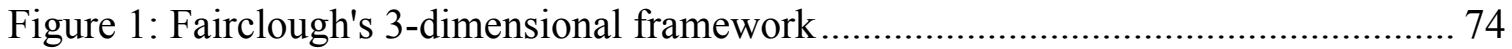

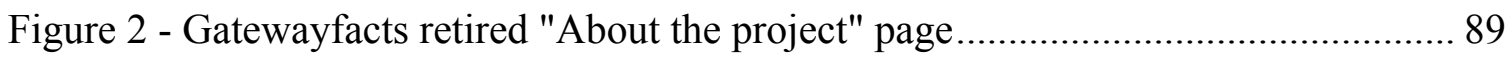

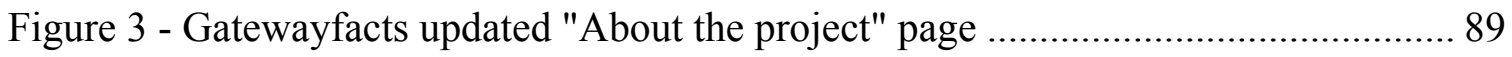

Figure 4: Gatewayfacts "Environmental responsibility: Land" page ............................. 91



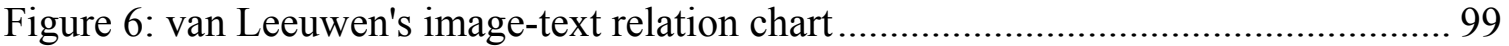

Figure 7: Gatewayfacts examples "Expert Perspectives" box .................................... 114

Figure 8: Gatewayfacts challenge and solution design.............................................. 124 


\section{List of Appendices}

Appendix A........................................................... 142

A.1 Janks' (2005) Linguistic Analysis Rubric...............................142

A.2 Liu's (2015) Visual Analysis Rubric....................................... 144

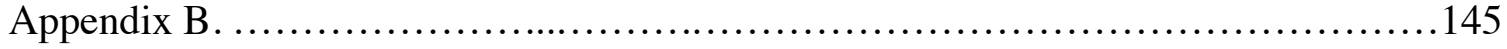

B.1 Expert Opinion Sections - Linked Texts...............................145 


\section{Chapter: Introduction}

With the goal of better understanding how corporations discursively legitimate themselves, their actions, and their projects, this thesis is dedicated to investigating how a corporate project website discursively constructs, and legitimates, a controversial project. An in depth exploration of one-case, the Canadian controversial Northern Gateway Pipeline, this study is situated in the existing body of literature that investigates corporations' discursive practices. This thesis follows the view that discourse is not merely a reflection of social reality, but is constitutive of it (Berger \& Luckmann, 1967; Fairclough, 1992). In the context of this study, this view of discourse - as an intimately important influence on and factor in the creation and maintenance of social reality - is applied to corporate discourse to highlight the significant role corporate language can have in the construction of knowledge and 'reality'. Additionally, a discourse analysis approach reminds us that corporations, as social constructions, are themselves products of discursive creation - they are built up, shaped and propagated by the words we use to describe them and the words they use themselves (Aritz \& Walker, 2012). In everything corporations do, but especially their choices of language, we can see reflections of "social situations, social processes, social relationships, and social roles, which embody language, ideology, and power" (Fox \& Fox, 2004, p. 9). Thus, in analyzing the discourse of institutions, we may seek to gain an understanding of organizational structure, order, and understanding and hope to open a window into the ideologies that shape that particular corporation. Demonstrating the ideological nature of corporate discourse through a critical discourse analysis and multimodal discourse analysis, this study hopes 
to shed light on legitimation in corporate discourse and the relatively new genre of corporate websites.

In what follows I will briefly introduce the social issue that motivated this study. I will then offer an overview of the body of literature in which my research is situated and from which this study orients itself. I will overview my analytical framework and research questions, and finally present a summary of the chapters contained in this thesis.

\subsection{The issue at hand}

Corporations are one of the pillars upon which our modern economies are founded (Breeze, 2013). In the $21^{\text {st }}$ century, they constitute a majority of the world's largest economic entities, even often surpassing countries in economic status. Given their role in the global economy, and our intimate involvement with them - as consumers, employees, clients, shareholders, etc. - it seems obvious and necessary that we should be interested in their actions, words, and beliefs. To understand these actions, words, and beliefs, we must look into the notion of ideology: the basic principles of a group's beliefs, and those principles which "allow people, as group members, to organize the multitude of social beliefs about what is the case, good or bad, right or wrong, for them, and to act accordingly" (van Dijk, 2000, p. 8; emphasis in original). Ideologies, for their part, are enacted through discourse (van Dijk, 2006) and text (Thompson \& Hunston, 2000). Discursive analysis of corporations can offer a window into how the members of a group understand, communicate and organize the world around them. A unique insight into the complex web of beliefs, relationships, interests and values of modern corporations, discourse analysis can show "how language is being used to inform, persuade or manipulate in the ongoing creation, maintenance and reshaping of social roles and 
relations" (Breeze, 2012, p. 1). We know that corporations play powerful roles in modern society, in the economy and in our day-to-day lives. Discourse analysis allows us to understand from an ideological perspective just how these roles are enacted and how they influence our social reality.

With corporations' role in the global economy, and their intimate involvement in just about every aspect of our lives, critical linguistic inquiry into how corporations hold influence in spheres of environmental issues remains a vitally important area of study (Anderson, 2015; Hansen, 2015). Research highlights that it seems impossible in our day of "corporate globalization" to believe that humanity's complex relationship with the natural world is not mediated by corporate action (Alexander, 2009). This is concerning, since, as Fairclough (1989) describes that when ways of seeing, behaving and believing become part of common sense assumptions, they become naturalized and can then evolve into ideologies which are no longer questioned. The ways in which corporations are legitimating themselves and their actions thus require critical investigation. This is especially true in cases of controversial projects, where corporations are seeking to build social acceptance to continue their actions and industrial developments.

This thesis is focused on oil corporations, as they are often faced with serious public dissent, and since, in recent decades, many of their development projects are extremely controversial. Consequently, the oil industry is faced with a crucial need to legitimate itself and its projects (Breeze, 2012). Legitimation, achieved through discourse, is one of the ways in which oil corporations can attempt to build public trust, soothe concerns, and generally present a cleaner image to the public. Corporate discourse is a broad category, and can include anything from press releases to internal documents to 
websites. As I am interested in corporate legitimation however, I have chosen to focus on websites, as increasingly websites are seen as a critical development in how companies can offer information to the public, and are a particularly effective platform for conveying socially responsible information (Coupland, 2005; Guimarães-Costa \& Pina e Cunha, 2008).

\subsection{Aim of my research}

It is from this primary interest in corporate legitimation that this study takes its concern with the corporate public website of Enbridge, a Canadian oil and gas corporation, relating to their pipeline project, entitled the 'Northern Gateway Pipeline'. This choice of data - an online, multimodal discursive event - is highly relevant in today's communication context, which Chouliaraki and Fairclough, following Giddens, describe as 'late modernity' (Giddens, 1990, as cited in Chouliaraki \& Fairclough, 1999). Late modernity is characterized by the overwhelming onset of online media and information technology in parallel to (and some would argue in replacement of) traditional media such as print media, radio, and television. This new age of communication presents particular interest to language researchers, as this 'new media' has become an extremely important and influential source of information (Ross, 2008). However, as Mautner (2005) points out, online media, while a relevant and important domain, has been a relatively infrequent focus of critical discourse analysis research, and while this trend is certainly changing, online discourse still presents a particularly fruitful area for study.

Outside of critical discourse studies, research that has investigated corporate discourse suggests the importance of corporate websites in the formation and promotion of a corporate identity and image (Breeze, 2012; Winter, Saunders \& Hart, 2003; Pollach, 
2005; Heinze \& Hu, 2006). As just described, corporate websites are also increasingly being seen as important sites for conveying information about the company, and in particular, information about a corporation's corporate social responsibility - that is, actions taken not primarily for profit, but for the benefit of stakeholders.

While websites are increasingly being recognized as important phenomena within corporate discourse, studies frequently fail to comment on the discursive construction of these websites, or on their role in knowledge creation, social roles, and power and influence. Research that has investigated corporate discourse more broadly suggests that corporations frequently use direct forms of communication - those messages which reach the public directly - to participate in legitimatory activities; those activities which Breeze (2012) describes as "not precisely advertising, but [intending] to generate a positive evaluation and public image, combining classic promotional elements (self-praise, positive connotations) with aspects of explanation and self-defense designed to pre-empt or defuse criticism on concrete issues" (p. 5). Legitimation, as a discursive strategy, is one of the essential ways in which ideologies function through discourse (van Dijk, 1998; van Leeuwen, 2008; Breeze, 2012). van Dijk (1998) notes that although widely studied in the domains of philosophy, law, and social and political science, legitimation remains under-investigated in the field of discourse studies. In the present study, therefore, I seek to demonstrate how websites can be examples of corporate legitimation, and can thus offer a window into corporate ideology.

In the context of this study, legitimation in publically communicated corporate discourse is aligned with the notion of corporate social responsibility. Previous studies indicate that in the $21^{\text {st }}$ century corporations are under pressure to move their discourse 
away from a single focus of economic development towards also incorporating an interest of environmental responsibility and good will (Scherer \& Palazzo, 2007). This has been particularly true for corporations in the oil and gas sector, arguably partly due to the highly visible and frequently reported negative environmental impacts of such sectors' activities (Livesey, 2001; Frynas, 2009). Often described in organizational and business literature as an element of corporate social responsibility (Joustenvirta, 2011), this accountability to environmental concern is often most visible in discursive attempts "to legitimize or delegitimize contested issues, persuade other actors, and negotiate over (new) meanings for corporate responsibilities" (Joustenvirta, 2011, p. 58). These discursive legitimation efforts, as described earlier, are often constituted in publically communicated corporate, such as corporate sustainability reports (Hahn \& Lülfs, 2014), or as in the case of this study - websites.

\subsection{Research questions and analytic framework}

The main goal of this study is to investigate how the gatewayfacts website discursively represents the NGP project in order to gain insight into how corporate discourse legitimates controversial projects. To this end, I have devised the following research questions to guide my project:

1. How does the "Gateway Facts" website discursively represent (i.e., construct, construe, allude to) the Northern Gateway Pipeline project?

2. In what ways do the different discursive representations serve to frame, treat and construct a legitimation (i.e. justification, rationalization) of the project?

In order to answer these research questions this project relies primarily on the interdisciplinary research programme of critical discourse analysis (CDA), a research 
orientation which, as Fairclough and Wodak (1997) emphasize, "sees itself not as dispassionate and objective social science, but as engaged and committed. It is a form of intervention in social practice and social relationships" (p. 258). Thus while these questions have been formulated as a relatively neutral starting point, they guide a study in which I take a critical stance towards the presentation of the controversial and environmental issues in corporate discourse, seeking to understand the connection between discourse and ideology. It is important to note that CDA does not see a deep commitment to one's research as incongruous with valid inquiry. Rather, committed researchers must simply take great strides to be transparent and self-reflexive (Wodak, 2001a). Throughout this thesis, I strive to make my choices and motivations clear, and at all times have sought to remain critical, while maintaining an appreciation for the scope and limitations of my work.

As this project is an investigation into online discourse, it relies on both critical discourse analysis (Fairclough, 1995b) and multimodal discourse analysis (Kress \& van Leeuwen, 1996/2006). There is a growing understanding among linguistic and communication scholars that meaning is conveyed not only through spoken and written language, but also through that which is visual (Machin \& Mayr, 2012). Many texts, especially those in our age of the internet, communicate through visual features in addition to text. Websites are critical developments for discourse studies in that they are a massive repository of data about modern ways of communicating, thinking and doing (Pauwels, 2012). However, it has taken some time for discourse studies and communication scholars to develop appropriate methods for the analysis of these forms of text, as they present several challenges to established, more verbally oriented methods 
of analysis (Pauwels, 2012). Websites are not static texts, but rather can be seen as "sites of display” (Jewitt, 2006; Jones, 2009). A 'site of display’ is not simply a display of text or images, but rather is an interaction between the display and the audience (Jones, 2009). Thus, websites must be examined as 'sites', and all of their elements, including text, images, links, and design, must be taken into account to effectively understand how they organize social practices. To achieve this, I have adopted a blending of methods, and rely on Fairclough's three-dimensional framework as well as multimodal discourse analysis. While the choice of these methods is not without its limitations, I believe it provides a strong theoretical foundation from which to appreciate the complexities of online discourse.

\subsection{Thesis chapter structure}

The present study is organized as follows. In the next chapter, I provide an overview of the situational, political, social, and economic contexts surrounding the Northern Gateway Pipeline project. This is done in order to better inform the analysis and to understand the ideological complexity in which the "Gateway Facts" website is embedded. Furthermore, this chapter is a reflection of the 'sociocultural' dimension of Fairclough's three-dimensional framework, and fulfils what other CDA scholars (e.g., van Dijk, Wodak) highlight as an essential element of discourse analysis: context.

In Chapter 3, I provide an overview of the relevant literature related to this research, namely literature on legitimation, corporate social responsibility and corporate discourse. This chapter seeks to highlight the importance and applicability of a discourse approach to the study of legitimation in corporate discourse, and thus discusses crucial 
studies that have undertaken investigation in this domain. Chapter 3 will also, as a result, outline the theoretical framework I have adopted for this thesis - that of CDA.

Chapter 4 outlines the methods I have employed in this study. I detail my methods of data collection and analysis. This chapter seeks to provide a detailed description of the website itself, as well as the analytical tools I have used. To this end, I overview Fairclough's three-dimensional framework as I have interpreted and applied it, as well as two linguistic and visual analysis rubrics adopted from CDA and multimodal discourse analysis scholars.

Chapter 5 presents the findings of my analysis. I structure my findings using four emergent themes. Each of the themes is discussed separately, with corresponding relevant aspects of the website highlighted through a lens of either CDA, multimodal analysis, or both. As I am following Fairclough's approach, this chapter is not merely a description of textual or visual elements, but seeks to situate my observations and findings within a sociocultural context. Thus, my findings are contextualized with references to other scholars, existing literature, and additional relevant information.

Chapter 6 is a discussion of the findings presented in the previous chapter. Here I will return to the literature and theories I presented earlier in this thesis. I discuss where my findings confirm and differ from existing studies, as well as note the implications of this study and my findings.

Chapter 7 is the conclusion and final chapter of this thesis. Here I revisit my research questions and overall ambitions, and summarize my theoretical framework, methods and findings. In addition, I briefly outline my contributions to the existing body 
of literature. Finally, I discuss the limitations of this study and suggest some possibilities for future research endeavors. 


\section{Chapter: Background on the Northern Gateway Pipeline}

\section{$2.1 \quad$ Introduction}

Enbridge, the largest natural gas provider in Canada and a major pipeline operator in North America, is seeking to construct a twin pipeline through the Canadian western provinces of British Columbia (B.C.) and Alberta. The project is controversial for numerous reasons, but primarily due to its potentially devastating environmental impacts. Enbridge, like other oil corporations worldwide, has been forced to devote large amounts of time and energy to justify and promote this proposed project, the Northern Gateway Pipeline (NGP). The objective of my research is to investigate how the gatewayfacts website discursively represents the NGP project in order to gain insight into how corporate discourse legitimates a controversial project. In this chapter, I will provide some background on the NGP project as viewed in the context of this study.

Fairclough (2012) posits that textual analysis is only ever at its most effective if situated within a discussion of the object of research in terms of the wider social, historical, and contextual relations and practices. Texts do not exist in a vacuum, but rather their textual and multimodal properties are shaped by the intertextual and social worlds in which they exist. To provide this necessary context, this chapter will trace the history of the NGP project as an emotionally charged event in Canada, discuss the multifaceted context surrounding the pipeline, and highlight why the project constitutes an interesting and valuable focus of study.

\subsection{Situational context}

The NGP is a proposed project that will carry bitumen - "a heavy and viscous tar-like oil, contained in a mixture of sand, clay and water" (Richardson \& Standing Committee 
on Natural Resources, 2013, "The Resource”, para. 1) -from the town of Bruderheim in the Alberta oil sands ${ }^{1}$ to a proposed port in Kitimat, British Columbia on the Pacific Ocean. This project would be constructed as a twin pipeline; one line would run EastWest and would carry 525000 barrels of diluted bitumen per day to the B.C. coast, while the second line would run West-East and would transport 193000 barrels of imported oilbased thinning agent back into the Alberta oil sands (Enbridge Northern Gateway Joint Review Project, 2013). The proposed route runs a distance of 1177 kilometers through the provinces of Alberta and British Columbia across a wide variety of terrain including mountains, prairies, lakes and rivers. The port in Kitimat, one end of the pipeline, would serve as a gateway for the bitumen to be put on large oil tankers to be shipped to Asia and other international markets.

A multifaceted project with numerous interested parties, the NGP's key stakeholders include: Enbridge, the Canadian Government, public and private investors, oil sands workers, foreign markets, the Alberta and B.C. provincial governments, environmentalists, economists, and communities - including and importantly First Nations communities. Stakes for this project are very high. Industry, business, think tanks, the media and at times the Canadian Government all have commented on the impact this project could have in bolstering the Canadian economy and job market as well as on the country's relationship with foreign oil markets (Arcand, Burt \& Crawford, 2012; Holden, 2013). For example, the Canadian Chamber of Commerce, the largest

\footnotetext{
${ }^{1}$ In the body of literature on the Canadian and Albertan hydrocarbon sector there exists a variety of spellings of "oil sands". This includes "oilsands" and "Oil Sands". In this paper, I have chosen to follow to spelling of the Canadian Government, that is "oil sands".
} 
business association in Canada (The Canadian Chamber of Commerce, n.d.), published a letter in conjunction with many of the country's business leaders in support of the NGP, underscoring the importance and benefits of the project: "It is critical that Canada open up new markets so that taxpayers get full value for our energy resources and that our natural resources find a way to those markets as quickly as possible" (The Canadian Chamber of Commerce, 2014). Janet Holder, the self-described project leader of the NGP decrees: "Northern Gateway is important to Canada's future. It will open up new markets for our most valuable resource, creating thousands of jobs and new opportunities for British Columbians and Canadians" (Holder, 2014).

However, as previously mentioned, the project is extremely controversial, and many actors are strongly opposed to the NGP, voicing their contrariety through publications, media articles, protests and public calls to action (see for example "Northern Gateway pipeline opponents", 2015; Judd, 2014; Uechi, 2012). Pull Together, an organization formed expressly to oppose the project, states that "two thirds of British Columbians don't want this project that threatens the oceans, wildlife, communities, and unique coastal economy of BC. It must never be built" (Pull Together, n.d.). The project has garnered the attention of heavy-weight international groups as well; Amnesty International has voiced their opposition to the project:

Amnesty International isn't opposed to all resource development or pipeline construction, but we have said that Northern Gateway should not go ahead. As international human rights bodies have long recognized, a high standard of precaution is essential in any decision that could compound the harms that have already been inflicted on Indigenous peoples. The federal government, which 
gave conditional approval for Northern Gateway in a decision announced in June, has fallen far short of this standard of precaution. (Amnesty International, 2014) The reasons for opposition to the NGP vary greatly. Groups opposed include First Nations, environmentalists, human rights groups, residents of British Columbia and Canada, academics, journalists, and coastal sector employees among others. Despite the vocal opposition from various parties, however, the project was supported by the former Canadian Federal Government (Government of Canada, 2012). However, acutely aware of the polarized interest in the project, the Canadian government has put the NGP through a process of approval that has taken several years. The next section of this paper will overview this process and of the progression of the project in general.

\subsection{The assessment process}

The NGP project was officially launched in 2004 by Enbridge, with the corporation announcing their preliminary plans for a pipeline linking the Alberta oil sands with the Canadian west coast. One year later, in 2005, Enbridge further developed the idea in announcing a $\$ 2.5$ billion deal with PetroChina International Company Limited to transport oil along the pipeline for export to China and other Asia-Pacific markets (Enbridge, 2005a). That year, Enbridge also announced Kitimat, B.C. as the proposed end-point for the pipeline, citing its deepwater port and abundant industrial land as key reasons (Enbridge, 2005b). In 2006, the project was delayed in favor of dealings with the U.S. market. Despite this delay on the part of Enbridge, the NGP still held significant potential and was put under review by the Canadian Minister for the Environment, Rona Ambrose, in September of the same year (Canadian Environmental Assessment Agency, 2006). 


\subsubsection{Environmental assessment and the CEAA, 2012}

Environmental assessments (EA), as a reflection of the remarkable growth in concern for and interest in environmental issues over the past few decades, have become an immensely important aspect of the relationship between development and the environment (Jay, Jones, Slinn \& Wood, 2007). Subject to a wide range of definitions, EA can be described as responding to the need "to identify and predict the impact on the environment and on man's health and well-being of legislative proposals, policies, programmes, projects and operational procedures, and to interpret and communicate information about the impacts" (Munn, 1979, p. 23). While broad, this oft-quoted definition offers a perspective on the EA as a process, but also speaks to the scope of EA. Not only interested in impacts on the physical environment, EA can speak to the employment opportunities, community structure and services, and lifestyle and values which may be affected by development actions (Glasson, Therivel \& Chadwick, 2005). This is particularly relevant in the context of the NGP, as the EA process involved was a significant event in communities along the pipeline route.

Within Canada, prior to 1970 , little to no consideration was given to the environmental consequences of development projects (Becklumb \& Williams, 2012). However, this lack of assessment and appropriate prevention could leave the Canadian government responsible for the fiscal, social and environmental recovery of projects gone awry. Thus, following in the footsteps of the United States, Canada's federal government began to recognize the value and need for appropriate environmental planning and assessment legislation. However, legislation for EA would not make it into federal law until 1992 (Becklumb \& Williams, 2012). Reflecting the broader global landscape of 
changing perspectives on EA (Pope, Bond, Morrison-Saunders \& Retief, 2013), Canada's EA processes have evolved over time. In 2012, due in part to the global economic crisis of 2008, the Canadian federal government, perceiving the EA process as a "hindrance to economic development" (Becklumb \& Williams, 2012, p. 1), replaced the existing federal EA process with a new, greatly debated process outlined in the Canadian Environmental Assessment Act (CEAA, 2012). It is within this context and legacy that the Enbridge's NGP project was put under review. A large-scale development project, it was within the scope of several potential areas of consequence outlined in the CEAA, 2012. Indeed, the NGP required a higher level of EA than might normally be prescribed, as outlined in the CEAA, 2012, as a "panel review" (CEAA, 2012). This type of EA may only be implemented should the Minister of the Environment be "of the opinion that to do so is in the public interest, considering various stipulated factors, including whether the designated project may cause significant adverse environmental effects and public concerns related to those effects" (Becklumb \& Williams, 2012, p. 5). Of note for EA panel reviews is that they necessitate the public dissemination of all relevant information. Additionally, the review panel must "hold hearings that offer interested parties an opportunity to participate" (Becklumb \& Williams, 2012, p. 5). Thus, an EA panel review constitutes to a certain degree a negotiation with interested parties, not merely a procedural evaluation of potential adverse environmental effects.

I highlight this piece of legislation because the relationship between the NGP and the CEAA, 2012 is not quite straightforward. While the NGP was first put under review in 2006, the Joint Review Panel appointed by the Minister of the Environment did not begin their assessment until years later in 2012. As CEAA, 2012 was put into law later 
the same year, many of the changes it made to the EA process do not affect the NGP's assessment. However, the CEAA, 2012 does affect the project's assessment in some notable ways. Of note is that the CEAA, 2012 offered the federal government the power to reject any public review panel's decision - thus in this case granting the final authority on the NGP's approval. This “ultimate power" (Esler, 2013) could be viewed as problematic for several reasons, one of which is the Canadian government's close ties with the oil and gas industry (which will be detailed in the section discussing the political context). This could be viewed as a conflict of interest, and indeed as limiting the federal government's ability to put forth an unbiased decision (Esler, 2013).

The CEAA, 2012 also affects the NGP's assessment process in that it places a time limit upon it (Kent \& Caron, 2012). Under the CEAA, 2012, EA panel reviews must be completed within two years (Becklumb \& Williams, 2012). This time constraint, never a condition under earlier legislation, applies directly to the case of the NGP, as the Minister of the Environment reduced the time allowed for the NGP assessment to two years. Prior to this change, the review panel for the project had no time constraint whatsoever. The Minister of the Environment, using the power allocated to him by the CEAA, 2012, set a deadline for the review panel of December 2013 (Whittington, 2012). While certainly indefinite EA processes would be impractical, this new time constraint can be viewed as troubling in the case of the NGP, as since it is such a large-scale project, "limiting the amount of time the Northern Gateway Assessment Panel can conduct public consultation and scientific review means that that environmental effects of the pipeline cannot be thoroughly studied" (Esler, 2013, p. 23). Indeed, Fisheries and Oceans Canada (DFO), in a letter written to the Joint Review Panel, stated that they were unable to finish 
a thorough investigation of the potential risks to waterways, watershed and marine life in the allotted time: "As DFO has not conducted a complete review of all proposed crossings, we are unable to submit a comprehensive list as requested; however, this work will continue" (DFO, 2012). It is curious as to why this time limit was deemed necessary in the case of the NGP, as assessments for the similar pipeline project, the Mackenzie Valley Pipeline, took over three years (Esler, 2013). Unfortunately, there is no obvious explanation on the part of the Canadian government as to why this two-year limit was chosen and deemed necessary in the case of the NGP.

As a final consideration, the CEAA, 2012, included a narrowing of scope concerning the scientific and environmental risk assessments. Differing from the previous EA process, the CEAA, 2012, requires that cumulative impacts only be "considered", not “assessed" (Esler, 2013, p. 24). Cumulative effects are defined as those "project effects remaining after mitigation that may interact with other projects and activities that exist or are reasonably foreseeable” (Enbridge Northern Gateway Project Joint Review Panel [ENGPJRP], 2013a, "Views of the panel", para 1). Again, in terms of the scale of the NGP project, this narrow approach could be seen as concerning, as the Joint Review Panel was now only under obligation to "consider" the significance of such impacts as proximity to other projects, industrial expansion, increased marine traffic, effects on air quality, river pollution, wildlife habitat disturbance, etc. (ENGJRP, 2013a). The Joint Review Panel, addressed the issue, explaining:

Northern Gateway limited its cumulative environmental effects assessment to circumstances where there was a reasonable expectation that the project's contribution to cumulative environmental effects would affect the viability or 
sustainability of the resource or value. It characterized two aspects of cumulative environmental effects on a valued ecosystem component or key indicator species: the overall cumulative effect of all past, present, and reasonably foreseeable future projects and activities in combination with the environmental effects of the project; and the contribution of the project to overall cumulative effects.

(ENGJRP, 2013a, "Northern gateway and participant views", para 2)

Thus, the NGP Joint Review Panel did incorporate an evaluation of cumulative effects in their assessment process, though the change from "consider" to "assess" leaves the activity open to interpretation. Unfortunately, the CEAA, 2012 did not define what was meant by "consider", and the explanation the Joint Review Panel gives is the following somewhat vague phrase: "the Panel considered cumulative effects and provides a rationale for not including a detailed discussion of cumulative effects in its analysis" (ENGJRP, 2013a, "Views of the panel", para 5). A further point of controversy for the NGP, it is interesting to consider why this change in assessment practice was needed in the case of Enbridge's project, as the Joint Review Panel indicated that cumulative effects were highlighted as a prominent point of concern by interested parties (ENGJRP, 2013a).

Ultimately, the connection and influence of the CEAA, 2012, as well as the overall NGP assessment process was an important point of concern for many groups opposed to the project (see for example Dogwood Initiative, 2009). The ramifications for the NGP's assessment serve to promote the project as a controversial development, and as Elser (2013) argues: "control knowledge production at the Northern Gateway Pipeline hearing, [and] give the federal government the discretionary power to approve the pipeline" (p. 22). Ultimately, while this paper does not have the scope to include a full 
discussion of the Canadian government's institutional action related to the project, this brief overview of the CEAA, 2012 hopes to demonstrate the deep roots of the NGP within Canadian society - social and political.

\subsubsection{The hearings}

Despite those opposed to the changes ushered in by the CEAA, 2012, the Joint Review Panel (under the National Energy Board) appointed by the Minster began holding EA hearings across the western provinces of British Columbia and Alberta in 2012. These hearings, required under the CEAA, 2012 legislation, must be offered by the Joint Review Panel to allow all "interested parties an opportunity to participate in the environmental assessment before the panel submits its report" (Becklumb \& Williams, 2012, p. 5). Beginning in Kitimat in January 2012, the proposal port site, the hearings moved across B.C. and Alberta for 18 months.

The public process of the hearings is described by the Canadian Environmental Assessment Agency (“The Joint Review Process”, n.d.) as an assessment of all information on the "record". The record consists of all information submitted to the panel through a preliminary request for information process and the public oral hearing sessions. As an interested party, individuals had four options for participating and offering information to the joint review process: submit a letter of comment, make an oral statement, become an intervenor, or become a government participant (CEAA, n.d.). The latter three options required registration, and as the hearings were held in various locations, an assignment of a date and place. The hearings resulted in a huge amount of public interest and participation, over 9000 letters of comment were received, and 1790 persons offered oral evidence (National Energy Board[NEB], 2013). 
The hearings, as might have been expected, were a controversial activity in and of themselves. As Esler (2013) remarks, the fairness of the hearings can be, and was, questioned for a variety of reasons. Opponents to the pipeline took issue with the Joint Review Panel Board, remarking that there were no appointed citizens from British Columbia (Forest Ethics, 2012) despite the province's obvious stake and interest in the project. Commenting on the hearings themselves, opponents challenged that Enbridge's responses seemed scripted, and that witnesses and Enbridge company experts were permitted to confer before answering questions (Hume, 2013). Spectators were also banned from certain hearings (Lavoie, 2012), and the federal government has been accused of attempting to limit the types of questions posed at the hearings (Esler, 2013). The hearings drew numerous protests in communities in B.C. ("Protesters arrested at pipeline hearing", 2013; Hunter, 2012; Stoymenoff, 2012; "Rally draws thousands", 2012) and certain hearings were even cancelled due to to protest activity ("Gateway hearing cancelled", 2012). These concerns, coupled with the controversial CEAA, 2012, resulted in several implicated First Nations groups to pull out of the hearings (Moore, 2013).

Despite the tension and opposition, the hearings were carried out in accordance to the CEAA, 2012, and were completed in June 2013. The Joint Review Panel in Volume 1 of their report, identified as satisfied with the hearing process, remarking that the process had been rigorous and substantial. The panel acknowledged the numerous participants, wide variety of views presented, the aboriginal knowledge shared, and commented that they had learned "about the connectedness of everything and that our approach must be holistic, understanding the entirety as well as the parts" (ENGJRP, 2013c, p. 76). This 
next sub-section will elaborate on the final steps in the NGP assessment, the Joint Review Panel's final report and recommendations.

\subsubsection{The Joint Review Panel report}

Under the new CEAA, 2012 and with the completion of the hearings, the Joint Review Panel had until December $31^{\text {st }}$, 2013 to release its final report to the Canadian Federal Government (Kent \& Caron, 2012). The report would be released in two volumes, entitled Volume 1 - Connections and Volume 2 - Considerations. The report was lengthy and wide-reaching, and seemed to attempt to address the many concerns put forward by

participants during the assessment process. The document also outlined the scope and mandate of the Joint Review Panel and the EA process, marking the boundaries where they stopped their considerations. The report summarized the different issues, risks, and benefits associated with the project and ultimately offered a conclusive recommendation to the Governor in Council. With the release of this report, the Panel was no longer involved with the project. The final report recommended that the Federal Government approve the project, subject to 209 conditions. The Joint Review Panel, in Volume 1 of the report justified their decision stating: "We determined what we believed were the major benefits and burdens associated with this project and found that the public interest of Canada was best served by recommending that the project should be approved" (ENGJRP, 2013c, p. 76). This quote was followed by an encouragement to read the second volume to gain a deeper understanding behind the approval.

Of great interest to many were the 209 conditions outlined by the Joint Review Panel. These conditions addressed different phases of the project: pre-construction, construction and operations. Throughout each of the phases some conditions were 
marked as requiring that "Northern Gateway must file with the [National Energy Board] for approval" (ENGJRP, 2013d, p. 375), thus establishing an additional level of approval. Many of the conditions addressed areas of concern that the Joint Review Panel noted as identified through the hearings and EA process (see ENGJRP, 2013c, p. 18-19) or through the wider debate surrounding the project. Some conditions of note were those requiring the consultation of aboriginal groups, documentation, consultation and diligence during watercourse crossings, the protection of animal habitats (notably woodland caribou, freshwater fish, whales and marine birds), and marine spill prevention and cleanup (ENGJRP, 2013d).

Since the Panel's report constitutes a recommendation and not a decision, the conditions outlined within are subject to governmental review. Under the National Energy Board Act (NEB Act), the conditions outlined by the Panel cannot be altered or rejected by the Federal Government, but can be sent back to the National Energy Board (the governing body of the Joint Review Panel) for reconsideration (ENGJRP, 2013d). It would be up to the NEB to consequently make changes or not. Not all conditions in the Joint Review Panel's report fall under the NEB Act however, and any conditions which fall under the CEAA, 2012 can be altered or supplemented by the Canadian Government (ENGJRP, 2013d).

\subsubsection{Governmental approval}

Ultimately, as stated by the Joint Review Panel, their role was regulatory, and the report was only a recommendation to be taken into consideration by the Federal Government in their ultimate deliberation on the NGP: 
The final decision on whether or not the project should proceed will be made by the Governor in Council. As part of its decision, it will determine whether or not the project is likely to cause significant adverse environmental effects and, if so, whether those effects are justified in the circumstances. (ENGJRP, 2013d, pp.

In other words, the lengthy documentation and reporting on environmental impacts would serve as guidelines and hold no real decision making power. The Canadian Federal Government, as outlined in the CEAA, 2012, would have the ultimate and final say in approving the pipeline and determining its environmental effects.

In June of 2014, the Governor in Council approved the NGP project, subject to the 209 conditions set out by the Joint Review Panel being met. In applying the 209 conditions, the Federal Government required that Enbridge must comply with each and demonstrate to the National Energy Board and the Government how they will meet them. This approval stated "that the Designated Project is not likely to cause significant adverse environmental effects" (NEB, 2014, para. 3), except in the case of certain populations of woodland caribou and grizzly bears. The report went on to qualify that the "significant adverse environmental effects" to these animal populations are "justified in the circumstances" (NEB, 2014, para. 4).

The governmental approval was met with widespread political distaste; each of the major opposing Canadian political parties - Green, NDP, and Liberal - voiced their concern and discord with the decision, the leaders of the NDP and Liberal parties both vowing to overturn the decision if elected (Mas \& Payton, 2014; McCarthy, Chase \& Jang, 2014). The approval was also met with contention by environmental and First 
Nations groups; following the decision statement eight First Nations ${ }^{2}$, four environmental groups $^{3}$, and one labour union ${ }^{4}$ brought 18 legal challenges against the Canadian Federal Government's decision (Smith \& Desmond, 2015). Addressing a wide variety of concerns, these legal challenges touched on issues such as the claim that significant adverse effects to wildlife were justified, a failure of the Joint Review Panel to adequately consider public interest and issues relating to First Nations and a failure of the Government to provide proper reasons for its decision (Smith \& Desmond, 2015). The hearings for the legal proceedings involving First Nations groups took place in the Federal Court of Appeals in Vancouver over the course of six days in October of 2015 (Smith \& Desmond, 2015; Omand, 2015). The Court recently released its decision, overturning the approval of the pipeline. The Court argued that Canada failed to adequately consult with First Nations groups, stating: "we find that Canada offered only a brief, hurried and inadequate opportunity ... to exchange and discuss information and to dialogue" (Proctor, 2016). As this decision was only released in late June, 2016, the fate of the pipeline project remains uncertain.

\subsection{Political and economic context}

While the Federal Government's approval of the NGP project was generally not well received, it is helpful to consider the context in which this decision was made to

${ }^{2}$ Gitga'at First Nation; Gitxaala Nation; Haida Nation; Haisla Nation; Heiltsuk Nation;

Kitasoo Xai'Xais Nation; Nadleh Whut'en; Nak'azdli Whut'en;

${ }^{3}$ BC Nature; ForestEthics Advocacy Association; Living Oceans Society; Raincoast Conservation Foundation

${ }^{4}$ Unifor 
understand the reasoning behind it. Canada's relationship and history with resource extraction and oil production is an important factor.

While the Alberta oil sands were first surveyed in 1875 (Richardson \& Standing Committee on Natural Resources, 2013), Canada's oil production remained a small aspect of the economy prior to the 1950s (Esler, 2013). Two huge oil sand projects completed in 1967 and 1978 would serve to change this relationship drastically, and by the 1970s Canada was producing 290000 cubic meters of oil per day and exporting half to the United States (Esler, 2013). A decade later, with the election of a majority Conservative government, the Canadian energy agenda began to shift towards increased deregulation of extraction, transportation and trade of hydrocarbons, a pattern which Doern (2005) argues has continued ever since.

Since the late $20^{\text {th }}$ century, the production and trade of hydrocarbons stemming from the Alberta oil sands has constituted a major source of growth and wealth in the Canadian economy (Doern, 2005; Esler, 2013). A report by Richardson \& The Canadian House of Commons Standing Committee on Natural Resources (2007) references that "the development of the oil sands has been described as a Canadian success story" ("Developing the oil sands-Canadian innovation at work", para. 2) and that "the oil sands are of great strategic importance for Canada" ("The oil sands-a resource of strategic importance to North America”, para. 1). Some argue that Canada is continuing on a path to become an "energy superpower" (Taber, 2009; Clarke, 2008) and has entered the top tier of global crude oil producers (Stefanick \& Shrivastava, 2015).

Canadian oil and gas revenues are divided between the Federal and Provincial governments, as the resource extraction largely falls within provincial jurisdiction but is 
partially federally regulated (Esler, 2013). Alberta, the Canadian province that accounts for nearly three quarters of all Canadian oil and gas production (Brownsey, 2005), sees substantial revenues from the hydrocarbon sector. As Brownsey (2005) argues, "the oil and gas industry is essential to Alberta's prosperity" (p. 203). In 2014, 25\% of Alberta's GDP, $70 \%$ of its exportation, as well as $35 \%$ of provincial government revenues came from the oil and gas sector (Stefanick \& Shrivastava, 2015). Alberta, despite constituting only 11 percent of Canada's total population, accounts for 17 percent of the country's gross domestic product (GDP). 28 percent of that number comes directly from the oil and gas sector (Stefanick \& Shrivastava, 2015). Alberta's oil sector is also marked by strong industry-friendly taxes and a favorable revenue-sharing regime, leading to a pattern of remarkable corporate returns (Campanella, 2012). For example, Royal Dutch Shell, a major international oil and gas corporation, announced in 2007 that the Canadian oil sands operations earned them the highest profit per barrel, nearly double of what they earn worldwide (Mortished, 2007).

Stefanick and Shrivastava (2015), in their discussion of the social, political and economic aspects of Alberta's petroleum industry, point out that this economic prosperity is due in large part to a pattern of government support and favorable political and policy trends - both at the provincial and national level. Of interest here is the federal involvement, which the authors point out has been a primary force in the expansion of Alberta's oil economy. They note that due to the nature of Alberta's bitumen reserves difficult to extract, deeply lying deposits requiring more processing and refining (Clarke, 2008) - this expensive and unconventional oil development is only profitable thanks to federal investments, subsidies and tax breaks. The former Canadian Federal 
Government's relationship and ties with Alberta oil are frequently noted as exemplified by the past leadership of Stephen Harper and his Conservative Party, leading to what some argue is the Canadian "petro-state" (Nikiforuk, 2010; CITE). Indeed, Peyton and Franks (2015) in analyzing the relationship between the Harper government and Canada's relationship with oil, go so far as to describe it as "a totalizing strategy" towards "increasingly voracious resource extraction" (p. 3). While this language is in the extreme, it is certainly true that Canada's former conservative government, throughout its nearly decade-long leadership, implemented policies and legislation to bolster and promote the oil and gas industry. For instance, following the 2008 financial crisis, Stefanick and Shrivastava (2005) note that the fiscal impact on Canadian bitumen production was mitigated by the Canadian government through "ceding more regulatory control to industry; opening new doors for foreign acquisitions; and increasing financial, social, and environmental subsidies" (p. 20). Additionally, between 2009 and 2012, while federal and provincial taxes fell, subsidies to the oil sector continued to rise (Dobson \& Asadollahi, 2014).

The Harper-led government consistently reinforced its favor and support of the oil and gas sector, as well as its interest in the development of pipelines and export of bitumen overseas (Government of Canada, 2012a; Tutton, 2013; Sorenson, 2015). In 2012, the Federal Government was involved in a scandal involving internal documents discussing approaches to alter European perceptions of Canada's oil sands. The documents referred to the media, environmental and aboriginal groups as "adversaries" and industry associations, energy companies and the Canadian National Energy Board as "allies" (Vanderklippe, 2012; Fitzpatrick, 2012). Concerning the NGP in particular, 
former Prime Minister Harper voiced his strong support for the project, asserting his party's commitment to getting Canadian hydrocarbon to foreign markets during a speech in China: "Our government is committed to ensuring that Canada has the infrastructure necessary to move our energy resources to those diversified markets" (Ljunggren, 2012, para. 5). Members of the former Harper government also voiced their opinions on the project; Natural Resource Minister Joe Oliver remarked controversially that groups opposed to the NGP "threaten to hijack our regulatory system to achieve their radical ideological agenda" (Payton, 2012, para. 6) and that "they're trying to block development; they're trying to block projects which will create hundreds of thousands of jobs and billions of dollars in government revenue and trillions of dollars in economic development" (Payton, 2012, para. 18). The former Conservative Government's vocal support of the NGP and strong favor towards the oil industry and diversifying Canadian oil markets led many to question their ability to make an objective decision concerning the project (see Esler, 2013). Discussed earlier, these concerns were highly relevant as the CEAA, 2012 legislation introduced during the EA of the NGP placed final approval entirely in federal hands.

\subsection{Empirical studies investigating the NGP}

As discussed throughout this chapter, the NGP project, while federally approved, is still in ongoing debate in Canadian society and the courts. As construction has not started and the project remains in the 'proposed' stage, there is not a huge body of academic work conducted to date on the case. That said, there is an interesting collection of communication and discourse oriented literature. This section will overview a selection 
of studies that discuss Enbridge and the NGP to highlight the applicability of discourse analysis to the case.

\subsubsection{The political context of the NGP}

Following the long tradition of environmentally-oriented critical analyses of media discourse (see for example Carvalho, 2007; Boykoff, 2008; Kojola, 2015), the recent work of Raso and Neubauer (2016) explores news articles discussing the NGP. They argue that examples of the most common pro-pipeline stories illustrate how discourses preferred by the political elite structure news stories. Through a content and discourse analysis, these authors show that the Canadian news media's articles and sourcing show a bias that is hostile towards those opposed to the pipeline while favouring elites' economic and political ideas. In providing context for their study, they argue that the NGP is facing an "overall crisis of legitimacy" (p. 117), and is thus engaged in an ongoing battle to build its own legitimacy while delegitimizing its opponents. This battle, they argue, is being waged by both certain Canadian news media and "New Right" political actors. Raso and Neubauer situate their work among that illustrating the widespread media tendency to privilege discourses favored by political and economic elites. They claim that for decades, "a networked movement of corporate-backed New Right civil society groups [have] coordinated the promotion of environmental skeptic discourses in the public sphere" (p. 118). Backed by a "hegemonic rise over the past 40 years of a neoliberal ideology" (Raso \& Neubauer, 2016, p. 118), the NGP is presented in news media as an economic imperative while at the same time delegitimizing pipeline opponents. This was generally achieved through positioning official sources, such as the conservative federal government and industry representatives, as primary definers. 
This work supports my focus on legitimation, providing a discursive window into how the pipeline is being represented in Canadian media. I have argued that the project is controversial among the Canadian public and that it has been a major discussion point in Canadian media. This study highlights both those facts, and carries out an empirical analysis of the media representations of the project. Furthermore, similar to Livesey's (2001) study discussed earlier in this chapter, Raso and Neubauer (2016) reference the relationship between oil corporations and discourses of neoliberalism and economic development. Also important in providing context for the political reality in which the NGP is situated, Raso and Neubauer's work discusses the Canadian conservative government and its role in the pipeline project's proposal.

Also working at the intersections of politics and environmental issues, Esler (2013) conducted a Foucauldian analysis ${ }^{5}$ of the Canadian federal government's role in the NGP debate. His work was conducted during the environmental assessment of the pipeline project and argues that the government used rhetorical language, disciplinary measures, as well as legislation changes to grant themselves authority to approve the pipeline's construction. Some of these are: commercials, muzzling scientists, changing laws, and issuing statements. Similar to Raso and Neubauer (2016), Esler (2013) points to the neoliberal ideologies motivating the former Canadian federal government, and argues that the wealth generated by oil and gas in Canada has resulted in the federal government

\footnotetext{
${ }^{5}$ Esler points out that there is no single definitive way to conceive of and perform a Foucauldian analysis. Each Foucauldian analysis is specific and tailored to the context at hand. His work takes a genealogical approach to examine how operations of power create assymetries between social actors in a matrix. His work focuses on the discourse of the Canadian government, not all discourses associated with the pipeline, and he thus terms it a limited geneaology.
} 
creating policies and legislation that promote hydrocarbon extraction and exportation. In the case of the NGP, this state-of-affairs becomes obvious, as the Esler argues that the "federal government is proactively promoting the pipeline and is using its regulatory, legislative, and rhetorical powers to try and ensure pipeline construction" (p. 45). Ultimately, despite this proactivity, Esler points out that the federal government was largely unsuccessful, as at the time of his writing, the project was still facing huge backlash from the Canadian population, and was in a generally uncertain position. Several years later, and further in the development of the project, his work on the role of the federal government in promoting and approving the pipeline provides a fascinating backdrop to my study of the legitimatory practices of the corporation behind it. While the focus of this thesis is not on the Canadian federal government, this work on the political context of the NGP, as revealed by Raso and Neubauer (2016) and Esler (2013), is crucial to understanding this case. These studies also point to why this case-study is a worthy research project, and the degree to which it provides a window into Canada's complex and challenging relationship to energy development projects.

\subsubsection{Resistance to the NGP}

Several authors examine resistance to the NGP within a broader discussion of opposition to extractivism, natural resource production, and fossil fuel infrastructure projects. The vocal opposition to the NGP, as a huge development project with roots in the Alberta oil sands, can be seen as a manifestation of a larger Canadian shift in opinion towards reliance on fossil fuels and development of the oil sands (Veltmeyer \& Bowles, 2014). Relating to the political discussion presented above, there is a large body of literature that discusses Canada's shift to a resource-based economy under the late federal government. 
Veltmeyer and Bowles (2014) argue that the former federal government "staked Canada's future on natural resource development, including the production for the exportation of Alberta tarsands oil" (p. 64), and that opposition to this pipeline is largely representative of a wider rejection of the neoliberal policies of the federal government. Looking at differences between B.C. and Alberta, Axsen (2014) shows that while Albertans are likely to show support for the pipeline, B.C. residents continue to resist and voice their discord with the project. It is worth considering that this may be that Canadians outside Alberta are beginning to disfavor extractivism and related development projects.

However, the differences in opposition to the NGP between Alberta and B.C. could also be because the project is likely to result in very different impacts in the two provinces. Alberta is more likely to gain economically from the NGP, whereas B.C. is more likely to experience environmental risks. Axsen (2014) notes that not only are Albertans less likely to oppose the project, they are also more likely to view it as a provider of economic benefits, such as a job creator. British Columbians, on the other hand, are more likely to see the NGP as an environmental risk. Referenced earlier, this division is one commonly seen in contexts of environmental issues: economic benefit opposed to environmental risk. Indeed, Raso and Neubauer's (2016) work (discussed in the previous section) highlights that not only is this antagonism present in opposition to the project, it is also seen in Canadian media stories about the NGP. Axsen (2014) notes that the tradeoff between environmental risks and economic benefits is a particularly strong theme in the case of the NGP. 
Where opposition is strong, it is largely drawn from the power of the indigenous communities retaining territorial rights in the path of the Enbridge pipeline. Invoking indigenous law, the First Nations leaders stake their opposition to this project as not only threatening their territorial rights and status as sovereign nations, but also as encroaching upon their responsibility to the natural world, and ultimately their traditional culture and way of life (Veltmeyer \& Bowles, 2014). The NGP project would cut through traditional hunting and fishing grounds, thus breaking down indigenous communities' existing relationships with their land. The pipeline is consequently viewed by those opposed as a project incurring much greater risk than other extractivist projects that are more geographically limited. Echoeing the argument that opposition to the NGP is representative of a much larger issue, Veltmeyer and Bowles (2014) argue that "capitalism stands in a relation of fundamental contradiction to the ability of First Nations communities to protect their traditional and modern culture, determine their own future, and to exist as a people and as a society" (p. 66).

Not only does this project represent a potential threat to indigenous land and life, it has also been argued that the regulatory process is a continuation of colonial dispossession. The regulatory process, according to Mcreary and Milligan (2014), fails to interpret, translate, and ultimately appreciate, indigenous geographies. References to indigenous territories are reduced to neatly bounded and discrete, localized and labeled, "patches of Indigeneity" (p. 122). Assessments that claim to include indigenous peoples, such as in the case of the NGP, need to acknowledge not only different understandings of territory, culture and knowledge, but also the long-reaching history of colonialism. Instead of acknowledging Canada's tumultuous and exclusionary relationships with 
indigenous people, the process used to evaluate the pipeline confines Indigeneity to "a politically constrained and knowable condition” (Mcreary \& Milligan, 2014, p. 125). Indeed, this state of affairs was only not noticed only by these academics; the pipeline was in the Canadian court system for the past two years, being evaluated for whether or not it adequately consulted indigenous peoples. As noted earlier, The Federal Court of Appeal recently overturned the approval of the NGP, stating that the Canadian government failed to consult with First Nations. Thus, it can be argued that the indigenous communities standing against the pipeline are not only resisting this project, but also resisting the operative capitalist and colonial system.

\subsection{Conclusion}

Ultimately, the social, political and economic context surrounding the NGP is wrought with the debates of complex issues in the domains of economic development and environmental issues. As Esler (2013) asserts, "The case of the Northern Gateway Pipeline very much embodies the conflict between resource development and environmental protection" (p. 7). The former Canadian government, fiscally and socially conservative (Stefanick \& Shrivastava, 2015), largely positioned itself as interested in economic development and in the expansion in the Alberta oil sands, which in turn manifested as support for the NGP. This stance, and the actions associated with it (i.e., legislation, comments, etc.), have served to fuel the controversy surrounding the NGP. The NGP has evolved into a development project reflecting the tensions of the larger Canadian political economy.

Consequently, given the controversy and generally uncertain future of the project in relation to public opinion, Enbridge has needed to take considerable trouble to defend 
themselves from negative perceptions and foster social acceptance for the project. It is therefore not surprising that the gatewayfacts website, created as a communication platform to offer information about the project to the Canadian public, should put great effort into shining a positive light on the pipeline. In short, Enbridge, was faced with a need to legitimate itself and the NGP to the public in general, with a special emphasis on those citizens opposed to the project - such as those concerned about the environmental impacts. As will be discussed in the following chapter, existing work on corporate discourse shows that in the wake of controversial events, negative public opinion, and a shift in stakeholder understandings of corporate responsibility, corporations often turn to discursive legitimation to aid in asserting the rightness of a project or action. 


\section{Chapter: Literature Review and Theoretical Framework}

\subsection{Introduction}

Legitimation is a central issue for organizations generally, and is a particular concern for multinational corporations (Geppert, 2003), those operating in contested markets (Anteby, 2010; Elsbach, 1994), and those heading controversial projects (Vaara $\&$ Tienari, 2008). The fossil fuel industry, and notably oil corporations, frequently fall into all three of these categories. Consequently, oil corporations can be said to have a particular need to legitimate themselves and their actions (Breeze, 2012; Livesey, 2002). Despite the saliency of legitimation to the study of corporations, many authors note that examinations of organizational practices have been relatively 'realist' and disconnected from an appreciation of the discursive practices that shape organizational behaviour (Phillips, Lawrence \& Hardy, 2004). Perhaps in response to this gap, research has been increasingly looking into discursive aspects of corporate legitimation (e.g. Phillips, Lawrence \& Hardy, 2004; Vaara \& Tienari, 2008; Livesey, 2002, Breeze, 2012; Fuoli, 2012). Such inquiries often adopt a guiding view of language as social action. While this notion has long been foundational in discourse studies (see the CDA section of this chapter), it is relatively new to the study of organizational discourse. Immensely useful, this discursive approach to investigations of legitimation in organizational discourse can help illustrate "that organizations are not just social constructions, but social constructions constituted through discourse" (Aritz \& Walker, 2012,p. 2). It is thus in this still-existing gap that my research situates itself. A discourse analysis approach offers a theoretical lens and practical method to understanding, analyzing and challenging organizational order (Hartelius \& Browning, 2008). 
To broadly introduce the existing scholarly literature that investigates how corporations discursively represent and legitimate themselves and their actions, I will touch on the following bodies of this literature: studies of discursive legitimation, of the field of corporate social responsibility, and of particular work on legitimation in oil corporations' public discourse.

\subsection{Legitimation in corporate discourse}

\subsubsection{Legitimacy theory as an explanatory framework}

Legitimacy theory is described as "the current dominant explanatory framework for social reporting, which identifies the need for legitimating an organization's actions as the primary driver behind the disclosure of social and environmental information" (Fuoli, 2012, p. 56). According to Fuoli (2012), empirical support for this theory is demonstrated by a positive correlation between organizations' voluntary disclosure and issues and events such as dangerous factory incidents, environmental damage, and media exposure. Scherer and Palazzo $(2007 ; 2011)$ claim that legitimacy is critical issue for corporations, as it is a precondition for their continued existence and success. Large corporations are increasingly having to devote large amounts of time, money, and energy to bolster their public image and to convey their actions in a positive light, but also to legitimate their behaviour, justifying, rationalizing and defending them (Breeze, 2012). Certainly in the case of oil and gas, corporations have had to immediately employ this type of communicative activity following incidents such as oil spills (see Breeze 2012), but have also taken to proactively legitimating and emphasizing their positive attributes and moral, legal, and economic rightness (Frynas, 2009). Confronted with issues such as 
labor disputes, community resistance, government regulation, and recently climate change (see Klein, 2015 for a discussion), oil companies have had to strategically maneuver their discursive representation of themselves, their industry, and their actions. Legitimation is one strategy by which oil corporations can build public trust, foster social license, and generally create a positive space for their existence and their activities.

\subsubsection{Defining legitimation}

Legitimation usually refers to the rationalization or justification practices of an institution, asserting the rightness or legitimacy of the institution's actions. Legitimation, as a discursive strategy, is one of the essential ways in which ideologies function through discourse (van Dijk, 1998; Breeze, 2012). Despite this, van Dijk (1998) argues that legitimation has been under-investigated in the field of discourse studies when compared to the domains of philosophy, law, and social and political science. van Dijk defines legitimation as:

Related to the speech act of defending oneself, in that one of its appropriateness conditions is often that the speaker is providing good reasons, grounds or acceptable motivation for past or present actions that has been or could be criticized by others. However, ... theoretically, legitimation is not an illocutionary act at all, but (like argumentation or storytelling) a more broadly defined communicative act that ... may be a complex, ongoing discursive practice involving a set of interrelated discourses. (p. 255)

This discursive strategy is thus ideological in nature-institutions employ legitimation to persuade, manipulate and convince audiences in order to enjoy enough social acceptance to operate and pursue activities freely (Breeze, 2012). The audiences are most often the 
public, but could also include governments and regulators.

Legitimation, as described, is not a neatly defined speech act, but rather a broad and complex communicative practice. Corporations may choose to employ discursive legitimation practices to build social acceptance, but the ways in which they achieve this vary greatly. The next section will investigate some of the ways in which corporations choose to discursively legitimate themselves.

\subsection{Corporate social responsibility as discursive legitimation}

As the ways in which corporations communicate both internally and externally are extremely varied, examples of discursive legitimation could be found in a number of places. One way to investigate the discursive legitimation of corporations is by looking closer at the theory of Corporate Social Responsibility (CSR). Through new corporate genres such as CSR reports, fossil fuel corporations are increasingly employing this discursive strategy to voice their voluntary alignment with better social and environmental practices and mitigate risks associated with CSR-related issues (Ziek, 2009). There is a large body of work on the topic of CSR, much of it situated in business and organizational communication scholarship. While all of the literature related to CSR provides a theoretical foundation for this thesis, this section focuses primarily on CSR work that is oriented more towards discourse, and that which takes a more critical perspective. This section intends to illustrate how CSR can be tied to discursive legitimation, and as I argue here, can indeed be seen as a specific practice of it. 


\subsubsection{CSR and the environment}

\subsubsection{Defining CSR}

Reflecting a broader change in how we view organizational responsibility, the theory of CSR has received significant attention in the study of organizational and corporate discourse over the past decade (Ghobadian, Money \& Hillebrand, 2015). At the center of many social and environmental debates, the fossil fuel sector is critical for studying corporate environmental and social responsibility (Livesey, 2001). CSR has at its core the notion that all organizations should be, and are, bound by duties to their stakeholders, that is, all those groups and individuals that are affected by their activities (Lichinsky, 2015. Increasingly, the environment is being viewed as a key stakeholder in an organization's network of relationships (Weber \& Marley, 2012). Through CSR practices, corporations can demonstrate that they are "doing the right thing", and that they are acting to consider, and potentially even protect, the environment.

\subsubsection{CSR and oil corporations}

Oil corporations, over the past few decades, have increasingly been subject to a shift in how the public views their inherent responsibilities. In response, the oil and gas industry has been a champion of CSR in recent decades (Frynas, 2009). This is in part due to highly visible events such as oil spills and conflicts with environmental groups and indigenous people, but certainly within the Canadian context, the potential for negative environmental impact also plays a significant role. Livesey (2002) remarks that the oil industry is particularly vulnerable to negative public opinion, and has been periodically threatened by perceptions of monopolism, greed and insensitivity to the natural 
environment. The public is seemingly demanding that fossil fuel corporations take better care of the environment in their operations. Thus, CSR practices related to corporate environmental reporting (CER) could be seen as responding to this shift, and an example of the industry's discursive legitimation efforts to appease public opinion and generate positive affect regarding their organization and its activities. Increasingly, CSR practices are becoming a norm in corporate discourse; it would be unusual for large corporations, especially oil, to not engage in CSR reporting to one degree or another. Important for the context of this study, disclosure of CSR behaviours, as well as more specific examples of CER, can be found in many instances of corporate discourse, including annual reports, letters to shareholders, environmental or sustainability reports, nonfinancial reports, organizational codes, and on corporate websites.

\subsubsection{Oil corporations' discursive CSR practices}

Most, if not all, oil companies engage in discursive CSR reporting through the issuing of (often extensive) environmental reports (Frynas, 2009). Oil and gas corporations disclose these reports more extensively than other sectors, and a majority use third-party verification of their environmental reports (Kolk, Walhain \& van de Wateringen, 2001; Kolk, 2008; Frynas, 2009). The increase in frequency of this style of reporting has resulted in the emergence of CER as a field of study in and of itself (Cerin, 2002). While CER will not be a primary focus of this study, it is my intention to highlight the environmental-leanings of CSR reporting, and to note that it is already established that environmental references are central to CSR.

Reports are not the only site of CSR reporting however. Coupland (2005), in his study of CSR reporting on oil company websites, finds that web pages are a fruitful 
source of CSR behaviours, and constitute different "virtuous circles" of legitimation. Indeed, with the increase in popularity of the internet for retrieving information about corporations, Guimarães-Costa and Pina e Cunha (2008) argue that organizational websites represent a crucial development in the landscape of organizational discourse, and are the best medium for companies to convey socially responsible information.

However, as studies of web-based CSR reporting, especially of oil and gas corporations, are far and few between, Coupland (2005) notes that more work in this area would lead to a broader understanding of how corporations construct themselves, and their activities, as socially responsible and legitimate. In my own investigation, I will be particularly interested in looking at how the gatewayfacts website may employ CSR related discursive practices to demonstrate Enbridge's adherence to socially and environmentally responsible activities. I intend to demonstrate how CSR reporting, presented in dynamic discursive settings such as websites, can be an excellent window into how corporations choose to discursively legitimate themselves and their activities. The next section will illustrate how corporations may choose to legitimate themselves through overviewing existing research in this domain.

\subsection{Examples of legitimation in corporate discourse}

While it is generally well-known and accepted that legitimation is crucially important to corporations in general, and fossil fuel corporations in particular, there have been relatively few studies investigating the particular legitimatory practices of these types of organizations. Studying these instances of legitimation are particularly interesting, as oil, gas, coal, and other fossil fuel related actors are often in positions of crisis (Breeze, 2012), or negative public opinion (Livesey, 2001), and can richly illustrate the role that 
corporate discourse plays in constructing and maintaining organizational legitimacy and stability (Livesey, 2002). This section will overview some of the most prominent studies investigating oil corporations' discourse and their legitimation strategies.

\subsubsection{Legitimation strategies of oil corporations}

\subsubsection{Eco-identities and the socially constructed nature of the environment}

In her work on corporate eco-identities, Livesey (2001) conducted a social constructionist investigation of the 'discursive struggle' between Royal Dutch/Shell Group (referred to hereafter as Shell) and its critics in the conflict and controversy surrounding its plans for an oceanic disposal of the Brent Spar (an immense oil storage and landing platform) and inaction against the Nigerian government's execution of nine environmentalists.

Particularly relevant for this thesis and its use of CDA, a social constructionist approach to research sees language as constitutive of a particular view of reality. This relationship between language and reality is recursive, such that language shapes reality, and reality also shapes language (Livesey, 2001). Livesey (2001) conducts a discourse analysis, following Fairclough (1992), of the "language games" that played out between Shell and its critics. By "language games" she means the discursive back-and-forth occurring between Shell and its critics. These "games" are texts issued by Shell in wake of the controversial events, such as an annual social report, and texts correspondingly issued by groups critical of Shell, such as articles or commentary from groups such as Greenpeace. In focusing on texts that reference and oppose each other, she emphasizes the socially contested nature of discourse touching on the environment and economic development and highlights its role in shaping oil corporation's eco-identities. Essentially, she points to the critical idea that our understanding of the 'environment' as a concept is born of the 
social discourses we use to talk about it. The environment is not a static, mutually agreed upon term, but rather is fought over by different groups. Our perception of the 'natural' and the 'environment' is socially constructed, and socially contested.

The discursive conflict between Shell and its critics served to move the corporation from the long-favoured discourse of economic development to a more cautious adoption of a discourse of sustainable development. The latter attempts to balance interests of economic development with environmental well-being. Though Livesey does not tie this to CSR, it is arguably an early example of CSR reporting and legitimation. Reeling from severe criticism, Shell chose to discursively mitigate negative public opinion by presenting their activities, and their organization generally, as socially and environmentally responsible.

Important for this thesis, the emergence of corporate eco-identities and the variety of discourses associated with them is an important means of understanding the dynamic power of "corporate rhetor" (Livesey, 2001) on our interpretation and perception of environmental issues and corporate social responsiveness. Livesey highlights that the topic, at that time, "[had] received virtually no attention" (p. 82), despite offering “dramatic and salient examples of, and new perspectives on, issues of boundary blurring that are of interest in the literature on corporate identity" (p. 83). A powerful call for an increased focus on corporate discourse in the realm of environmental issues and crises, Livesey's work also points to the significance of certain discursive forms - notably websites. She points out that technological advancements and innovations present on the web have introduced a new kind of "argumentative interaction" (Hajer, 1997, p. 54 as cited in Livesey, 2001). Livesey's work on eco-identities is a crucial theoretical 
foundation for my work on oil corporations. Her productive use of discourse analysis and Fairclough's method illustrates the effectiveness of such an approach, and her comments on the opposition of discourses of economic development and environmental well-being are highly salient to this project. However, Livesey does not focus on the relevance of legitimacy theory. I intend to continue in her footsteps, but rather than focusing on corporate identities, I hope to illustrate corporations' discursive legitimation practices.

\subsubsection{Discourses of legitimation}

\subsection{Economic development}

As is beginning to become clear, corporate discourse plays a powerful role in influencing public understanding of and actions towards environmental issues. These environmental issues might be specific crises, such as oil spills, or more global issues, such as climate change. Often, texts constitute a legitimation of the corporate status-quo and facilitate future action on their part through promoting narrow and specific "corporate understandings of the natural environment" (Livesey, 2002, p. 118). As I have noted in my discussion of legitimacy theory and CSR, oil corporations are in a position where they need to legitimate themselves and their actions. They achieve this through a variety of strategies, one of which is employing a discourse of 'economic development'.

Livesey (2002) notes that the oil corporations often rely on "utilitarian discourses of economic rationalism" (p. 140). This type of discourse touts the importance of 'the market' and insists that it produces rational decisions for the social good. This type of economic discourse legitimates 'the market', while also de-legitimizing environmentalism, governmental action, and climate science. This can be argued to be an 
example of neoliberal ideology, a theory of political economic practices that sees human well-being as best served by an institutional framework that prioritizes free markets, free trade and private property rights (Harvey, 2005). Neoliberalism is an important theme in the study of fossil fuel interests and economic discourse, notably in discussion of the emergence of 'petro-states' and the dangers of climate change (Karl, 1997; Chen \& Gunster, 2016).

Breeze (2013), also highlights the reliance on economic discourses infused with the "ideologies of late capitalism" (p. 16), though she applies a narrower focus, and labels it financial solidity/solvency. This type of discourse is a specific order of legitimation, one described as 'pragmatic legitimation' (Suchman, 1995) as it speaks to a reader's selfinterest. Whether that be speaking to shareholders' concerns about profitability or an individual's interest in finding employment, oil corporations frequently rely on this pragmatic legitimacy of economic discourse to build social acceptance of their actions.

An interesting way in which oil corporations choose to employ discourses of economic development is through the use of numbers and statistics. Cmeciu (2014), borrowing the term from van Dijk (1998), explains this as the 'number game' category of argumentation. Using 'facts', instead of opinion, this type of argument appears objective and assumes expert status. van Dijk (1998) also notes that a use of numbers suggests scientific credibility. The numbers used by oil corporations frequently reference profitability, as would be expected, but also are used to quantify oil corporations' social investments. This might be stating the dollars committed to clean-up efforts after a spill, or the amount invested in community developments. This is notable, as this blending of financial and social 'profits' points again to a widespread leaning towards CSR reporting. 


\subsection{Industrial leadership - a new strategy}

This reliance on a discourse of 'economic development' is not new, as discussions relating to fossil fuels, the economy, and employment have circled carbon industries since their nascency. However, Schlichting (2013) has demonstrated that this discourse is now encompassed in a wider shift in the strategic framing of industry actors, including oil and gas corporations. Working specifically on the issues of climate change, she identifies three distinct and consecutive 'phases', each with its own master frame. These phases evolve from 'scientific uncertainty', to 'socioeconomic consequences', to finally, the current dominant frame of 'industrial leadership'. Schlichting, like Livesey, argues that this discursive reality illustrates how "industry actors attempt to influence how the society perceives the issue and how the political authorities respond to it" (p. 494). This work is particularly important, as it shows how focusing on legitimation strategies can highlight a pattern in the way the fossil fuel industry chooses to interpret environmental issues. As it is established that corporate understandings of the environment play a powerful role in shaping public understandings of the environment, this highlights how a discursive approach to investigating corporations is immensely valuable.

The 'industrial leadership' frame is the dominant frame across all industry sectors in all world regions. It is typically found in CSR reports and is marked by several distinct discursive strategies: the depiction of voluntary action as a powerful asset in response to environmental crisis, a portrayal of industry actors as drivers of ecological modernisation, an acceptance of responsibility for industry's role in environmental issues, and a depiction of technological innovations as the most powerful tools to combat environmental problems. 
It is interesting to note that in reading different analyses of oil corporations' legitimation strategies, the 'industrial leadership' frame is often alluded to, but not fully acknowledged. For example, Breeze (2012) in her work, notes that oil corporations acknowledge responsibility for their role in the spill but then move on to describe themselves as "world benefactor[s]" (p. 13). She points to a blending of discourses of profitability and responsibility.

Another way in which the 'industrial leadership' frame makes an appearance is through the use of a "role model authority" (Cmeciu, 2014, p. 58). This discursive strategy relies on the use of superlatives and analogies to reinforce a corporation's position as a leader among their competitors. Often, corporations will also highlight the 'challenges' they face, and position themselves either as survivors or leaders responding to those challenges. As I will show later in this thesis, this last point is quite important for this study, as the references to 'challenges' are an important aspect of the gatewayfacts website.

Most importantly for the 'industrial leadership' frame, however, is the depiction of technological innovation as the most powerful way to respond to environmental issues. Oil corporations can employ the "promise of technology" to background the degree to which they must change their actions and development projects. The onus of change is put on the future, as these corporations seek to convince audiences that technological innovations will ultimately be the answer to problems such as climate change. Note that this is a subtle shift that directs attention away from current practices to potential or future practices. This reliance on technology also ties into a final discursive strategy I wish to discuss, the use of scientific and technical language. 


\subsection{Scientific and technical language}

Lemke (1995) argues that technical discourse can be problematic, as it "minimizes the use of the interpersonal, exchange and dialogical resources of language because it claims to be a value-neutral, objective reportage of the facts" (p. 50). Looking at discourse from a social constructionist perspective, there are no 'value-neutral' nor 'objective' facts, but rather all discourse is socially constructed, including that we term factual.

Oil corporations frequently rely on scientific and technical discourse to legitimate themselves and their activities. Breeze (2013) points out that oil companies consistently rely on a range of scientific and technical terminology to describe their extractivist operations. She argues that this terminology is likely inaccessible to many readers, and connotates complexity, objectivity and expertise to assume an authoritative voice. Using convoluted, technical language helps oil corporations to portray themselves as authoritative experts. This may offer them a sense of credibility, and build trust towards other claims such as their financial solvency, environmental protection, and social conscience.

Cmeciu (2014) notes that oil corporations frequently use superlative adjectives and positive terms to legitimate their activities within a discourse of scientific expertise. Similar to the previous discursive strategy of 'industrial leadership', this often foregrounds the exceptional status of different employees, operating procedures, safety precautions, etc. Interestingly, according to Cmeciu (2014), oil corporations also employ a discourse of scientific expertise when discussing regulators. This is seen in cases such as oil spill crisis, where oil corporations will background their own knowledge/responsibility/role, and instead bow to the 'expertise' of the regulators. This is 
a strategy that minimizes the blame placed on the oil corporation's responsibility in such an event, and instead makes it seem as though weak regulations are to blame. It is notable that this last strategy seems opposed to the 'industrial leadership' frame. Oil corporations seem to be both lauding themselves as ahead of the industry, voluntarily going beyond existing standards, while simultaneously claiming they are subservient to regulators.

\subsubsection{Summary}

The literature presented here illustrates how oil corporations discursively legitimate themselves through using different strategies and adopting different discourses. It has been well established that oil corporations are faced with a critical need to legitimate themselves and their activities. The way in which they choose to do this is important, as it projects particular "corporate understandings" of environmental issues. As scholars have shown, a discursive approach to the study of corporate discourse and corporate legitimation can help foster an understanding of the ways in which our socially constructed ideas of the 'environment' are influenced by powerful actors. Certain texts, such as annual reports and letters to shareholders, have been the focus of very interesting work, and scholars have shown that these texts often are good examples of CSR reporting and discursive legitimation practices. However, there has also been a call for studying investigating online discourse, such as corporate websites, as they are a critical development in corporate discourse and are increasingly the place of choice for corporations to disclose information about their social and environmental practices.

This provides a theoretical underpinning for this thesis, which focuses on the gatewayfacts website to investigate how, in the context of a particularly controversial project, Enbridge chooses to legitimate itself and its actions. As will be discussed in 
greater detail when presenting and discussing my findings, I intend to illustrate how economic discourses, as well as discourses of leadership and scientific terminology are all employed to legitimate the corporation and the project.

My literature review has illustrated the value of discourse analysis to the study of corporate legitimation. The following sections will outline my framework of critical discourse analysis. I have adopted a framework based on the foundational work of Norman Fairclough $(1989,2001)$, and follow the critically and socially oriented perspective of his work.

\subsection{Critical discourse analysis}

CDA is a particular approach within the larger field of Discourse Analysis (DA), that takes on a critical approach to the study of language and texts (Hodge \& Kress, 1979; Fairclough \& Wodak, 1997; Fowler \& Kress, 1979; Chouliaraki \& Fairclough, 1999; van Dijk, 1985). CDA has grown out of the field of Critical Linguistics (CL), a critical approach to the study of language that began in the 1970's (Blommaert \& Bulcaen, 2000; Wodak, 2011). CL, developed largely by a collection of linguists at the University of East Anglia in the United Kingdom, was based in Michael Halliday's metafunctional grammar and Systemic Functional Linguistics (SFL). Following Halliday, CL relies on the theoretical premise that language and society are inseparable (Halliday, 2003). Fowler and Kress (1979), two pioneers in the field of CL, describe their reasoning behind the need for a more critical, and integrated, approach to the study of language and society: There is a problem for us in discussing established sociolinguistics, which is that the concepts 'language' and 'society' are divided by the sociolinguists, so that one is forced to talk of 'links between the two', whereas for us language is an integral 
part of social process.... Sociolinguistics speaks only of the influence of social structure on (the use of) language. Our analyses suggest that the influence works in the other direction as well. (pp. 189-190)

$\mathrm{CL}$ asserts the notion that there are inextricable mutually constitutive connections between language and society, and follows Halliday's view of language as a "social act" (Halliday, 1993).

Following the appearance of CL, CDA emerged as the field evolved, developed and broadened. CDA is now the more frequently used term of the two, and was largely popularized by Norman Fairclough (1989;1992). Fairclough's 1989 work Language and Power, is often cited as the publication that served as the starting point for CDA. In this first foray in CDA, Fairclough undertook a thoroughly critical and politicized discussion and analysis of powerful discourses. As Blommaert and Bulcaen (2000) describe, Fairclough "offered the synthesis of linguistic method, objects of analysis, and political commitment that has become the trademark of CDA" (p. 454). In his later works, Fairclough (1995a) raised some concern with the early work of CL, commenting on the lack of consideration of the role of audiences, and the absence of intertextual analyses. These comments, among others, reflect the "shifts of focus and developments of theory" (Fairclough, 1995a, p. 28) that have resulted in CDA maintaining a long-standing relationship with CL, but emerging as a distinct approach to the critical study of complex social issues.

van Dijk (1986) describes the aims and goals of CDA as aligned with those of critical science more broadly: 
Beyond description or superficial application, critical science in each domain asks further questions, such as those of responsibility, interests, and ideology. Instead of focusing on purely academic or theoretical problems, it starts from prevailing social problems, and thereby chooses the perspective of those who suffer most, and critically analyses those in power, those who are responsible, and those who have the means and the opportunity to solve such problems. (pp. 4)

$\mathrm{CDA}$, from its critical orientation, is thus fundamentally interested in analyzing and making transparent relationships and connections between discursive practices, social practices and social structures (Fairclough, 1993). These relationships are typically analyzed through the medium of written and spoken texts, and are most often representative of "social inequality as it is expressed, signaled, constituted, legitimized and so on" (Wodak, 2001a, p. 2). However, CDA again distances itself from other forms of DA in that texts are not the sole objects of inquiry. As Wodak (2001a) describes: A fully 'critical' account of discourse would thus require a theorization and description of both the social processes and structures which give rise to the production of a text, and of the social structures and processes within which individuals or groups as social historical subjects, create meanings in their interaction with texts. (pp. 2-3)

Following Wodak, the study presented in this thesis has sought to provide a social, historical and contextual background to the text under analysis. It is important to situate the gatewayfacts website within the social structures that it is shaped by, and is shaping. I have introduced these structures and the context in the chapter that precedes this one. However, to be able to thoroughly and effectively analyze these social processes and 
structures, alongside the linguistic properties of texts, I will draw on CDA's use of a variety of complex social theories and constructs. Thus far in this section, I have provided a brief historical and theoretical discussion of CDA as a holistic research programme. This provides some background to the upcoming section, where I will explain the approach that I have used in this thesis and will overview several key concepts such as 'social practice', 'power', and 'ideology'. This is to clarify the understanding of these concepts from a CDA perspective, and indicate how they will be used in this study.

\subsubsection{Key concepts in CDA}

\subsubsection{Discourse}

Discourse is a term that can reflect profoundly different understandings of the relationship between language, ideology and society (Pennycook, 1994). Discourse can be used as narrowly as to mean language use beyond the sentence level (Brown, 1980), or as broadly as to take a view of the exchange of all individual and collective knowledge throughout all time (Jäger, 2001). Gee (1990) distinguishes between capital 'D’ Discourse, and small ' $d$ ' discourse. The first denotes groups of distinctive identities, beliefs, values, and activities, where language and other forms of social interaction are shaped by specific conventions and norms. For Gee, Discourse denotes an expression of identity and meaning that extends across time and through different iterations of language: "ways of recognizing and getting recognized as certain sorts of whos doing certain sorts of whats" (Gee, 2012, p. 3, emphasis in original). In contrast, Gee (2012) describes small 'd' discourse as referring more restrictively to "any stretch of language in use" (p. 1). 
CDA thus conceptualizes discourse in a very specific way, as a complex process that is inextricably and reflexively linked to the social context in which it is created and used. For example, Machin and van Leeuwen (2007) describe discourses as "socially constructed knowledges of (some aspect of) reality" (p. 59). Chouliaraki and Fairclough (1999) refer to discourses as "semiotic elements of social practices" (p. 38). Wodak (2002) explains that "describing discourse as social practice implies a dialectal relationship between a particular discursive event and the situation(s), institution(s) and social structure(s) which frame it" (p. 7-8). Thus, CDA considers discourse to be both embedded in and constitutive of society - reflecting an important 'social' understanding of language.

For this thesis, I adopt Fairclough's (1993) dual definition of discourse. He defines discourse as both an abstract noun, representing language use conceived as social practice, as well as a count noun, representing different ways of signifying experience based on particular perspectives. With this dual interpretation, I can discuss both Enbridge's corporate discourse - particular instances of language use - as well as various discourses that might influence, shape and determine the former. Additionally, Fairclough's definition foregrounds the importance of language as social practice, a concept which is foundational for this study, and one which I will detail next.

\subsubsection{Language as social practice}

Following Halliday's work, CDA is driven by a foundational understanding of discourse, and language, as inherently social. CDA practitioners see language in use, within a particular context, as "social practice" (Wodak, 2011). This conceptualization of language implies a relationship between a discursive event and the social situation in 
which it exists: the event is shaped by the situation, but also shapes it. As Fairclough and Wodak (1997) describe:

Discourse is socially constitutive as well as socially conditioned - it constitutes situations, objects of knowledge, and the social identities of and relationships between people and groups of people. It is constitutive both in the sense that it helps to sustain and reproduce the social status quo, and in the sense that it contributes to transforming it. (pp. 258)

This view is related to the broader epistemology underlying social constructionism, which holds that "meaning is not discovered, but constructed" (Crotty, 1998, p. 9). This notion also relates to CDA's interpretation of the term 'critical', as it is used in the contemporary sense of a socially and politically informed understanding of society (Wodak, 2011). According to Fairclough (1995b), ‘critique', within CDA's social premise, is "essentially making visible the interconnectedness of things" (p. 36). As discussed in the previous sections of this chapter outlining the existing relevant body of literature, a social constructionist approach to corporate discourse is immensely valuable. I follow corporate discourse analysts such as Livesey (2002) who posit that language is not neutral in its effect but is actually 'doing something'; it is constructing and transforming social conditions and realities. This is also true, as I have previously argued, in considering our interpretations and understanding of environmental issues. In adopting a social constructionist perspective, I argue that notion such as the 'environment' and the 'economy' are not static or neutral, but rather are socially contested and constructed through discourse. The gatewayfacts website is a discursive event that is socially constructed. It is shaped by, and plays a role in shaping existing 
ideas about the world. The way in which that is achieved is through the textual and multimodal choices that its producers have made.

\subsubsection{A system of choices}

Another central assumption of CDA, rooted in SFL, is that communication is achieved through a system of choices regarding grammar and vocabulary. This assumption is derived largely from social semiotics and the work of Halliday, and assumes that as speakers use language, they select specific linguistic forms and processes over others. As Fowler and Kress (1979) argue, these choices are "principled and systematic [rather than] arbitrary or conventional", so that "form signifies content" (p. 188). Put another way, van Dijk (2001), describes how lexical choices and meaning at a local level are "the result of the selection made by speakers or writers in their mental models of event or their more general, socially shared beliefs" (p. 103). Words and local meanings thus can reflect back the mental models - opinions, attitudes and beliefs - of speakers. In sum, language choices are ideologically driven.

\subsubsection{Ideology}

The notion of 'ideology' is a crucially important aspect of CDA. Thompson (1990), describes the study of ideology as "the ways in which meaning is constructed and conveyed by symbolic forms of various kinds" (as cited in Wodak, 2001, p. 10). van Dijk (1998), further specifying the concept, defines ideologies as "the foundation of the social beliefs shared by a social group ... those general and abstract social beliefs, shared by a group, that control or organize the more specific knowledge and opinions (attitudes) of a group" (p. 49, emphasis in original). As just discussed, CDA sees the ideologies of 
speakers as reflected in their language choices. Since CDA views discourse as "doing ideological work" (Fairclough \& Wodak, 1997, p. 262), a fundamental goal of CDA is to highlight the hidden ideologies that are entrenched in and through language use (Pennycook, 2001). As van Dijk (n.d.) describes: "the ideologies of speakers or writers may be 'uncovered' by close reading, understanding or systematic analysis" (p. 135). However, Fairclough (1995) cautions against the assumption that ideological processes may be uncovered through text analysis alone, and describes how in their pursuit of ideology, critical discourse analysts must take into account how:

Ideologies cut across the boundaries of situation types and institutions, and we need to be able to discuss how they transcend particular codes or types of discourse ..., how ideology relates to the structuring and restricting of relations between such entities. (pp. 72)

Ideology then, for CDA, is not solely viewed as existing in lexical choices or local meaning, but rather is present in various levels of a discursive events. This view drives a study of texts and language use, but also the social contexts in which they occur; "ideologies are also being expressed and reproduced by social and semiotic practices other than those of text and talk" (van Dijk, 1998, p. 191, emphasis in orginial). This sensitivity to reducing ideology to the study of discourse relates to the importance of studying semiosis beyond text.

This is a critically important issue, as CDA scholars argue that text analysis on its own it is inadequate as ideological analysis. For this reason, I have chosen to adopt Fairclough's three-dimensional framework (which will be detailed in a following section), which situates textual analysis within further analyses of the production and 
consumption of discourse as well as of the social and historical context. Chapter 2, "Background on the Northern Gateway Pipeline", has provided a thorough background to the case of the NGP and the gatewayfacts website, and seeks to tease out the 'other' social and semiotic practices aside from the text itself. Additionally, as I am investigating online discourse, it is imperative that my analysis, alongside a deeper social understanding, take into account the dynamic and multimodal nature of such texts. To do so, I have incorporated multimodal discourse analysis into my method. This will also be described in greater detail further on in this chapter.

\subsubsection{Power}

The question of power is central to CDA. Foucault (1992) defines power as, "many individual, definable and defined mechanisms which appear capable of inducing behaviour or discourses" (as cited in Jäger, 2001, p. 61). Since discourse shapes and is shaped by social practices, it can have an important impact on the production and reproduction of unequal power relations. As Fairclough and Wodak (1997) state, "the discursive event is shaped by situations, institutions and social structures, but it also shapes them" (p. 258). Language does not merely reflect social processes, but is itself a means of power and dominance. van Leeuwen (1993) refers to discourse as both "the instrument of power" and the "instrument of the social construction of reality" (p. 193). Power is not derived from language, but often contributes or is used to exercise, challenge or alter power distributions (Wodak, 2001). CDA does not view language as inherently powerful, but rather becomes powerful or powerless in the hands of those who use it. This idea is central to CDA, and one of its main aims are to understand and uncover how language functions in the exercise of power (see Wodak, 2011; van Dijk, 
2008; Fairclough, 1995). The notion of power is central to a critical understanding of corporate organizations and will be discussed in the following section.

\subsubsection{Power and organizations}

From a critical perspective, organizations are viewed as political sites where various forms of power and domination are active and can influence decision making and social harms (Alvesson \& Deets, 2000). Organizational discourse has long been a focus of CDA research, and many researchers have attempted to understand and interpret the ways in which organizations "control the way we live and influence the way we think" (Bloor \& Bloor, 2007, p. 5). Critical approaches to organizational research view organizations as having important control in shaping experiences and understandings of the world. Mayr (2008) states that organizations "are primary sites for 'reality construction"” (p. 3). According to Mayr, this reality construction is centred around activities that seek to legitimize organizations' interests and behaviours by transforming or recontextualizing the social reality.

According to Iedema and Wodak (1999), power in organizations is both a product and a process through which an organization organizes activities and sets priorities. Power in this context is (re)produced and propagated through organizational discourses and may restrict people's access to meaning and resources (Mayr, 2008). In this regard, organizational power is closely linked with CDA's stated goals. Critical approaches to organizational research, similar to CDA, often aim to articulate how organizations produce and employ "ideologies which legitimize and strengthen specific societal and organisational social relations and objectives" (Alvesson \& Deetz, 2000, p. 83). 
Through this lens, it is clear that the study of organizational and corporate discourse is an extremely valuable focus for CDA. Powerful corporations shape and construct our social reality through their ideologies. As ideologies are propagated through discourse, and especially through discursive legitimation, studies such as the one presented here offer a perspective onto how corporations are influencing our understanding of specific issues. To achieve my research goals and uncover how the gatewayfacts website represents the NGP, and to what degree it is a legitimation of the project, I have chosen to adopt Fairclough's approach to CDA. The next section will overview this approach, and how it applies to this study.

\subsubsection{Fairclough's approach to CDA}

There are a variety of different approaches within CDA; however, for the present study I have chosen to rely primarily on Fairclough. I also draw on other approaches when appropriate, as different approaches within CDA are complementary. I have elected to follow Fairclough, as not only is his work central to CDA as a research programme, but it is also a flexible approach that applies well to this case.

Over the past 20 years, Fairclough has developed a three-dimensional framework for understanding and analyzing discourse. First outlined in his 1992, Discourse and Social Change, his framework constitutes one of the most comprehensive within CDA (Blommaert \& Bulcaen, 2000; Wodak, 2011; Chouliaraki \& Fairclough, 1999). Figure 1 illustrates this framework: 




Figure 1: Fairclough's 3-dimensional framework

The first dimension of Fairclough's (1992) framework, i.e. the smallest box, is 'discourse as text', i.e., the concrete textual and linguistic features of an instance of discourse. Within this dimension, Fairclough refers to different 'headings' for text analysis: vocabulary, grammar, cohesion, and text structure as well as the 'force' of utterances, the coherence and intertextuality of texts. He posits that these headings pave the way for a complete analysis of the production, interpretation and formal properties of a text. The focus at this level of analysis is the text itself - for this thesis, the gatewayfacts website. In my study, the analysis of text is of critical importance, since the content of the website, including, text, images and design, will be key to answering my research questions.

At this first textual level of analysis, it is also important to highlight that linguistic features such as grammar and vocabulary are not the sole elements worthy of analysis. Since Fairclough first outlined this framework in 1992, CDA has increasingly seen an orientation towards an appreciation of multimodality - the communication of meaning through semiotic modes as well as through language. Multimodal discourse analysis 
(MDA), a method for precise, systematic analysis of semiotic elements has many of the same goals as CDA - that is to investigate the power and meaning of texts. It is novel, however, in that it investigates texts which employ several modes (such as visual, verbal and aural). This approach is central to my study, as in analyzing a website, it would not be a faithful representation to simply look at linguistic elements.

The internet, online media, and computers in general have unquestionably altered the way in which we interact with semiotic modes. Websites are complex, dynamic discursive events; screens rely much more on multiple modes such as images, animations, video, voice, and music than do a traditional 'pages' (Kress \& van Leeuwen, 2001). Websites and other forms of new media have been described as 'sites of display' (Jones, 2009), described as an interaction between the site and those using it. Websites unique characteristics of interactivity, textuality, dynamism, and multimodality make them perfect subjects for MDA.

The approach that will be utilized in this thesis is MDA following Kress and van Leeuwen (1996/2006). This approach, updated and adapted for online media by subsequent scholars, allows for a broad perspective on discourse, and can capture the novel and interesting ways in which websites "constitute a huge repository of potential data about contemporary ways of doing and thinking" (Pauwels, 2012, p. 247). The specific framework, as well as the ways in which MDA has been applied in this thesis is described in greater detail in my "Method" chapter. For the present discussion, I situate my use of MDA within Fairclough's framework. My use of MDA does not neatly fit into one 'dimension', but rather is incorporated through all levels, including the second and third dimensions. 
The second dimension of Fairclough's framework is discourse practice, which "involves processes of text production, distribution, and consumption, [with] the nature of these processes [varying] between different types of discourse according to social factors" (Fairclough, 1992, p. 78). Put simply, this dimension is the aspect that links texts to situational context; it concerns discourse as it is created, distributed, manipulated and used in society. For Fairclough, "discourse practice straddles the division between society and culture on the one hand, and discourse, language and text on the other" (1995, p. 60). Thus, discourse practice can be summarized as 'how words are used'. Fairclough (1992) provides examples of discourse practice as how a text is produced. A new story may have multiple produces (e.g. writer, editor, sources) due to the social context in which that text is produced. The way in which a text is consumed is also not necessarily straightforward. A textbook versus a diary will have very different patterns of consumption - whether they are consumed "collectively" or "individually" will depend on context.

The third dimension is discourse as social practice and references two foundational concepts to his framework and CDA more broadly: ideology and hegemony. Fairclough argues that "ideology is located both in the structures ... which constitute the outcome of past events and the conditions for current events, and in events themselves as they reproduce and transform their conditioning structures" (1992, p. 89). Furthermore, he is not of the view that all discourse is necessarily ideological, but rather that certain discursive practices are more ideologically invested depending on how and to what degree they contribute to maintaining or altering power relations. Fairclough (1992) defines the concept of hegemony as: 
Hegemony is about constructing alliances, and integrating rather than simply dominating subordinate classes, through concessions or through ideological means, to win their consent. Hegemony is a focus of constant struggle around points of greatest instability between classes and blocs, to construct or sustain or fracture alliances and relations of dominance/subordination, which takes economic, political and ideological forms. (pp. 92)

It is from the theories of ideology and hegemony that Fairclough crystallizes his approach to change. As hegemonies and power relations shift and change over time, these evolutions are reflected in discursive change.

Hegemony has a strong connection to legitimation, a focus of concern in this thesis. Hegemony is manufacturing consent and social acceptance not through violence or overt domination, but rather through discourse. Legitimation, similarly, employs discourse to persuade, manipulate, and convince an audience of the rightness of some behaviour to achieve enough social acceptance to operate and pursue it freely (Breeze, 2012). In this way, it can be argued that hegemony is a form of legitimation. Through legitimatory practices, corporations are seeking not to dominate the public, but rather to win their consent. The ties between hegemony and legitimation are a reason for the usefulness of Fairclough's framework for this thesis. As my research questions center around legitimation, parsing the power relations of such discursive practices is crucial.

To summarize, Fairclough's three-dimensional framework incorporates an analysis of a text itself and its textual features, of the discourse practices surrounding the text, and of the social and cultural context in which the text is situation. Chouliaraki and Fairclough (1999) describe Fairclough's framework (in its contemporary form) as a view 
of "what is involved in actually doing critical discourse analysis" (p. 59), and point out that despite its complexity, it can be modified and edited down to the particular case at hand. They posit its value is derived from its ability to "produce theoretically grounded analyses in a wide range of cases" (p. 59). In this thesis, I situate my textual data, i.e. the content and form of the website, in the innermost box, the third dimension of the framework. I interpret the production and reception of the website between Enbridge and the Canadian public in the middle box, the second dimension. Finally, the social and historical context in which the NGP, Enbridge and the website are situated are interpreted through the largest box, the first dimension of Fairclough's framework.

\subsubsection{Validity and limitations of CDA}

CDA, within the paradigm of qualitative research, has been subject to critique and spirited discussions of the limitations of the nature of its existence and practice. As for most qualitative work, within CDA the researcher is the pillar from which data analysis, collection, and interpretation builds. This inherently opens the researcher, and their investigations, to considerations of bias, lack of scientific rigour, and interpretivism. Toolan (1996) claims that "too often, an elaborate theoretical and interpretative superstructure is built upon the frailest of text-linguistic foundations" (p. 93). TyrwhittDrake (1999) strongly voices his rejection of CDA, claiming its "ambivalence towards accuracy and detail", "its penchant for guessing at people's attitudes and motivations", and "its apparent blindness to the danger that is establishing its own hegemony" (p. 1087). Flowerdew (1999) responding to Tyrwhitt-Drakes, argues that this critique largely misses the point, as this reformulation of scientific positivism is irrelevant within CDA. Flowerdew explains that "just as in everyday conversation utterance interpretation 
consists of a narrowing down of possible ambiguities based on context, so it is in discourse analysis"; "where there are multiple possibilities, CDA should put forward alternatives and argue for the most plausible one" (p. 1091). CDA does not strive for absolute 'fact', nor generalizability, but rather implicature and reflexivity (Flowerdew, 1999).

In his vocal critique, Widdowson (1995) argues that CDA is "interpretation, not analysis" and that "what is actually revealed is the particular discourse perspective of the interpreter" (p. 169). His perspective posits that researchers within CDA are driven by their own ideological leanings, and that their choice of texts and analyses correspondingly support their preferred interpretations. In response to Widdowson, Fairclough (1996) argues that his critique does not fully consider the transparency with which researchers in CDA put forward their positions. Within all research, both qualitative and quantitative, it is naïve to see researchers as blank, opinion-less and objective. Researchers, while they may be insulated from their data to varying degrees through their methods, are always ideologically driven. As Titscher, Meyer, Wodak and Vetter (2000) argue, in other social research methods, researcher's underlying motivations, assumptions and ideologies are simply more implicit or not recognized, rather than being absent or harnessed. Put another way, "neutrality itself is not the absence of a position, but one position among others" (Flowerdew, 1999, p. 1097).

Ultimately, CDA is a qualitative research programme that does not claim high moral, analytical, or theoretical grounds. Its findings, interpretations and conclusions are certainly limited to a certain extent. However, "the reflexive and rigourous methods of CDA inquiry enhance [the] researcher's ability to generate valuable interpretations and 
explanations (Liu, 2015, p. 133). Not in search of a singular factual answer, but rather as "students of language", those researchers working within CDA approach texts with a deep appreciation, curiosity and reflexive awareness of the possibilities and limitations of their language (Flowerdew, 1999, p. 1097). However, to achieve the greatest degree of scientific rigour, and to respond to the critiques and inherent limitations of their chosen methodology, CDA practitioners "should try to make choices at each point in the research itself, and should make these choices transparent" (Wodak, 2001, p. 65), and furthermore, "research in CDA must be multitheoretical and multimethodical, critical and selfreflective" (p. 64). In response to these recommendations, my analysis draws from two well established frameworks of textual and visual analysis (see previous sections), and my own perspective and position as the researcher of this study will be illustrated.

\subsubsection{My stance and motivation}

My personal experiences, perspectives, as well as my professional and academic interests all come together to shape my interest and motivation in the current study. Growing up Canadian, in rural Quebec, I was raised to take nature for granted - in the sense that a lush, endless backyard, huge maple trees and a lazy river were steps from my childhood home, and never seemed to me to be anything that would warrant concern, protection or even a second thought. Rather, in my teenage years, raking the endless piles of leaves, living through the 1998 North American ice-storm, and weeding the garden for hours seemed like chores I could not wait to be rid of. Though I didn't know it at the time, I was being raised in a small town where the social norm of left-leaning, environmentalist, and communal thought ruled. After a trip to Prince Edward Island, my 9-year-old self wrote an impassioned letter-to-the-editor to our local paper calling for better recycling 
practices. I played a starring role in our elementary school's musical theatre entitled "Save the Red-Redhorse Fish", in opposition to the expansion of a local bridge. In highschool, my best friend and I giggled as we watered her father's backyard marijuana plants. Aside from what lay outside the door, being raised in a bilingual community also spurred my interest in language. As a part-time minority Anglophone, I was privy to some of the things minority language speakers experience all over the world - something that frankly shocked me. Titled as "L'Anglaise" in a French-language high-school, and frequently told to "go back where you came from", I began to think there was something a little more complicated about language than simply learning it or not.

Moving to British Columbia and the Yukon following my undergraduate degree, my scattered interests of language and the environment came together when I found myself in a community fighting for their natural landscape - at that time the "Protect the Peel" movement to prevent development in the Yukon Peel Watershed. This was against the backdrop of the huge media storm surrounding Enbridge and the Northern Gateway Pipeline. That next summer, I began working for the British Columbia Wildfire Service. Watching first-hand the devastation of logging practices, mono-species reforestation, the Mountain pine beetle outbreak and larger-than-ever wildfires, I was determined to use my graduate degree to learn more about the environmental practices within Canada.

This interest led me to Enbridge and the pipeline project, for all of the reasons I have already stated. As a huge development project, and one that stirs Canadian opinions - mine included - it also presented a unique discursive event in the form of their gatewayfacts website. My interest doubled after discovering that not only was this website a wealth of interesting information and statements on the part of the corporation, 
but the federal government was also directing the public to it for information. Formal contact with the field of discourse studies, critical discourse analysis and multimodal discourse analysis came through my Master's degree, and through two inspiring courses in CDA and environmental discourse.

I wish it to be no secret that I have chosen this topic of study out of personal and academic interest. I would consider myself left-leaning, and certainly care deeply about the environment and western Canada. However, I would never title myself anti-industry, and this study was motivated simply by a desire to understand how the immense project that is the NGP was, and still is, being discussed and negotiated in the public sphere. Due to the small number of studies examining online corporate discourse relating to environmental issues, I believe this study offers a contribution to the existing work on the subject and may serve as a foundation for future research.

\subsection{Conclusion}

A review of the relevant body of literature has shown that oil corporations frequently rely on reporting elements of CSR to refine their dissemination of information on environmental and social activities. Through certain genres of corporate discourse such as annual reports, letters to shareholders, newsletters, and importantly, websites, corporations may employ CSR to discursively legitimate themselves and their actions. Studies that have looked in greater detail at these genres, such as Livesey $(2001,2002)$, Breeze (2012), and Cmeciu (2014), find that indeed these texts do serve as discursive legitimations both on macro and micro levels. Legitimation is often achieved through employing discourses of economic development, a frame of industrial leadership and scientific and technical discourses. However, scholars note that the work on discursive 
legitimation in corporate discourse, and specifically that of oil corporations, remains limited. Indeed, to my knowledge, there is no previous example of an investigation of oil corporations' online discursive legitimation, nor one which examines corporate websites as holistic discursive entities. The case-study presented in this thesis contributes to this important area of discursive legitimation work, as it provides a first foray into examining an oil corporation's project website.

The literature overviewed here also demonstrates the degree to which a discourse analysis approach is useful to the study of corporate discourse generally, and to legitimation in corporate discourse specifically. CDA is a critical and context-sensitive research approach that aims to investigate and influence, unfair social and power relationships mediated through discourse. Under a broad programme of approaches and tools, I have chosen to adopt a combination of Fairclough's three-dimensional framework and multimodal discourse analysis. Responding to important considerations that textual analysis is insufficient for ideological analysis, I believe this blending of approaches allows for a deeper analysis of the social, historical, and political contexts of the NGP and the gatewayfacts website as well as a faithful investigation of the fluid and multimodal nature of online discourse.

Additionally, while Enbridge and the NGP are well covered in the news media, case-study research on Enbridge and the NGP remains limited. Despite being an extremely controversial and significant project in the Canadian context and the project of a powerful and far-reaching national energy corporation, there remains little empirical work on the topic. While the studies that are presented in Chapter 2 provide excellent explorations of the political context, of media representations, and of community 
oppositions, there are no studies to my knowledge that investigate Enbridge's discursive legitimation surrounding the NGP. Thus, this case-study is among the few studies that seeks to examine the NGP in greater detail, and is perhaps the first to offer a greater understanding of the discursive legitimation strategies that Enbridge is employing to shape public opinion regarding the pipeline.

Now, having discussed the scholarship from which this thesis grows, as well as my theoretical framework, in the next chapter I will outline the specific methods I adopted for this study. 


\section{Chapter: Method}

\subsection{Introduction}

This chapter outlines the methods of data collection and analysis used for this study. The primary motivation for the choices I discuss were my research questions, and the research approaches used by existing studies in the literature. My research questions are:

1. How does the "Gateway Facts" website discursively represent (i.e. construct, construe, allude to) the Northern Gateway Pipeline project?

2. In what ways do the different discursive representations serve to frame, treat and construct a legitimation (i.e. justification, rationalization) of the project?

As has been discussed throughout this thesis, but primarily in my "Literature Review and Theoretical Framework" chapter, there is a solid foundation of discursive analysis within the study of corporation and legitimation.

The structure of this chapter is as follows: first is a section detailing the selection of my case and my sampling strategy; next, I discuss the data collection, and describe the data - i.e. the gatewayfacts website; finally, I outline my method of analysis, including the different rubrics adopted for textual and visual analysis, as well as the different analytical tools I have adopted for this study.

\subsection{Selection of a case study}

Purposeful sampling was adopted for this thesis, as this technique allows a researcher to select samples, or in this instance a particular case, on which they can focus in great detail (Patton, 2002; Dornyei, 2007). According to Patton (2002), "the logic and power of purposeful sampling lie in selecting information-rich cases for study in depth" (p. 230). Previous work has shown purposeful sampling to be appropriate and effective for 
investigations of online material (e.g. Liu, 2015; Gee, 2005). Additionally, a smaller sample is useful in CDA for conducting a close and in-depth analysis (Fairclough, 1992; Wodak, 2001b; Liu, 2015).

The NGP was chosen as a particularly interesting and rich case for several reasons. As a large-scale industrial development proposal, this pipeline project has been the subject of enormous political and public discussion - it is a window into $21^{\text {st }}$ century Canadians' divisive opinions over energy and environmental issues within their borders (see Chapter 2 for an in-depth discussion). Due to the intense media scrutiny and public engagement that has followed the project throughout its lifespan, the NGP presents an interesting opportunity to engage with corporate online discourse that has been created, arguably, largely due to this controversy and public interest. Since the project has been approved by the federal government, but not yet fully accepted by the Canadian population, the gatewayfacts website can be seen an interesting example of corporate discourse that is neither responding to an event that has already occurred, as with oil disasters such as the Deepwater Horizon spill, nor offering information in a standardized format such as a report, or letter to shareholders, but rather is a novel discursive event. This makes the gatewayfacts website somewhat contemporary in the scholarly study of corporate discourse, as it is not what is traditionally described as a corporate website, since it relates to a specific project, not to a corporation generally. At the same time, this website is certainly not unique in this sense - there are increasing numbers of projectrelated corporate websites, or project/event websites - and I believe they provide a nuanced and interesting focus for research. 
Additionally, the Enbridge gatewayfacts website was specifically chosen as it is referenced and linked to by the Canadian Environmental Assessment Agency's official webpage. The Enbridge Northern Gateway Project Joint Review Panel's website indicates that "for additional information on the Enbridge Northern Gateway Project, please visit the website of the applicant at www.gatewayfacts.ca " (ENGPJRP, 2012). This is a significant reference, as it offers the website the weight of the endorsement of the federal government. Further, the reference changes what could be seen as a simple promotional, public-relation type website into a source of government endorsed information on the project.

Finally, the NGP is a particularly topical case within the study of environmental discourse, as the oil and gas sector is increasingly becoming a significant concern of public interest and scholarly study. Increasingly the focus of negative attention (see Klein, 2014; McKibben, 2012) relating to environmental issues, the energy industry has shifted in recent years to move towards communicating environmental concern and investment (de Vries, Terwel, Ellemers \& Daamen, 2015; Schlichting, 2013). Correspondingly, the investigation of the oil and gas industry's corporate discourse as related to environmental issues has been of great interest, and has been increasingly called for by scholars in the field.

\subsection{Data}

\subsubsection{Data collection}

Data was collected in the April of 2015, and was captured in the form of screen shots of each of the individual pages and linked documents available through the website. This is a somewhat disingenuous static and two-dimensional representation of the inherently 
interactive and mobile nature of online discourse, but was deemed necessary within the constraints of this analysis (for a discussion see Bergman \& Meier, 2004). Based on a pilot study of the website in April 2015, the analysis described in this thesis started in August of 2015, and continued over the following six months. Carried out in what roughly approximates to three stages - textual analysis, multimodal analysis, and social analysis -the analytical process will be described in greater detail in the following sections.

\subsubsection{The gatewayfacts website}

The data for this thesis comprises the www.gatewayfacts.ca website, more specifically, several 'pages' within this website relating to Enbridge's proposed, promised or stated remarks about the pipeline project. At the time of analysis, the website was divided into six main sections, indicated by headings running across the top of each page of the website: About the Project, Conditions, Environmental Responsibility, Owning our Future, Benefits, and Engagement.

Reflecting one of the challenges in investigating online discourse, the website has since been updated (see, for example, Figures 2 and 3): the main sections of the website are now About, Our Focus, Aboriginal Ownership, Sustainability, Safety, Benefits, Regulatory, and Connect. Future, Benefits, and Engagement. 


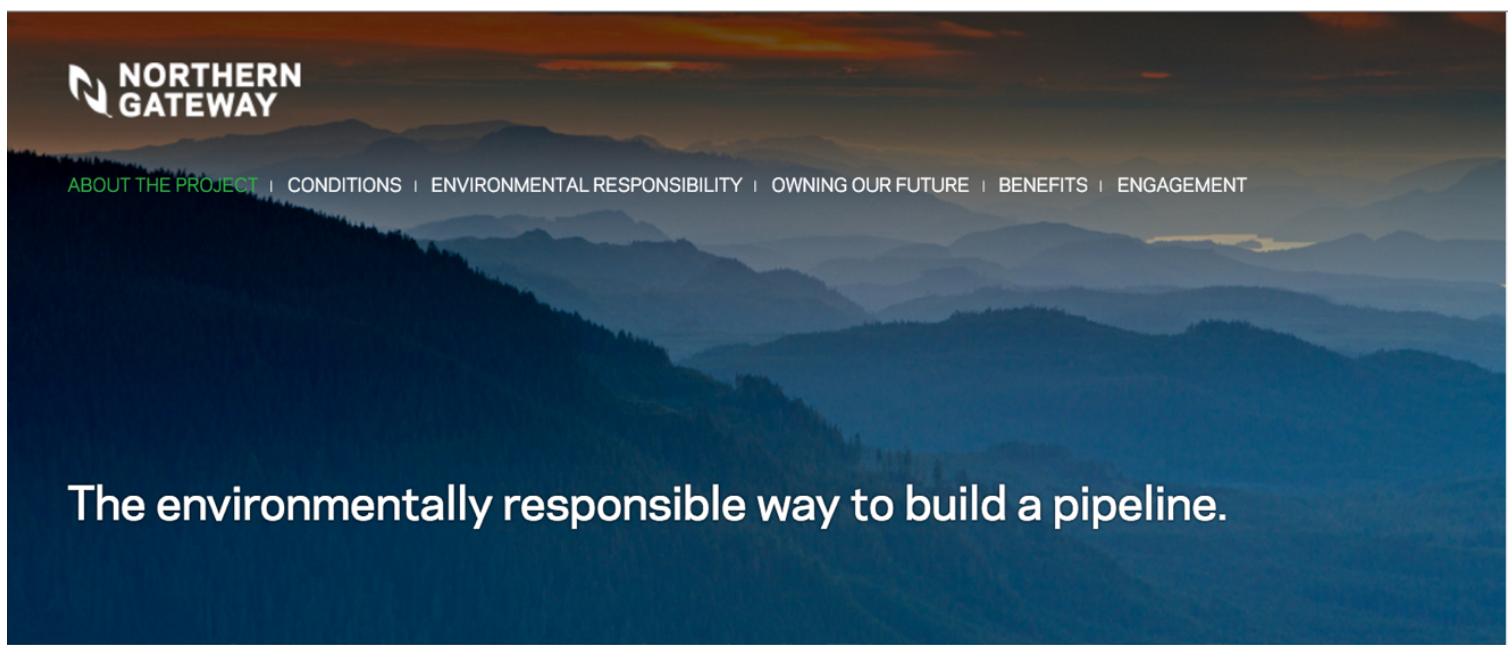

Was this informative? Share it here. $\mathbf{f} \mathbf{g}^{+}$

The Challenge

Canada's most valuable resource is crude oil, with $99 \%$ of all our oil exports going to the United States at discounted prices.

\section{Our Solution}

The $\$ 6.5$ billion Northern Gateway Pipeline will provide access to new markets in the Pacific Rim. More than that, the pipeline will be a model of world-class safety and environmental standards.

Figure 2 - Gatewayfacts retired "About the project" page

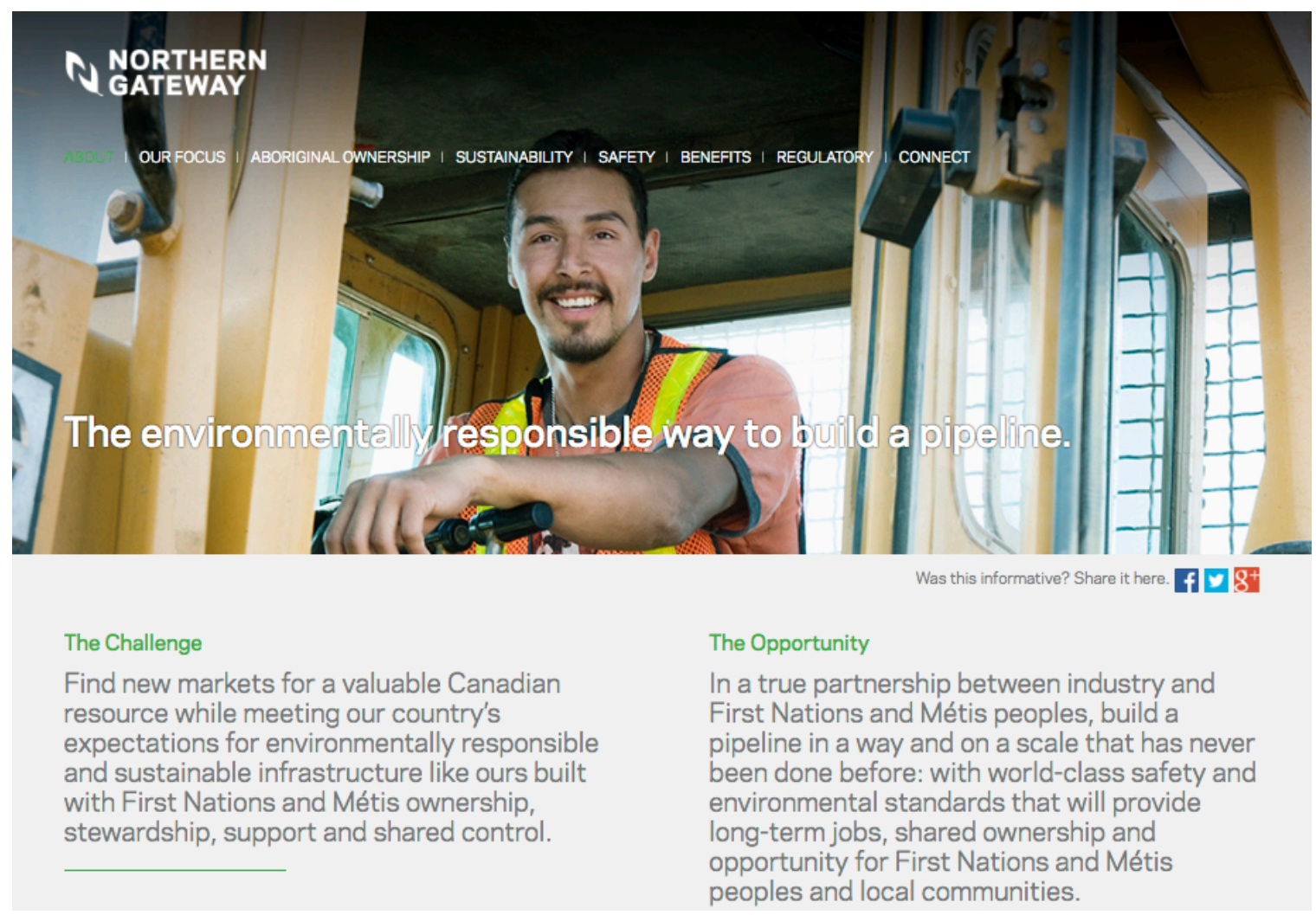

Figure 3 - Gatewayfacts updated "About the project" page 
This change was made in late spring 2016, following the bulk of the analysis for this thesis, and so the discussion and conclusions drawn from my study will be based on the earlier configuration of the website. It is worth mentioning that while this fluid nature of online discourse can be challenging to a researcher reliant on static text, the discursive shift within this website also presents a fascinating opportunity for future study.

The main headings of the website are themselves sites of action (Adami, 2014); if hovered over with a mouse/pointer, they present a further layer of headings, what I will term here the subheadings of the website. Thus, the hierarchy of the website is the following:

- About the Project

- Overview

- Conditions

○ 5 BC Conditions

○ NEB Conditions

- Environmental Responsibility

○ Land

○ Marine

- Owning our Future

- Benefits

- Benefits to Alberta

- Benefits to BC

- Economic Benefits

○ First Nations

○ Jobs and Training

○ Opportunities

- Engagement 
Through interaction with either a heading or subheading, a user is taken to the corresponding webpage, where they are presented with text, images and often hyperlinks to further documents, or to other websites. All of the pages are very similar in design, with a prominent image at the top of each page followed by short blocks of text and simplistic images lower down on the page (see Figure 4).

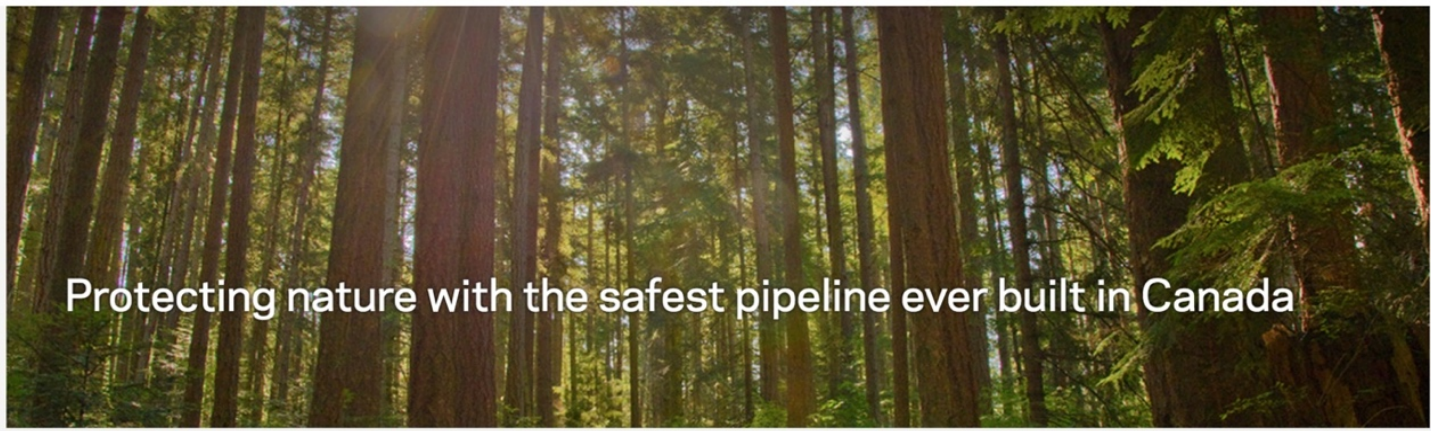

The Challenge

British Columbia's five conditions for pipeline approval include a land safety provision with world-class prevention, response and recovery standards.
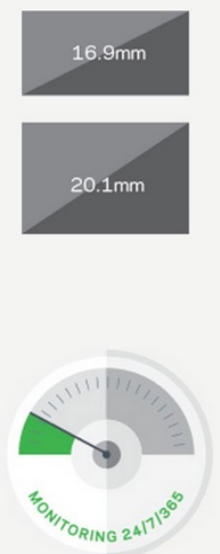

A better pipeline by design

Our pipelines will be constructed to new standards, including:

Steel that is, on average, $20 \%$ thicker than required.

X-ray or ultrasonic testing of all welds.

Durable coating system and cathodic protection against corrosion.

Around the clock monitoring

The pipeline will be monitored 24/7 from our control centre. Remote pump stations will be staffed piperial surveillance of the pipeline will occur bi-weekly,
Our Solution

From pipeline safeguards through route planning, construction, monitoring and emergency response, we're going over and above to build the safest pipeline Canada has ever seen.

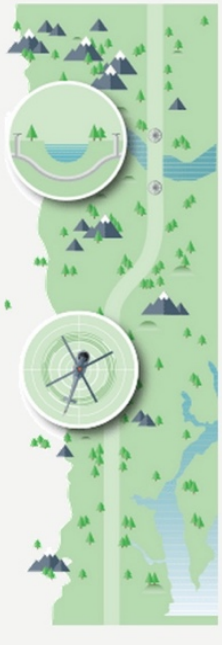

A land route that minimizes our footprint

Previously disturbed land will be used for $70 \%$ of the pipeline route, including old forestry roads, cut blocks and other linear corridors. The pipeline will be dug deeper under watercourses for added protection. Ten pump stations will be powered by electric pumps to limit noise and greenhouse gas emissions

Adding safety features for added protection

We will have 132 remotely operated isolation valves on each pipeline, dual leak detection analysis and additional in-line inspection systems to ensure safe operation of the pipeline.

Figure 4: Gatewayfacts "Environmental responsibility: Land" page

The complete content of the gatewayfacts website, including all the subpages, and various other relevant linked websites and documents, such as media articles or 'fact 
sheets', constitute the data for this thesis, and have been analysed using critical discourse analysis and multimodal discourse analysis. Both the linguistic text, as well as visual aspects such as photographs, icons, maps, etc., were collected, as visual information is always inseparable from the text with which it is paired, and because visual information is a powerful semiotic tool that can help persuade audiences (Kress \& van Leeuwen, 1996; Phillips \& McQuarrie, 2004). More specifically, I have employed several specific tools under the umbrella of these methodologies, such as analyses of lexical choice, overlexicalization, metaphors and euphemisms, page design and image composition. These tools will be discussed in the following section.

\subsection{Method of analysis}

As just described, the method of analysis that I have adopted for this thesis is a combination of analytical tools employed by CDA and MDA practitioners. This follows with the core principles of CDA, as mirroring the lack of a single theoretical backing, "neither is one specific methodology characteristic of research in CDA" (Wodak, 2011, p. 50). Instead, CDA frequently employs a wide range and variety of analytical and grammatical approaches (Wodak, 2011). Falling under the broad research paradigm of qualitative research, $\mathrm{CDA}$ and MDA are often iterative, emergent, and interpretative processes (Fairclough, 2001; Creswell, 2014; Denzin, 2004). This thesis follows this qualitative approach, as my analysis was carried out in multiple stages over a period of 8 months but did not necessarily follow a linear progression.

As outlined in my "Literature Review and Theoretical Framework" chapter, this thesis generally follows the work of Norman Fairclough, and employs his threedimensional framework (for greater detail on this framework, see section 3.5.2). To 
summarise, this framework includes a consideration of text, discourse practice and sociocultural practice. In applying this framework to my analysis, I have followed Janks' (1997) interpretation and use of Fairclough's work. She notes that the framework is designed so that an analyst may move between different levels of analysis as they see fit, since the different 'boxes' are not separate from one another, but rather are filled in iteratively and as is most appropriate. Practically speaking, to achieve this, I built an extensive collection of notes, observations and impressions. I returned to this notes throughout my analysis, but also throughout my extensive literature review, confirming, modifying and adding to them as I went along. By using this method of analysis, I was able to iteratively situate my findings within Fairclough's framework. Importantly, while this notes were recorded manually, they were guided by specific analytical tools, which will be briefly outlined in the following sections.

\subsubsection{Textual analysis}

Fairclough (1989) posits that "a text's choice of wordings depends on, and helps create, social relationships between participants" (p. 116). Lexical choices are ideologically significant and represent an important motivation on the part of the author. They convey meaning "in particular ways and to have particular effects" (Janks, 2005, p. 97). As illustrated throughout my review of relevant literature, lexical analysis has been widely used to study discourse, as it is through lexical choices (but not exclusively) that text producers make obvious their stance, representations, ideologies and discourses (Stamou \& Paraskevopolous, 2004; van Dijk, 2001). In order to maintain a systematic approach to textual analysis, I have adapted Janks' (2005) linguistic analysis rubric. Based on Fairclough's method of CDA and Halliday's (1985) functional grammar, this 
rubric allows for analysts to examine "a range of linguistic features" which in turn "[offer] a different window on the text" (Janks, 2005, p. 104). My coding process followed pertinent aspects of Janks' linguistic rubric (see Appendix A). While the rubric is extensive, and though it is beyond the scope of this thesis to elaborate on each of the elements, I will discuss a few in greater depth. These are some of the tools that are most relevant to this study, and those which are important in discussing my findings.

\subsubsection{Overlexicalization}

Overlexicalization, as simplified by Janks (2005), is using "many words for the same phenomenon" (p. 101). More than this however, it is ideologically driven in that the repetition of words or synonyms can often have a pejorative effect. Fowler et al. (1979) describe overlexicalization as a "pragmatic strategy of encoding ideology" (p. 21). Machin and Mayr (2012) also argue that by giving a text a sense over-persuasion, overlexicalization can be seen as evidence that something is problematic or of ideological contention. They offer an example, showing how phrases such as "the unpatriotic forces of Marxist subversion", are excessively descriptive, and point to some anxiety on the part of the author. Phrases such as this are notable, as they point to a preoccupation with a particular dimension of reality (Dunmire, 2005). An abundance of particular words, synonyms, or the like can point an analyst to sites of ideological struggle.

\subsubsection{Metaphor}

Fairclough (1995) argues that metaphors are ideological because of the way that they conceal and shape understandings while simultaneously making it seem like they reveal them. Metaphors are a useful linguistic resource when there is a desire to conceal 
processes, identities, and settings through replacing them with abstractions. By highlighting one aspect of a situation, and backgrounding others, metaphors can be used to legitimize some arguments and delegitimize others (Machin \& Mayr, 2012). An example of metaphor is a phrase such as 'the housing market bubble has burst'. Comparing the housing market to a bubble greatly simplifies the complex economic and social structures involved, and implies that the 'market' is always fragile (Machin \& Mayr, 2012).

\subsubsection{Euphemism}

Euphemism, as a discursive strategy, is the use of avoidance and evasive language to sidestep negative, offensive, or distasteful statements (Allan \& Burridge, 1991). van Dijk (2006) argues that like metaphors, euphemisms are used to emphasize or de-emphasize ideological meanings. Euphemisms, essentially using only positive terms to describe an entity or phenomenon, hide negative actions or implications. In this way they are crucial to discursive strategies such as legitimation, as they are clearly shifting readers towards positive interpretations. van Dijk (1992) demonstrates how euphemisms can represent a form of denial, as through minimizing acts and backgrounding those responsible, this discursive strategy can both dispute and conceal agency. He offers the example of racism in the press, where racism is described as 'the fragile nature of race relations' and as a 'misunderstanding and distrust between parts of the community' (van Dijk, 1992, p. 106). This euphemistic description of racism as 'fragile' and 'misunderstood', suggests that there is not one party responsible for the inequality, but rather it is the burden of the community as a whole. In this way, euphemism conceals the agents of racist behaviour and mitigates their responsibility. 


\subsubsection{Personification/objectification}

Personification is achieved through assigning human qualities to abstractions or inanimate objects (Machin \& Mayr, 2012). Similar to euphemism, this linguistic strategy obscures the actual agents and processes behind a reality, as it foregrounds an entity that cannot be an agent. Machin and Mayr (2012) offer the example of phrases such as 'democracy will not stand by'. As democracy is not an agent, through personification this phrase ultimately conceals who is actually being referenced. De Cilla, Reisigl, and Wodak (1999) illustrate how personification is often combined with other tropes of metonymy and synecdoche. These discursive strategies can create a sense of 'sameness', in that they take a large, often inanimate entity, and use it to essentialize and generalize stereotypes. These authors note that this is especially true when looking at the discursive construction of national identity, where the abstract entities of nations are frequently used to represent groups of people. This use of personification is illustrated by phrases such as 'Austria was not born to wage war' (De Cilla, Reisigl, \& Wodak, 1999). In this way, personification can be used to further a particular understanding and conception of ‘identity'. Vaara (2014) also notes that personification is an important discursive strategy of legitimation. He points out that personification is often employed to offer authority to inanimate entities, such as 'the market' in economic discourses. Explicit in phrases such as 'the markets responded in an excited way', Vaara argues that personification helps to position 'the market' as a central authority with the power to evaluate success and failure, and represents van Leeuwen's (2008) notions of 'expert' and 'impersonal' authority. As will be illustrated, legitimation, economic discourse and authority are all salient themes to this thesis and its findings. 


\subsubsection{Lexical cohesion and structural opposition}

Halliday's $(1978,1985)$ work explains that words exist as elements of a network of meanings, such that they are not independent. Summarized by Stamou and Paraskevopolous (2004), this notion refers to the "unifying relations established among elements of a text that ... give texture to a text, namely, the property to be a unified whole not a total of unconnected elements" (p. 113). Important for this study, within a network of meanings, many words exist in inherent opposition to one another, such as good-bad, light-dark, up-down, etc. The oppositions represent clearly opposing concepts, and when only one is used in a text, it often implies a difference from its opposite. Thus, when we discuss the behaviour of a 'good' person, we can assume that a 'bad' person would likely act in a completely opposite manner. Structural oppositions are not always as obvious as this, and often are achieved through using clusters of concepts. This essentially means that two different sets of terms are used to describe two entities. An example would be to discuss a sporting, ambitious, and handsome man versus a slipshod, slow and clumsy opponent. While there is no overt discussion of who is 'good' and who is 'bad', it is clear how the participants should be evaluated.

\subsubsection{Multimodal analysis}

As mentioned, in addition to text, visual information from the website was also collected and analyzed. My analysis follows the work of Kress and van Leeuwen (2006), and agrees with their view of "[seeing] images of whatever kind as entirely within the realm of the realizations and instantiations of ideology, as means - always - for the articulation of ideological positions" (p. 14). Images obviously constitute an incredibly important aspect of webpages, and certainly contribute to shaping the ideological slant of the 
website under investigation. Bergman and Meier (2004) posit that webpages should be understood as their own communicative genre:

Such pages normally consist of a wide variety of elements: formatted text, graphics, coloured background, animated illustrations, embedded video-clips and possibly background music merge here into a hybrid with different interpretation requirements than a text that is script-based or has linear construction. (pp. 244)

The framework presented by Kress and van Leeuwen offers a methodical and precise means by which to examine visual data in conjunction with text. However, as their framework applies to a wide scope of multimodal discourse, in order to further focus my analysis, I have adopted Liu's (2015) rubric for visual analysis, constituting a condensation of Kress and van Leeuwen's work as applied to online discourse (see Appendix A). As with the earlier section of this chapter on textual analysis, I will now briefly discuss some of the most relevant tools from this framework.

\subsubsection{Composition}

Composition is essentially the layout of text, images and other elements on a page. For analysis, composition is usually considered in terms of whether the elements appear on the left/right, top/bottom/center/margin, etc. Kress and van Leeuwen (1996/2006) posit that in Western cultures, the 'left' often represents information that is 'given' (known), while the 'right' often represents information that is 'new'. It is also associated with notions of the past and present: past is presented on the left, while the right presents the present or future. The 'top' and 'bottom' positions in compositions are associated with the 'ideal' and 'real', respectively (Kress \& van Leeuwen, 1996/2006). For a visual representation, see Figure 5. 


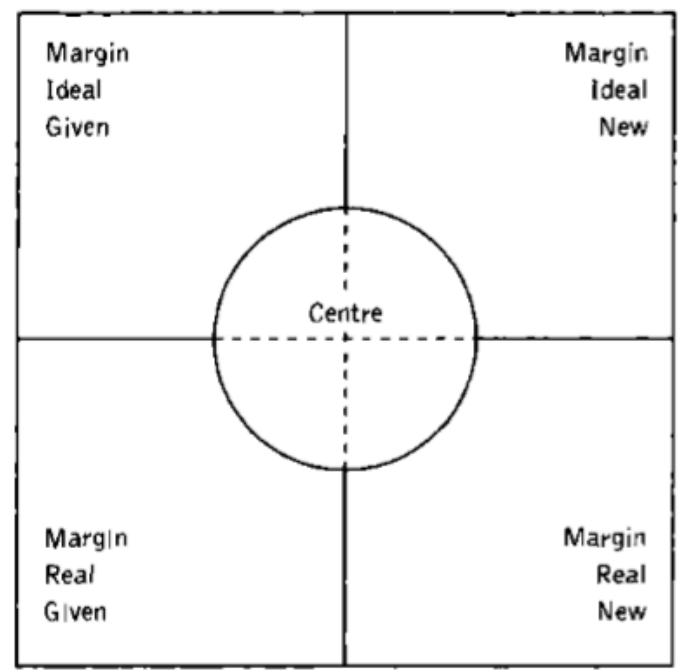

Figure 5: Kress and van Leeuwen's composition grid

\subsubsection{Text-image relations}

van Leeuwen (2005) has developed a framework to cross-analyze visual and textual elements of a text (see Figure 6).

\begin{tabular}{|l|l|l|}
\hline \multicolumn{2}{|l|}{ Image-text relations } \\
\hline Elaboration & Specification & The image makes the text more specific (illustration) \\
\cline { 2 - 3 } & & The text makes the image more specific (anchorage) \\
\cline { 2 - 3 } & Explanation & The text paraphrases the image (or vice versa) \\
\hline Extension & Similarity & The content of the text is similar to that of the image \\
\cline { 2 - 3 } & Contrast & The content of the text contrasts with that of the image \\
\cline { 2 - 3 } & Complement & $\begin{array}{l}\text { The content of the image adds further information to that of the } \\
\text { text, and vice versa ('relay') }\end{array}$ \\
\hline
\end{tabular}

Figure 6: van Leeuwen's image-text relation chart

This framework highlights two types of relationships between text and images:

elaboration and extension. The first is where an element repeats or restates information for the purposes of clarifying. The second is where an element adds new information that 
is linked to existing information. van Leeuwen (2005) offers several further distinctions of these relationships.

\subsubsection{Framing}

van Leeuwen (2005) discusses framing as how a text is divided into different sections. He notes six different types of framing: segregation, separation, integration, overlap, rhyme and contrast. Segregation is dividing an image into different sections through the use of clear boundaries or borders. van Leeuwen notes that segregation often creates a divide between fantasy and reality. Separation is division through the use of spacing and the use of distance. Integration is where a text and an image occur together in the same space. Overlap is when text and image occur in one another's spaces. Rhyme is when elements share similar qualities, such as colour, shape, pattern, typeface, etc. Contrast is the opposite - that is where elements have opposing qualities.

\subsubsection{Sociocultural analysis}

Finally, relying on Fairclough's (2001) theoretical perspective of the societal dimension of inquiry, I have chosen to round out the analysis presented in this thesis with a broad discussion of the larger cultural, historical, and social discourses into which this website is embedded. By moving from the textual and visual micro-level to this more explanative macro-level, this analysis aims to achieve CDA's overarching goal of raising awareness of social constructions: "making visible the interconnectedness of things" (Fairclough, 1995, p. 747). This also follows with Kress and van Leeuwen's (2001) recommendation that contemporary multimodal analysis should be situated within a broader analysis and discussion of discourse, design, production, and consumption. 
There are no set ways or tools by which to achieve a sociocultural analysis, and I have chosen to investigate the cultural, historical, and social through reading literature rooted in a number of different fields and theoretical perspectives, including Business Communication, Environmental Communication, Critical Discourse Analysis, Critical Theory, Political Theory, Media Studies, Organisational Studies, Eco-linguistics and Geography. This literature discussed, and both lauded and critiqued, corporate discourse and environmental communication. The literature helped me to understand the notions of corporate discourse, corporate social responsibility and legitimation, as well as the wider discourses and ideologies associated with the case of the NGP and the gatewayfacts website.

\subsection{Conclusion}

The function of this chapter was two-fold: to present and contextualize the data I have analyzed for this thesis and to explain the analytical tools I adopted for my analysis. I have also explained my reasoning for selecting the case of the NGP and the gatewayfacts website, and mentioned some of the challenges that have come with the selection of an online text. The next chapter will overview the findings from my analysis. 


\section{Chapter: Findings}

\subsection{Introduction}

The goal of this study is to investigate and come to understand how the gatewayfacts website employs language, both textual and visual, to discursively represent and construct a legitimation of the Enbridge NGP project. The purpose of this chapter is to provide a detailed analysis of the way in which this website uses text and visual design to present the NGP project in a positive light. This chapter outlines the textual, multimodal, and social analyses that I conducted on the gatewayfacts website.

The findings presented here focus on emergent themes (Given, 2008) derived from the data. Previous research in the areas of CSR, legitimation theory, as well as environmental communication and corporate discourse all inform this analysis (see the "Literature Review" chapter). This chapter is organized around the presentation of four themes:

1. Economic development

2. Scientific and technical expertise

3. Environmental stewardship

4. Industry leadership

\subsection{Review of analytic approach}

Following CDA, the approach used in my study relies on Fairclough's (1992) threedimensional framework as well as Kress and van Leeuwen's (1996/2006) multimodal discourse analysis. For textual data, my analysis focuses on aspects such as descriptors (e.g. word choice, sentence structure), use of metaphor, overlexicalization, use of 
personalisation, and lexical cohesion. For more detail, see Appendix A. The goal of textual analysis, according to Fairclough (1995), is to analyse both the content and form of texts. This necessarily involves consideration of linguistic elements (vocabulary, grammar, etc.) alongside visual elements (images, page composition, etc.). The multimodal and social analyses will be outlined alongside the textual analysis to provide depth and context to my findings. For the multimodal analysis, I have followed work of Kress and van Leeuwen (1996/2006) and Liu (2015), focusing on aspects such as composition, colour, font, spatial relationship, participants, symbolic attributes and sequencing of information. For more detail, see Appendix B. The social analysis, following Fairclough (2001), is a discussion of the broader cultural, historical and social discourses into which the gatewayfacts website is embedded. I have elected to integrate the social analysis into this chapter by providing a discussion and 'editorializing' of the emergent themes found in the data. The social analysis will also be elaborated upon in the following chapter, Chapter 6 , which provides a broader discussion and summary of my findings.

\subsection{Emergent themes}

\subsubsection{Economic development}

\subsubsection{An economic 'public good'}

The gatewayfacts website devotes enormous attention to the potential economic benefits of the NGP project, including employment (namely job creation), government revenue, foreign investment, as well as community revenue (First Nations communities are highlighted here). Highlighting and lauding economic benefits and development tied to natural resource extraction has become a common discursive strategy used by the fossil 
fuel industry and their proponents (see Chen \& Gunster, 2016; Davidson \& Gismondi, 2011; Gunster \& Saurette, 2014). Through the use of lexical choices, overlexicalization, modality, and other discursive strategies, the gatewayfacts website presents oil as an essential Canadian good, and the pipeline project as a universal benefit to Canadians. For example, the "About" page proclaims:

“Canada's most valuable resource is crude oil."

The "Benefits" page asserts that:

"The Northern Gateway Pipeline will bring significant and long-lasting economic and social benefits to Albertans, British Columbians and all Canadians.”

This claim portrays both oil and the NGP as a Canadian "public good" (Gunster \& Saurette, 2014), reinforcing the assertion that this project, coupled with the oil industry, is part of the economic engine of Canada that distributes benefits and wealth to all Canadians. This discursive strategy appears within discourses of economic development used elsewhere by proponents of the oil industry. Gunster and Saurette (2014) found that in the Canadian news media, "[oil] benefits were consistently described as flowing to all Canadians, positioning oil sands development as an unequivocal public good" (p. 344). However, despite this representation, there is a significant asymmetry between revenues derived from oil sands activity and royalties imposed by the Alberta and Canadian governments. The Parkland Institute, a progressive think-tank based at the University of Alberta posits that:

Since 1986, more than $\$ 285$ billion worth of bitumen and synthetic crude oil have been produced from the tar sands. From these resources the oil companies have netted approximately $\$ 260$ billion dollars in pre-tax profits, while the public has 
received less than $\$ 25$ billion in return... . That means roughly $6 \%$ of the total value extracted from the tar sands has gone to the public through royalties and land sales. (Campanella, 2012, pp. 7)

Unsurprisingly, the distribution of revenues is not addressed on the gatewayfacts website, despite the reliance on touting future economic prosperity and seemingly huge tax revenues that will result from the project. This leads to a situation where it is difficult for the average reader to interpret numbers such as "gains of over $\$ 80$ billion”. Without information on how the Canadian provincial and federal governments will profit compared to the corporations involved, it seems hard to interpret whether this project is truly a 'public good'. However, this representation is pervasive throughout the majority of the economic development theme.

There is also a particular emphasis on the need to 'diversify' and bring Canadian oil to foreign - namely Asian - markets. The website stresses the potential and importance of this economic diversification on several occasions, such as on the "About" and "Benefits" pages:

“The \$6.5 billion Northern Gateway Pipeline will provide access to new markets in the Pacific Rim.”

"Diversifying export markets for our most valuable resource is imperative to ensure the strength of our social programs."

Canada's former Prime Minister, Stephen Harper, has repeatedly echoed this imperative for diversification and expansion of Canadian oil markets:

We must diversify our energy export markets ... We have taken a significant price hit by virtue of the facts that we are a captive supplier and that just does not 
make sense in terms of the broader interests of the Canadian economy. (cited in Weese, 2012)

The economic growth we expect to have here in the future is going to be based on commerce with the Asia-Pacific region and we think it's important that we continue to diversify our exports through [British Columbia]. (cited in Fekete, 2012)

This 'diversification' and implied economic expansion are thus tied not only to the lives of Albertans and British Columbians, but to all Canadian citizens. Not only does this project hold huge potential for those in its direct path, the decisions tied to it will affect the Canadian economy as a whole. This discursive strategy of equating pipeline development with market diversification and consequently with economic expansion and stability thus positions those opposed to the NGP as not simply opposing pipeline construction, but opposing the Canadian economy. Similarly, this positions the project in a positive light, as not only is this in the interests of western Canadians, but this project will bring prosperity and benefits to all Canadians throughout the country.

Also in line with this representation of the NGP as an economic 'public good', the website emphasizes the ties between oil and Canadian social services. Here, the gatewayfacts website is tying into a noted discursive strategy of "'life' made possible through petroleum" (Huber, 2012).

“A vital infusion of funding for B.C.'s schools, healthcare system, social programs and infrastructure.” 
"Governments are expected to realize gains of over $\$ 80$ billion in tax and royalty revenues-that's a lot of money we can use to help fund our education, health and infrastructure needs.”

With phrases such as these, the website is subtly reminding readers that essential government services are crucially tied to the oil economy and may depend upon its revenue. This again echoes the subtle discursive shift to equating the pipeline to grander Canadian public needs, in this case not the economy, but government services. Those resisting the pipeline are thus presented as resisting additional funding for social services, and stand against 'injecting' money into schools, health care, and infrastructure.

This relationship of oil-services has also been discussed by others, though in less optimistic terms. Landon and Smith (2010), writing for the C.D. Howe Institute, describe Alberta's precarious revenue situation:

Government revenue volatility can have important negative consequences. A government that wishes to provide infrastructure and social services at a level that is sustainable in the longer term will have difficulty setting the appropriate level of spending when it is not clear what part of volatile revenue changes is permanent and what part is temporary. Revenue volatility can also make it more difficult for a government to put in place long-term plans if volatility undermines the government's credibility in terms of its ability accurately to forecast and manage revenues. The two provinces most heavily reliant on volatile energy revenues, Alberta and Saskatchewan, have the worst records at hitting budget targets. (pp. 1)

The Canadian Center for Policy Alternative (CCAP) notes: 
With virtually no oil wealth set aside and insufficient revenue flowing into government coffers, Alberta has been running deficits for the last three years. Its education, health care, and other public services are underfunded. Inequality and poverty in the province are among the highest in Canada. (Campbell, 2012)

It is unclear whether, and to what degree, development projects such as the NGP will benefit Canadian social services and infrastructure projects. The revenues derived from the oil and gas industry are certainly a healthy force within the Canadian economy and contribute to the funding of public services. Positioning the NGP as a direct source of wealth for "education, health and infrastructure", the gatewayfacts website presents this project as an undeniable economic public good.

\subsubsection{Job creation}

The website, within its theme of economic development, frequently details the job creation that will accrue from the NGP. For example, the "Benefits" page describes how:

"In B.C. alone, Northern Gateway will help create 3,000 new construction jobs and 560 new long-term jobs. The $\$ 32$ million per year earned in salaries will directly benefit the families and economies of these communities."

This statement is echoed, in fact almost directly repeated, on the "Conditions" page:

"B.C. can look forward to $\$ 1.2$ billion in tax revenue, and $\$ 9$ billion in government revenue over 30 years. Plus 3,000 construction jobs and 560 longterm jobs.”

Further, in the linked "Fact-Sheet Aboriginal Benefits" document, it is stated that: 
“Overall, Northern Gateway expects to create 62,700 person-years of construction employment through Canada over the 3-year construction period of which $24 \%$ will occur in Alberta and $57 \%$ will occur in BC".

Across the website, there is a clear overlexicalization of " 3,000 construction jobs" and "560 long-term jobs" as well as the terms 'employment' and 'jobs'. Frequently the same page will reference these statistics and the potential for job creation multiple times. It is also interesting to note the use of "62,700 person-years" as a metric for evaluating employment. I would argue this number is relatively unintelligible to most readers, and seems to be one example of a rather obvious attempt to use large, seemingly impressive numbers whenever possible.

This representation of job creation within the larger theme of economic development conforms to the well-known extractive conflict discourse of a job-versusenvironment dichotomy (Rich, 2016; Jakopovich, 2009; Matz \& Renfrew, 2015). Jakopovich (2009) notes that this "false dichotomy" (p. 79) has been reinforced by corporations and mass media, and has generally shaped a common-sense perception that environmental protection is contrary to economic expansion, employment preservation, and the interests of workers. He goes on to explain that this impression is largely unfounded, as research shows that environmental protection enterprises most often have a positive effect on levels of employment. For example, in the case of public transit, generally a campaign theme on the side of environmentalists, studies show potential for increased wages for the low-income working class (Heres, Jack \& Salon, 2014), boosting urban labor participation (Sanchez, 1999), as well as meeting the labour needs of employers and businesses (Topalovic, Carter, Topalovic \& Krantzberg, 2012). This is 
alongside health benefits such as the potential for reduced smog and air pollution (Kimball, Chester, Gino \& Reyna, 2013), lower obesity rates (Topalovic, Carter, Topalovic \& Krantzberg, 2012), and more general health benefits associated with active commuting (Sallis, Frank, Saelens \& Kraft, 2004). Unfortunately, because environmental protection proposals, such as public transit, are often in opposition to fossil-fuel industry interests, communities and workers are discursively presented with a false choice between employment and clean water, air, and land (Rich, 2016).

Enbridge engages in this "false dichotomy" discourse with job growth clearly a focus of their gatewayfacts website. This appears to be a strategy aiming to alleviate public concern through demonstrating the significance of the project and its connection to working-class Canadians. Bringing employment, in the form of 'construction' and 'longterm' jobs, can be seen as a sort of cost-benefit balancing of environmental harm. However, similar to the aforementioned use of huge sums (e.g., $\$ 80$ billion) without any relevant context, Enbridge's naming of " 560 new long-term jobs" and "3,000 construction jobs” is difficult to interpret objectively. Certainly, '3,000 jobs' sounds like a significant number. Once again, however, when placed in context with employment sectors of both B.C. and Alberta, these numbers do not appear as impressive as they might at first glance. As Le Billion and Vandecasteyen (2013) describe, even if the NGP was to result in the promised 3,000 construction jobs, these would largely be situated in Alberta. Approximately 133,000 people were employed in Alberta's energy sector in 2014 (Alberta Energy, n.d.). The number of 3,000 construction jobs, if compared to this statistic, would represent $0.02 \%$ of total employment. Any risk of environmental impact would see the most significant repercussions on the B.C. coast, home to over 56,000 
fishing and recreation jobs. Enbridge only promises 560 long-term jobs for B.C., barely $1 \%$ of the current coastal employment sector. Clearly, without knowledge of employment statistics, these numbers appear much larger than they might with contextual knowledge. As a final point, it is important to note the structural opposition of the terms 'construction' and 'long-term'. Presented always in pairs, these two terms may be seen as a euphemism for the more natural antonymity of short-term/long-term. It is interesting to note how the gatewayfacts website relies heavily on emphasizing 'long-term' jobs. Implicit in this word choice is the existence of short-term jobs. Enbridge appears to be using 'construction' to represent the alternative to long-term jobs, and thus it is a question whether these truly are jobs in the construction field, or rather they simply represent all jobs that are not 'long-term'. Since these terms are rather opaque and vague, it is difficult for the reader to determine what 'long-term' jobs might represent - in what fields, at what location, or at what point in the timeline? Construction jobs, by their nature, are necessarily temporary, and can be seen as a relexicalisation and euphemism for shortterm. The gatewayfacts website is focusing on job growth, within the broader theme of economic development, but Enbridge's discursive strategies are redirecting our attention towards impressive statistics and euphemistic terms. Upon deeper investigation, the job boost promised by this website is arguably minor and represents a small benefit compared to the potential risks.

\subsubsection{Scientific and technical expertise}

Discussing legitimation in corporate discourse, Breeze (2013) argues that:

The appropriation of scientific language to project an authoritative voice has been widely discussed ... particularly because it fits with broader sociological analyses 
that identify the sequestration of experience and the increasing dependence on 'expert systems' as traditional roles and cultural frameworks are eroded (pp. 15) Lemke (1995) notes that discourses of expert knowledge are problematic as they are presented as neutral, factual, and objective. They are represented as being outside of human agency and distinct from opinion or dialogue. As Lemke describes, "the world of technical discourse is a closed world which admits no criteria of validity outside its own. In Bakhtin's terms, it is a pre-eminent 'monological' discourse" (p. 50).

Aronowitz (1988), writing about the power of science, technologies, and their discourses, argues that we find ourselves in a thoroughly technological world where science and technology are hegemonic ideologies permeating state and civil society. Science lends itself to integration because it shares, with the rest of society, the teleology of domination over nature. Its incorporation into industry and the state may be necessary for the survival of nations, considering the world economic and political order. But ... such a close relationship between science and the forces of order means that industry has been able to multiply its productive powers by geometric proportions over industrial production in the (relatively) prescientific age. Specifically, the transformation of physical, chemical, and biological knowledge into instruments of economic, political, and military power is the foundation of our ecological crisis. (pp. 20)

The gatewayfacts website has multiple examples of the use of scientific and technical language. For example, the "Environmental Responsibility - Land" page states: 
“We will have 132 remotely operated isolation valves on each pipeline, dual leak detection analysis and additional in-line inspection systems to ensure safe operation of the pipeline."

"Our pipelines will be constructed to new standards, including:

-Steel that is, on average, $20 \%$ thicker than required.

-X-ray or ultrasonic testing of all welds.

-Durable coating system and cathodic protection against corrosion.”

The “Conditions - BC" page says:

" $20 \%$ thicker steel, on average, than required, safety monitoring at a level not practiced anywhere in the industry today, with 24/7 pipeline monitoring, dual leak detection analysis and remote pump stations staffed around the clock."

The "Environmental Responsibility - Marine" page states:

“Tankers must be double-hulled, under 20 years old and meticulously certified. Crews must be certified by the International Maritime Organization, and officers must be English speaking."

“Emergency response equipment, crews and training staff will be stationed at key points and communities along the marine routes as identified by state-of-the-art computer modeling and logistical planning."

These statements, relying on terminology that would appear to be difficult to interpret and unintelligible to most readers (e.g., ultrasonic testing, remotely operated isolation valve, cathodic protection, dual leak detection analysis), helps to boost the perception of Enbridge as a trustworthy, authoritative voice. These statements, repeated and 
relexicalized throughout the website, carry connotations of complexity, objectivity, and expertise (Breeze, 2012).

\subsubsection{Expert perspectives}

Alongside the frequent examples of scientific and technical language, there are also several overt examples of a reliance on a discourse of 'experts' or 'expert knowledge'. These take the form of small delineated boxes with a title of "Expert Perspectives" (see

Figure 7).

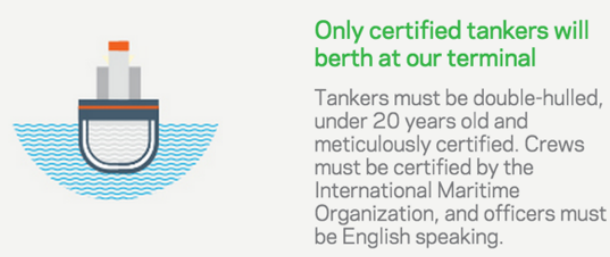

Advanced simulation backs our navigation plan

We tested our tanker operations at a state-of-the-art marine simulator in Denmark. The result was an endorsement of the shipping route from government departments and the British Columbia Coast Pilots.

\section{Expert Perspectives}

$>$ "Oil tanker traffic on BC Coast is routine and safe."

by Captain George Adams. Vancouver Sun, April 9, 2013

> "Point: Safe passage for tankers? Claims B.C. waters will become unsafe are groundless."

by Capt. Stephen Brown. Vancouver Sun, June 18, 2013

> "Anti-pipeline report fails real world test." by Keith Michel and Audun Brandsaeter. Vancouver Sun. May 14, 2013
Care taken during land to marine transfer

The Kitimat Marine Terminal will include two ship berths and 19 tanks for oil and condensate. While docked at the Terminal, tankers loading export oil will be surrounded by a containment
A spill response capacity $3 x$ better than required

Our spill response capacity will be more than $3 x$ the current Canadian regulation. In addition, tanker escort tugs will carry emergency response and firefighting equipment to be able to respond immediately.

\section{Figure 7: Gatewayfacts examples "Expert Perspectives" box}

These boxes link to additional documents, such as online newspaper articles, opinion pieces, pdf information documents, etc. The authorship of these additional texts is varied, some are prepared by Enbridge, such as the "fact-sheets", while others are private individuals with no obvious links to the corporation or the NGP project. See Appendix B for a complete list of linked texts.

van Leeuwen (2008) describes authorization as inherent in legitimation. He outlines various types of authorization, one of which is expert authority. These texts seem 
to clearly be an iteration of this type of discursive legitimation. van Leeuwen argues that cases of expert authority are legitimized through their expertise, and that they "often carry some kind of recommendation, some kind of assertion that a particular course of action is 'best' or 'a good idea"' (p. 107). This certainly applies in the case of the gatewayfacts website, as the texts referenced as 'expert perspectives' are all in favour of the pipeline, and in all cases constitute powerful advocacies for the project.

However, the gatewayfacts website reliance on 'experts' to recommend and legitimate their project brings to light a concern that Jasanoff (2005) outlines in her work on expert legitimacy: 'experts' are increasingly being relied upon to step outside narrow domains of expertise and offer opinions on complex, uncertain issues. These experts are elicited on issues outside of their disciplinary competence, and are expected to assert judgement in the public interest. Indeed, Jasanoff alludes to a state-of-affairs where experts are relied upon less for their technical expertise and qualifications, than for their ability and willingness to publically assert judgement in the face of uncertainty. As she posits, "In these circumstances, the central question is no longer which scientific assessments are right, or even more technically defensible, but whose recommendations the public should accept as credible and authoritative?" (p. 211). Certainly, the case of the NGP is an extraordinarily complex project. It seems unlikely that any one expert, regardless of his or her field of expertise, would be able to give a balanced and objective judgement on facts. Thus, it becomes interesting to examine further to whom the gatewayfacts website is assigning 'expert' status, and upon which credentials this title stands. 
Cary Pinowski, author of the "Jobs and Economic Benefits" text, is cited on his authored text as the president and chief executive office of Vancouver-based Astur Gold Corp. Astur Gold is a junior mining corporation focused on the acquisition, exploration, and extraction of mineral deposits (namely gold) in Spain (Astur Gold, n.d.). The piece authored by Pinowski is an opinion piece, posted on the newspaper's blog. Another expert is Colin Kinsley, the author of the "Quesnel needs oil as much as anywhere else" text. Kinsely is cited as "the former mayor of Prince George and current Chair of the Northern Gateway Alliance" (Kinsley, 2013). This text, similar to Pinowski’s, is not a journalistic piece, but is rather a letter to the editor. Stuart Houston, author of "Economic benefits", is a member of Alberta's Capital Regional Board and is chair of its pipeline linkages strategy committee (Houston, 2013). His text is also an opinion piece.

These are but three of the experts cited on the gatewayfacts website, but they begin to point to a particular pattern in the texts and individuals referenced. While some other experts cited on the website do seem to have relevant credentials - a retired marine captain, a former chief economist - their authored texts are, similar to those outlined here, not rigorous journalistic or academic texts, but rather special and opinion pieces. Indeed, there does not seem to be a single established scientific, technical, or academic perspective offered through the "Expert perspectives" section. There is no description of methodology, data collection, context of evaluation, peer-review, institutional affiliation, or other relevant information. Overwhelmingly, the texts linked to in these sections are opinion pieces posted online. While it may be true that these individuals are knowledgeable in particular domains, and are certainly in a position to state their opinions, views and advice, it seems ingenuous to apply a blanket 'expert' status to these 
people and their writings. Certainly, when considering a massive development project such as the NGP, it seems unlikely that a former mayor writing a letter to the editor of a small northern local newspaper would elsewhere be granted expert status.

This point is not to say that lay people and interested individuals do not have an important role in environmental governance and development decisions. Indeed, they do. Rather, I posit that in the case of the gatewayfacts website, this naming of 'experts' without qualifying why we should regard them as such "creates power asymmetries that may become a hazard to democratic equality" (Steffek, 2009, p. 313). A clear legitimation of the NGP, this discursive strategy relies on opinions that uniquely support the project from individuals that are arguably unqualified to evaluate the project as a whole. Readers are thus given narrow, and often interested, opinions on the pipeline under the guise of balanced, neutral, and honest 'expertise'.

\subsubsection{Environmental stewardship}

\subsubsection{The design of the website - the use of greens and blues}

As discussed, the potentially devastating environmental impacts of the NGP have been some of the most contentious aspects of the public scrutiny of Enbridge's project. The vulnerability of the terrain over which the pipeline would pass, in addition to the fragile ecosystem of the Pacific coast, has made this pipeline one of the most contested private enterprises in Canada's history. Most of the opposition to the pipeline on environmental grounds has roots in B.C., as it is feared that the NGP will disrupt sensitive ecosystems, wildlife, and the coastal integrity of the Pacific North Coast.

In light of such circumstances, the "Gateway Facts" website puts enormous effort into promoting Enbridge's concern for environmental safety. Notably, the design, as well 
as the text of the gatewayfacts website, serve to continuously project an image of Enbridge's environmental sensitivity. On various pages, including the "About", "Benefits to First Nations", “Conditions - BC”, “Conditions - NEB”, "Environmental Responsibility - Land", and "Environmental Responsibility - Marine" pages, the most salient element is a large environmentally themed photo that dominates more than the top two thirds of the page. These photos are primarily of the B.C. coast, and include images of mountains, coastlines, old-growth forests, whales, etc. Moving past these images necessitates action on the reader's part - you must scroll further down the page to find the text and information. This composition along a vertical axis is a case of what Kress and van Leeuwen (1996/2006) term the juxtaposition of the 'real and unreal'. Kress and van Leeuwen note that vertical composition is common in Western texts and advertisements, and that most often the upper section is presented to viewers as the 'ideal', while the lower section is presented as the 'real'. Thus, these images, placed at the very top of the pages, represent an idealized and generalized vision of the pipeline. The environmental images are ideologically foregrounded through the visual information of the large, colourful images, while the practical and informative text is backgrounded, and serves to elaborate on the images.

In addition to the images, on all of the pages colour serves an important reinforcement of this theme. The pages are minimal in background and text, but each heading is colored in green. Complementing the headlines, each of the 'expert perspectives' links are also in green typeface. Aside from the salience of green text, much of the colour palette of the website is dominated by blue. Many of the images are of water, sky or mountains, and many are primarily blue in colour. The overall impression 
of the website is one of blues and greens, presenting a calm, pleasing and attractive appearance. There are few warm colours (reds, oranges and yellows), and most of the colours are muted. The meanings of colours, the affects they are associated with, and the associations we have with them vary widely (Kress \& van Leeuwen, 2002). Ideas have long been expressed through colour, and within multimodal analysis it is assumed that not only do colours 'express' or 'mean' something to an audience, but that they are also actively used in text to influence and act on others (Kress \& van Leeuwen, 2002). While it is debatable what the colours blue and green may mean to different people, it seems clear that the gatewayfacts website is employing these two hues to reinforce an environmental theme. As many of the images are the dominant feature of the website's pages, the colours presented in them - primarily blue and green - associate with water, trees, sky, grass, etc. The colour scheme employed by the website serves to reinforce the theme of environmental stewardship by consistently reinforcing the notion of nature.

\subsubsection{An environmental headline}

The text of the gatewayfacts site also contains multiple examples of the theme of 'environmental stewardship'. Alongside economic benefits, the pages titled "Environmental Responsibility" are some of the few places where audiences have the to click and seek further information. It follows that, on a page titled "Environmental Responsibility" the text would present a theme of environmental stewardship. However, like the design of the website, the text throughout the site serves to represent the NGP, and Enbridge, as concerned for, and very much protectors of, the environment. 
On the "About" page, the reader is first presented with a shadowy, blue image of the silhouette of hills and mountains. Superimposed on this image is the phrase:

"The environmentally responsible way to build a pipeline"

Headlines have long been a focus of discourse analysis, and Teo (2000) notes that they are often a relatively accurate representation of the text that follows. Headlines are a concise representation of a text, and indicate to the reader how, and in what way, to process the content that follows (Teo, 2000). While my analysis does not focus on headline analysis, nor is it a typical analysis of a news story, I view the use of headlines on the gatewayfacts website as interesting, and I believe this points to the themes that Enbridge wishes to reinforce throughout the site. In this case, the use of a strongly environmentally themed headline on the "About" page - the page designed to give an overall impression and general information about the project - points to the significance of the theme of environmental stewardship. If following Teo's (2000) discussion of headlines, it could be said that this phrase points readers to process the rest of the page, and possibly others as well, through a lens of 'environmental responsibility'.

\subsubsection{The use of metaphor}

The "About" page also makes numerous other references to the theme of environmental stewardship:

“The pipeline will be a model of world-class safety and environmental standards"

"Plan a route that will have as little impact as possible on the terrain, waterways, wildlife and neighbouring communities." 
"Limit tree clearing and other disturbances by following existing linear disturbed areas.”

The last example also points to an interesting use of metaphor and euphemism to refer to the route of the pipeline. This is echoed several times on other pages and in other phrases throughout the website:

"After extensive planning, consultations, reviews and revisions, we have mapped out a route that runs 1,177 rational and respectful kilometers."

"70\% of the route utilizes previously disturbed lands"

"Following existing linear disturbed areas" (my emphasis)

The first reference is a clear example of personification, i.e., assigning human qualities to abstractions or inanimate objects (Machin \& Mayr, 2012). The second and third are a more concealing use of metaphor to background Enbridge's role in 'disturbing' the environment. Combined, these three examples show how the gatewayfacts website uses metaphoric language to highlight the NGP's commitment to the environment. In particular, this use of metaphor seems to reinforce the notion of the NGP as a respectful, considerate, and cautious project. However, as the project itself is not an agent, these notions can be seen to be subtly referencing, not the pipeline itself, but the corporation and people behind it.

\subsubsection{The use of 'safe'}

Throughout the website, there are multiple uses of the words 'safe' and 'safety'. Some examples are: 
"Protecting nature with the safest pipeline ever built in Canada"

"The safest pipeline Canada has ever seen"

"Adding safety features for added protection"

"The pipeline will be a model of world-class safety and environmental standards.”

There seems to be a overlexicalization of the morpheme 'safe'. However, while there are many examples of the word, it is less clear exactly what is implied by the use of this term. Obviously, as a huge development project, Enbridge considers safety as a necessary issue for the NGP project. It seems though, that in using the word 'safe' to describe the pipeline, the gatewayfacts website is not referencing the project in terms of construction or personnel safety. Rather, the 'safety' consistently referenced seems to apply to the NGP's relationship with the environment. While the majority of uses of the word 'safe' on the website are rather vague and do not provide much detail, some instances do provide a window into what the term is referring to:

"We will have 132 remotely operated isolation valves on each pipeline, dual leak detection analysis and additional in-line inspection systems to ensure safe operation of this pipeline"

Though this sentence is an example of the use of scientific and technical language, when parsed a little deeper, it also becomes apparent that the features described would be for oil-spill prevention and detection. Thus, the 'safe operation' described here can be seen as a relexicalisation of 'oil spill avoidance'. If one interprets the use of 'safe' in this way, 
it becomes obvious that phrases such as the "safest pipeline ever built", do not refer to worker or construction safety, but rather to the protection of the environment.

\subsubsection{Industry leadership}

As previously discussed in my "Literature Review and Theoretical Framework" chapter, recent work on the strategic framing of climate change by energy industry actors has shown that the current dominant frame is that of "industrial leadership" (Schlichting, 2013). This frame is typified by the acknowledgement of responsibility, the portrayal of climate change as a key business concern, and explicit commitments to emission reductions. It is a self-portrayal by corporations (and other actors) as a driving force behind actions to cope with climate change. The theme I am presenting here is similar in many ways to the "industrial leadership" strategic frame.

\subsubsection{Acknowledging responsibility}

Schlichting (2013) notes that within the frame of 'industrial leadership', industry actors consistently acknowledge corporate responsibility for issues such as climate change. Enbridge, through the gatewayfacts website, frequently does the same, though in this case it is in reference to the NGP, not climate change.

As a first point, the overall layout and design of the gatewayfacts website is consistent throughout a majority of the various pages. Following the large colour photo with superimposed text, the main body of a page is divided into two columns: the left titled with "The Challenge" and the right with "Our Solution" (see Figure 8). 


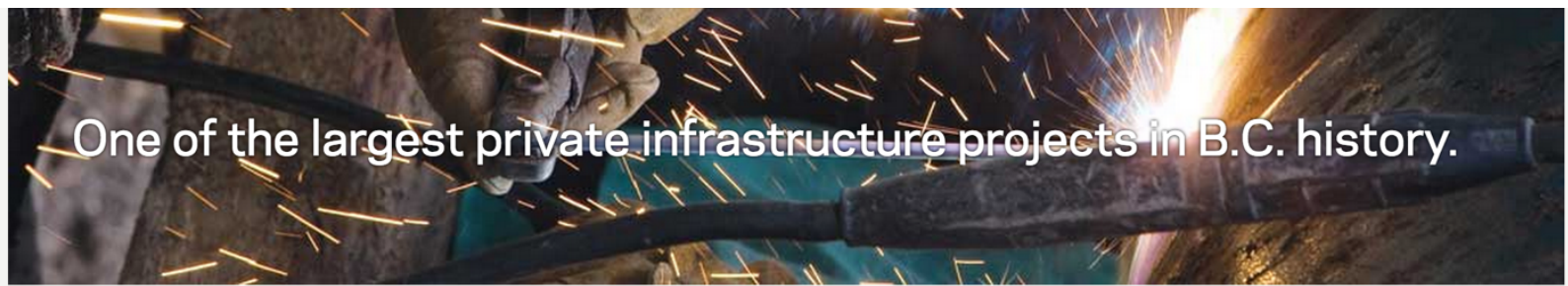

Was this informative? Share it here. $\mathrm{f} v \mathrm{~g}^{+}$

The Challenge

Ensuring B.C. gets its fair share of economic benefits from the Northern Gateway project, including long-term jobs that will benefit all citizens.
Our Solution

The project will create thousands of construction jobs and over 560 long-term jobs for British Columbians. Education and training initiatives are already in place.

Figure 8: Gatewayfacts challenge and solution design

Following these headings, there is a short paragraph of text discussing various aspects of the project as well as how Enbridge and the NGP will respond. This layout, similar to the composition along a vertical axis described earlier, is discussed in Kress and van Leeuwen (1996/2006). They argue that layouts in modern texts are often polarized, "with 'given' information on the left, and 'new' information on the right (Kress \& van Leeuwen, 1996/2006). Here, the 'given' is the challenge faced by the NGP. Through the inclusion of these 'challenges', the gatewayfacts website is making a great effort to show that they acknowledge the challenges and controversies faced by this project. By coupling these challenges with 'solutions', the website also acknowledges the NGP's, and Enbridge's, responsibility in responding to and managing those challenges.

Secondly, aside from the overall layout, the text on the pages also serves to reinforce an acknowledgement of responsibility: 
"We believe the five conditions reflect legitimate environmental, social and economic concerns of British Columbians. We are working hard to meet these tough conditions."

"The B.C. government's five conditions for pipeline approval call for a worldclass marine spill prevention, response and recovery system."

"Our goal is zero spills, but should there ever be one, our action plan mandates a swift and decisive spill response."

The last example is particularly illustrative of this 'acknowledgement of responsibility', as it is a subtle nod to the resistance the project faces vis-à-vis public fear of oil-spills. It is interesting to note that the website could have simply avoided mention of spills altogether, as they are an extremely controversial issue that does not shed positive light on pipelines in general nor on Enbridge in particular. Instead, the website acknowledges the possibility of spills, and seeks to demonstrate Enbridge's effort to assume responsibility for such an event.

\subsubsection{Above and beyond what is required}

Aside from acknowledging responsibility, the theme of 'industry leadership' is also strongly presented through a discursive strategy of hyperbole. The website frequently uses expansive language to represent the pipeline and all the decisions made regarding the project, as going above and beyond what is required. The gatewayfacts website represents the NGP as a project leading the industry in safety, design, benefits, etc. This is achieved through various linguistic features, notably an overlexicalization of several 
phrases such as 'the most', 'the safest', 'world-class', and 'world-leading'. These phrases are particularly obvious on the "Environmental Responsibility" pages:

"The pipeline will be a model of world-class safety and environmental standards."

"Protecting our waters with world-class environmental safeguards"

"We have the most comprehensive set of marine safeguards ever established in B.C."

"Protecting nature with the safest pipeline ever built in Canada"

"We're going over and above to build the safest pipeline Canada has ever seen." Aside from these overlexicalizations, there are also numerous examples of phrases demonstrating the NGP's industry leadership in going beyond what is required by current law or regulation. Examples include:

"Spill prevention and spill response resources and capabilities more than $3 x$ required by existing law."

“20\% thicker steel, on average, than required, safety monitoring at a level not practiced anywhere in the industry today"

"At its narrowest, the channel is $1.4 \mathrm{~km}$ wide, which is $3 x$ wider than Transport Canada's recommended width for two-way tanker traffic."

It seems clear that the website is putting great effort into representing the NGP, and the corporation behind it, as an industry leader. These examples demonstrate how the text is 
promoting a conception of Enbridge and the NGP as going beyond what is required of them by law, regulation, and even industry standards. This project is 'leading' the industry by voluntarily choosing to have stricter safety standards, more comprehensive evaluation procedures, etc. This discursive strategy is not unusual, as Schlichting (2013) notes that it is common within the dominant frame of 'industrial leadership': "The leadership frame often depicts voluntary action-not mandatory regulation-as the most powerful asset" (p. 503). Here, it is unclear whether the theme of 'industry leadership' is being employed to avoid or resist mandatory regulation. However, it does seem likely that it is being employed to legitimate the NGP, and soothe public concerns and hesitancy regarding the likelihood of environmental disaster.

\subsection{Conclusion}

The main sections of the gatewayfacts website that I have analyzed communicate information about the NGP in a particular way. The information is so that it seems factual, objective, scientific, and trustworthy. The text and images present the project and the corporation behind it in a positive light, illustrating to various degrees how the NGP will foster economic development and growth, has a solid scientific and technical foundation, will protect the environment, and will lead the industry as a safe and beneficial project. These themes are used to legitimate the NGP, and Enbridge, on various levels to different audiences. The website is seeking to justify and promote the project within a complex scenario, where resistance to and acceptance of the project is generated from different regions, interests, and different groups. The four themes presented here are woven together to address the concerns of potential readers while defusing and preempting criticisms. Faced with intense resistance to their project, 
Enbridge seems to have created the gatewayfacts website to reassure the Canadian public and restore confidence that the project will not result in environmental disaster, but rather is an important source of benefits for Canada.

In my next chapter, I will synthesize these findings and discuss them in terms of the overall context and implications. I will draw conclusions from the findings and discuss the contribution of this project to the existing body of literature. I will also discuss the limitations of this study, and present suggestions for future research endeavors. 


\section{Chapter: Discussion}

\subsection{Introduction}

In order to understand the previous analysis in terms of its social significance, this chapter is dedicated to a discussion of the findings I have just outlined. I will synthesize my findings with the key theories and constructs introduced in chapters three and four: corporate discourse, legitimation in corporate discourse, and corporate social responsibility. I will also revisit and answer my overarching research questions that have guided this study:

1. How does the "Gateway Facts" website discursively represent (i.e., construct, construe, allude to) the Northern Gateway Pipeline project?

2. In what ways do the different discursive representations serve to frame, treat and construct a legitimation (i.e. justification, rationalization) of the project?

This chapter is thus organized into three main sections: (1) needing to legitimate, (2) representing the NGP and (3) relying on established discourses. These sections will touch on all of the emergent themes I have identified in Chapter 5, and will offer an overview of my conclusions and interpretations in relation to existing literature. Finally, I will provide a brief discussion of the implications of my findings, and generally why I believe they are of interests and possible concern.

\subsection{Summary of findings}

The preceding "Findings" chapter presented the findings of my analysis of the gatewayfacts website. This website is presented to the public as an informational platform for those looking to learn more about the proposed NGP project. The website comprises a legitimation of the project, as it weaves together four discursive themes of 
economic development, scientific and technical expertise, environmental stewardship and industry leadership to rationalize, justify, and generally promote the NGP. The discursive strategy of legitimation can be argued to be ideological in nature, as institutions employ it to persuade, manipulate and convince the public to achieve social acceptance for various activities (Breeze, 2012). The website's text and design serve to reinforce these themes through various linguistic and multimodal strategies such as page composition, use of colour, use of metaphor, lexicalization, and so on. The themes outlined in this study are not new; rather, they have been demonstrated in previous scholarly work on the legitimation strategies of oil corporations.

\subsection{Needing to legitimate}

Legitimation is a crucial issue for organizations. It is particularly important for oil corporations, as increasingly over the past few decades they have been faced with an increase in public resistance towards their activities and developments. There has been a shift in the way publics perceive corporations' responsibilities towards people and the environment. Oil corporations have correspondingly had to disclose information on social and environmental behaviours. This is often termed corporate social responsibility. Fuoli (2012) argues that legitimation is a primary driver behind this type of disclosure. Thus, through the release of social and environmental information, oil corporations can discursively legitimate their behaviour - justifying, promoting and defending themselves through a guise of CSR reporting.

The NGP is an extremely controversial industrial development proposal, and has faced opposition and critique since its nascency. Enbridge, the corporation behind the project, has correspondingly devoted significant time and energy to promoting the project 
and itself to Canadians. I argue that the gatewayfacts website, though described by Enbridge and the Canadian federal government as a simple source of information on the project, is, rather, an extensive legitimation of the NGP. This website is a clear example of the blending of CSR and legitimation, where Enbridge uses social and environmental information to show the Canadian public how they are responding to concerns about the environment and to help to rationalize and justify the project. This reinforces Guimarãres-Costa and Pina e Cunha's (2008) argument that websites are a critical development in organizational discourse, as they are an excellent medium for companies to convey their CSR and legitimate their actions.

\subsection{Representing the NGP}

The gatewayfacts website, I argue, chooses to discursively represent the NGP within a broad sphere of CSR. The project is discussed not primarily in terms of profits to the corporation or shareholders, but rather as a Canadian 'public good' that will bring benefits to all Canadians. CSR is defined as the notion that corporations have inherent duties to all those effected by their actions. Through themes such as environmental stewardship and industry leadership, the gatewayfacts website pushes the notion that Enbridge, and the NGP, are responsible stewards that are responding to public concern and that they take seriously their duty to build a fair, safe, and propitious pipeline. There is an overwhelming sense throughout the website that the pipeline is not a huge multinational industrial development proposal intended to bring in profits to the corporation, but rather 'a project for all Canadians'. Enbridge's website reiterates that the pipeline will benefit all Canadians, will take care of the environment, and will constitute an important source of economic development for Canada. 


\subsection{Relying on established discourses}

In representing and legitimating the NGP, the gatewayfacts website relies on a number of discourses that have been well established in the literature investigating oil corporations' discursive legitimation. Reliance on a discourse of economic development is a frequent strategy when organizations attempt to legitimate corporate activities and projects (Livesey, 2001). As I have highlighted throughout my analysis, an extremely pervasive theme of economic development persists throughout the website. Frequently the gatewayfacts website resorts to a use of employment statistics, tax revenues, and trade benefits to bolster and rationalize the project. My findings support the notion argued by other scholars that this type of economic development discourse can be seen as a reflection of neoliberal ideology. A huge presence on the gatewayfacts website is the references to 'trade markets', and how diversifying Canada's oil markets will benefit all Canadians and the economy. This reflects a core notion of neoliberalism, that free markets best serve human well-being and that economic development should be a priority. Additionally, neoliberalism has at its center a rejection of state regulation, and as has been demonstrated by others - themes such as industry leadership can be seen as a reflection of this neoliberal principle. By showing Enbridge's voluntary, self-driven endeavors to perform better and build safer, this website presents a subtle argument for avoiding top-down regulation.

This reiteration of neoliberal priorities, however, may be out of touch with the public that Enbridge is trying to win over. According to Veltmeyer and Bowles (2014), resistance to the NGP may be less of an environmentally driven movement, but rather a rejection of Canada's extractivist culture and reliance on fossil fuels and the Alberta oil 
sands. This may be especially true in the case of the Indigenous peoples opposing the project, as they are often arguing for their traditional culture and way of life, not their economic position. Indeed, while the discourse of economic development is a common legitimation strategy employed by oil corporations, it seems out of touch with many of the Canadians that Enbridge may be trying to reach.

Aside from economic development, it seems clear that Enbridge has employed this website as a project-specific CSR text. My findings differ from some of the studies informing this thesis, in that while the gatewayfacts website is not a more traditional CSR genre such as a non-financial report, the gatewayfacts website contains many of the same discursive strategies. As discussed at length, CSR reporting is becoming more and more frequent within corporate discourse, and indeed can be argued to be an unwritten requirement of oil corporations' public discourse. Audiences now appear to expect oil corporations to explain, rationalize and justify their behaviours while showing what they are doing to benefit, or at the very least minimize harm to, the environment and communities. My findings support this assertion, as it seems clear that Enbridge is using the gatewayfacts website to demonstrate, explain and justify their actions surrounding the project. This is especially true with respect to issues of the environment, as Enbridge has consistently, throughout the website, legitimated the project through the use of the theme of environmental stewardship. They make it abundantly clear that they see themselves as inherently responsible for protecting the environment. The images, design, and text of the website all serve to reinforce to potential readers that the environment is a priority for the NGP project. I argue that foregrounding the environment in this way serves a strong legitimatory purpose, as it is responding to the most vocal public concerns about the 
project. Positioning the project as environmentally 'safe' is a crucial strategy, and although the credibility of this strategy might be questionable, it serves as a reassurance to concerned parties and helps represent Enbridge as responsive and environmentally responsible.

Finally, my findings reaffirm Schlichting's (2013) dominant frame of "industrial leadership". My work differs however, in that I am not focused on industry framing of climate change, but rather of a specific event. It is interesting to note that Schlichting posits that "it remains an open question of whether [the industrial leadership frame] will turn out to be a master frame in industry actors' strategic communication on other societal or global issues" (p. 505). While the single case-study presented in this thesis cannot provide a foundation for reaffirming the theme of 'industrial leadership' as a master frame, these findings point out that it is perhaps being used more extensively than just in climate change communications. Enbridge certainly has adopted this frame, in tandem with other frames, to position themselves in a positive light and show their intrinsic motivation for better action. I would also like to note that this frame is noteworthy, as while it is difficult to ascertain whether the statements of industry-leading safety, planning and technology are in fact true, the frame leads to a cautiously optimistic interpretation. While this may be the latest discursive strategy to manipulate the Canadian public into accepting further industrial development, it may also be the case that Enbridge, a very powerful player in fossil fuel development in Canada, is acknowledging the mistakes that have been made in their industry, and is seeking to do better. 


\subsection{Conclusions and implications}

As has been illustrated by the previous three sections, there are four important themes present in the gatewayfacts website: economic development, scientific and technical expertise, environmental stewardship, and industry leadership. Occurring in parallel, these themes work together to form a discursive legitimation of the NGP. This website is a social text that both produces and reproduces ideology (Fairclough, 1989). The gatewayfacts site makes available ideology to be consumed and reproduced by members of society. It reinforces a 'corporate understanding' (Livesey, 2002) of the natural world, the Canadian economy, and the pipeline project. In addition to the power and influence of organizations generally (Bloor \& Bloor, 2007; Mayr, 2008) the power of corporate legitimation practices is eminent (Breeze, 2012). For researchers, developing a critical understanding of legitimation in corporate discourse, especially in the case of novel forms such as websites, is valuable for gaining insight into how organizations influence acceptance, resistance, and general perceptions of industrial development projects.

What does this mean about the way in which we, the public, think about projects such as the NGP? It means that as corporate discourse continues to blend established, and arguably powerful, discourses of economic development, scientific expertise and environmental protection, it seems not only normal to consider these projects as part of our existence, but they seem inevitable. The problem with this is that economic issues, such as complex notions of trade and markets, and concerns over employment and personal upward mobility, are not at inherently at odds with the maintenance of our natural environment. Portraying the NGP as a project necessary to Canada, and one that can be built without destroying the environment minimizes arguments that this project is 
in fact part of a larger, societal issue tied to extractivism, reliance on fossil fuels and destruction of the environment. Building pipelines to export oil is not the only option Canadians have for economic prosperity. While this website makes it difficult to imagine projects that avoid making a deep footprint upon the earth, while also bringing social and economic benefits to Canada, such projects do exist. In his book, Crude world: The violent twilight of oil, Peter Maas (2010) reflects on the perceived powers of oil: "Across the world, oil is invoked as a machine of destiny. Oil will make you rich, oil will make you poor, oil will bring war, oil will deliver peace" (p. 5). However, despite a general view of oil as a singular force driving our world, oil and well-being are not immutably interdependent. Enbridge's legitimation of the NGP as a necessary, safe, and beneficial project is concerning as the consolidation of this project with the Canadian economy and protection of the environment lends itself to dangerous fallacies about alternative possibilities to carbon-based life. 


\section{Chapter: Conclusion}

The purpose of this study has been to investigate how Enbridge's gatewayfacts website discursively represents the NGP project in order to gain insight into how corporate discourse legitimates controversial projects. To achieve this, the analytical framework for this research included critical discourse analysis and multimodal analysis. These methods and their associated analytical tools allowed for a critical examination of the textual and visual modes of communication both separately and in conjunction with one another. My analysis has demonstrated that the gatewayfacts website constitutes a discursive legitimation of the NGP and does so through the following themes: economic development, scientific and technical expertise, environmental stewardship, and industry leadership. Through a discourse of economic development, the website stresses the project as a 'public good' and a job creator. The website devotes enormous attention to highlighting the potential economic benefits of the NGP, often through the use of large numbers and statistics. The gatewayfacts website also positions the NGP within a discourse of scientific and technical expertise. Through lexical choices as well as intertextual links to other texts, the website consistently seeks to legitimate the project as well as its evaluation, planning, and design as objective, trustworthy, and authoritative. In attempting to counter heavy controversy related to the project's potential environmental harm, the gatewayfacts website also presents a strong theme of environmental stewardship. Through textual and visual elements, the website presents environmental protection as a priority for Enbridge, and employs several metaphors to replace unseemly elements with abstractions. Finally, the gatewayfacts website employs a discourse of industry leadership, referring to the project and the corporation behind it as surpassing 
expectations and standards in all domains, while acknowledging their responsibility for protecting the environment, cleaning up spills, and offering equal benefits to all concerned parties. As discussed, these four themes are not unique to the NGP, however; rather, they are well-established in scholarly literature discussing corporate discourse and legitimation.

In addition to these findings, I have discussed the social and political context in which the project is situated, touching on circles of power and ideology. To do this, I have relied on theories of corporate discourse, legitimation, and corporate social responsibility, as well as on the method of critical discourse analysis. The results of this case-study reaffirm that legitimation is critical for organizations. Especially in the case of oil corporations, there is a need to justify, rationalize, and promote corporate activities and projects. The gatewayfacts website relies on a web of complex and powerful discourses to represent the NGP project as an economically driven, scientifically grounded, and responsible project that will benefit all Canadians. Through this representation, they attempt to legitimate the project and public acceptance and diminish opposition.

\subsection{Contributions to literature}

By analyzing the gatewayfacts website from a critical stance, this thesis provides a perspective to the burgeoning study of legitimation in corporate discourse and online communication. While there is a great body of research investigating oil corporations and their discourse, this study provides a particular contribution by focusing on a projectspecific website. The Internet, arguably above all else, is a significant source of information regarding corporations, their activities, and their projects. The Internet offers 
corporations an opportunity to share an unlimited amount of information with potential audiences (Insch, 2008). As more corporations turn to websites to share information about themselves and their projects with the public, there will be a great opportunity for communications and linguistic scholars to examine the effects of such information on audiences.

It is well established that corporate discourse is powerful in producing and reproducing ideology (Breeze, 2013). In contributing to the literature on legitimation in corporate discourse, this thesis responds to CDA's call for an understanding of structures of power and dominance. Additionally, environmental communication scholars point to the need to develop a better understanding of how corporations and other large businesses operate in, influence and manipulate the environmental communications environment (Hansen, 2015). This thesis contributes to this important domain of research. Given the powerful role of corporations in today's world, it is increasingly important to critically interrogate how their discourse is influencing our understanding of our realities. Most importantly, work such as this thesis is valuable in encouraging critical thinking on the part of audiences interacting with corporate discourse.

Additionally, this thesis contributes to the critical study of corporate discourse in that it adds to the scholarly discussions that surround CSR. Many scholars note that much of the work investigating CSR has been either descriptive, normative or positivist (Scherer \& Palazzo, 2007; Campbell, 2007). This thesis moves outside of this existing framework to discuss CSR and its ties to legitimation and corporate ideology. In this way, this thesis adds to theorizing CSR by considering the social, historical and contextual landscape and moves beyond a merely "instrumental interpretation of corporate 
responsibility" (Scherer \& Palazzo, 2007). Following the goals of CDA practitioners, this thesis shows the importance of considering the influential roles corporations have in shaping the very fabric of our society and how complex social constructs such as CSR may mediate those roles.

\subsection{Limitations and directions for future research}

Although this study relied on a sound foundation of case-study research in the field of legitimation in corporate discourse, I would be remiss to go without acknowledging that my conclusions are limited in their scope. As the website analyzed is tied to a particular project, I am unable to definitively say whether these findings apply to Enbridge's corporate discourse more generally. Indeed, it is also important to note that as my intention was to investigate representations of the NGP, and since this is a singular examination of one instance of Enbridge's corporate discourse, it may be that my findings are isolated, and that these themes are not carried over to other texts. I would be interested to compare my findings with other instances of Enbridge's corporate discourse, such as reports, press-releases, and other online texts, to investigate whether these findings are indicative of a broader pattern. However, as this thesis follows CDA, it is important to note that even if these findings are somewhat unique, that does not make the text analyzed any less ideological. CDA considers all language, whether spoken or written, consciously or unconsciously, to be ideological and consequential. This is especially true in the case of a corporate website, where it is likely that much thought and consideration was taken to construct and author this site.

It may also be a limitation that this study was carried out as a bounded analysis of an evolving text. As mentioned in my "Method" chapter, the website has already been 
changed and restructured from the time when I conducted the bulk of my data collection and analysis. Thus, my findings would likely be difficult to replicate, as some of the data now exists only in my hands. However, this is a limitation somewhat inherent to this type of analysis, and I do not believe it lessens the significance of the valuable insights I have gained here. I hope that in further developing my analytical abilities, and in broadening my understanding of and familiarity with online discourse, my future research might avoid such issues. Subsequent studies may learn from this, and seek a faithful representation of dynamic texts such as websites.

Finally, it is important to note that my analysis is based on the interpretations of a sole analyst - myself. I have not conducted interviews with the authors of this website, nor with its users. Thus, I am limited in saying to what degree these findings would resonate with either of these groups. Future research would likely benefit greatly from incorporating a secondary qualitative element such as in the form of audience reception research. It would be immensely interesting to investigate how critical audiences receive texts such as the gatewayfacts website. Given the opportunity, I hope to continue work in this domain in future years. 


\section{Appendices}

\section{Appendix A}

\section{A.1 Janks' (2005) Linguistic Analysis Rubric}

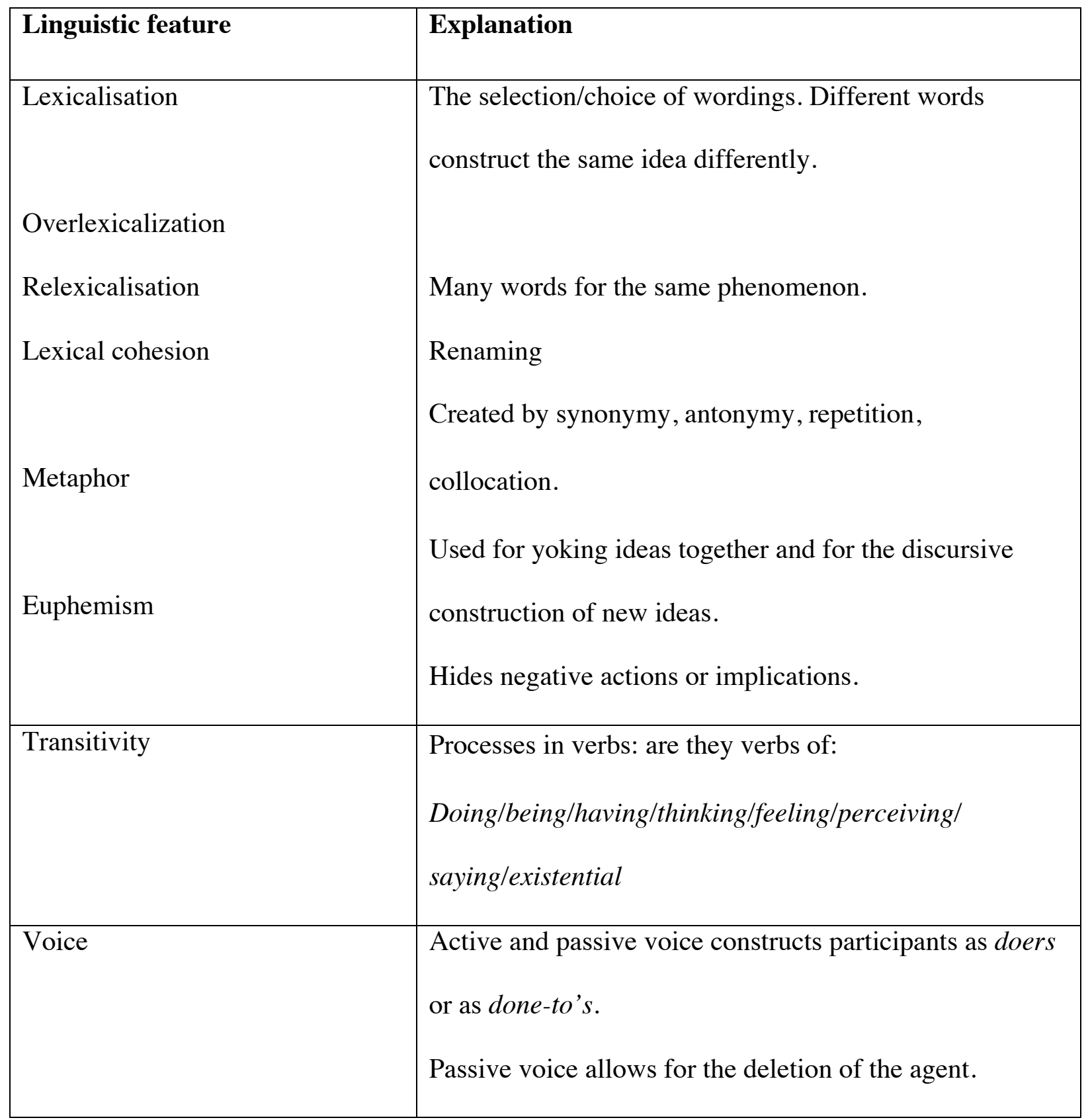




\begin{tabular}{|c|c|}
\hline Nominalisation & $\begin{array}{l}\text { A process is turned into a thing or an event without } \\
\text { participants or tense or modality. } \\
\text { Central mechanism for reification. }\end{array}$ \\
\hline Mood & Is the clause a statement, questions, offer or command? \\
\hline Pronouns & $\begin{array}{l}\text { Inclusive we/exclusive we/you } \\
\text { Us and them: othering pronouns } \\
\text { Sexist/non sexist pronouns: generic "he" } \\
\text { The choice of first/second/third person. }\end{array}$ \\
\hline Sequencing of information & Sequence sets up cause and effect. \\
\hline $\begin{array}{l}\text { Logical connectors - } \\
\text { Conjunctions set up the logic of } \\
\text { the argument }\end{array}$ & $\begin{array}{l}\text { Conjunctions are: } \\
\text { - Additive: and, in addition } \\
\text { - Casual: because, so, therefore } \\
\text { - Adversative: although, yet } \\
\text { - Temporal: when, while, after, before }\end{array}$ \\
\hline
\end{tabular}




\section{A.2 Liu's (2015) Visual Analysis Rubric}

\begin{tabular}{|c|c|}
\hline Visual feature & Explanation \\
\hline Descriptors & $\begin{array}{l}\text { A basic description of the visual elements such as: actors } \\
\text { and carriers; angle; colours; graphics; font; settings; } \\
\text { spatial relationships }\end{array}$ \\
\hline Actor & $\begin{array}{l}\text { The active participant(s) in an action process is the } \\
\text { participant(s) from which the vector emanates or which if } \\
\text { fused with the vector. }\end{array}$ \\
\hline Goal & $\begin{array}{l}\text { The passive participant in an action process is the } \\
\text { participant at which the vector is directed. }\end{array}$ \\
\hline Interactors & $\begin{array}{l}\text { The participants in a transactional action process where } \\
\text { the vector could be said to emanate from, and be directed } \\
\text { at, both participants. }\end{array}$ \\
\hline Transactional reaction & $\begin{array}{l}\text { An eyeline vector connects two participants, a reacter and } \\
\text { phenomenon. }\end{array}$ \\
\hline Non-transactional reaction & $\begin{array}{l}\text { An eyeline vector emanates from a participant, the } \\
\text { Reacter, but does not point at another participant. }\end{array}$ \\
\hline Setting & $\begin{array}{l}\text { The setting of a process is recognizable because the } \\
\text { participants in the foreground overlap and hence partially } \\
\text { obscure it (e.g., soft focus, over/under colour saturation) }\end{array}$ \\
\hline
\end{tabular}




\section{Appendix B}

\section{B.1 Expert Opinion Sections - Linked Texts}

TABLE 1. Expert opinion sections - linked texts

\begin{tabular}{lc}
\hline Section & Titles of linked texts
\end{tabular}

Environmental Responsibility: Marine Safety

Environmental Responsibility: Land Safety

Benefits: For B.C.
- "Oil tanker traffic on BC Coast is routine and safe." By Capt. George Adams, Vancouver Sun, April 9, 2013.

- "Point: Safe passage for tankers? Claims B.C. waters will become unsafe are groundless.” By Capt. Stephen Brown, Vancouver Sun, June $18,2013$.

- "Anti-pipeline reports fails real world test." By Keith Michel and Audun Brandsaeter, Vancouver Sun, May 14, 2013.

- "Sustainability of Pipelines." By Dr. Patrick Moore, cofounder of Greenpeace. London Free Press, March 30, 2013.

- Emergency Preparedness and Response - Fact Sheet (downloadable PDF)

- "Jobs and economic benefits." By Cary Pinkowski, The Province, January 24, 2013.

- "Economic benefits." By Mayor Stuart Houston, Vancouver Sun, January 30, 2013.

- "Northern Gateway and market diversification." By Don Zurowski, The Prince George Citizen, March 14, 2013.

- "Quesnel needs oil as much as 
Benefits: Alberta

Benefits: First Nations anywhere else." By Colin Kinsley, Quesnel Cariboo Observer, June 7, 2013.

- "The world will not wait for Canada's oil." By Sherry Cooper, The Globe and Mail, August 6, 2013.

- Sustainability of Pipelines. By Dr. Patrick Moore, CoFounder of Greenpeace, London Free Press, March 30, 2013.

- Aboriginal Benefits - Fact Sheet (downloadable PDF) 


\section{References}

Adami, E. (2015). What's in a click? A social semiotic framework for the multimodal analysis of website interactivity. Visual Communication, 14(2), 133-153.

Alberta Energy (n.d.). Our Business: Facts and statistics. Retrieved from http://www.energy.alberta.ca/oilsands/791.asp

Alexander, R. J. (2009). Framing discourse on the environment: A critical discourse approach. New York: Routledge.

Allan, K., \& Burridge, K. (1991). Euphemism \& dysphemism: Language used as shield and weapon. Oxford: Oxford University Press.

Alvesson, M., \& Deetz, S. (2000). Doing critical management research. London: Sage.

Amnesty International. (2014, July 14). Behind Amnesty International's decision to oppose Northern Gateway. Retrieved from http://www.amnesty.ca/blog/behindamnesty-internationals-decision-to-oppose-northern-gateway

Anderson, A. (2015). Reflections on environmental communication and the challenges of a new research agenda. Environmental Communication, 9(3), 379-383.

Anteby, M. (2010). Markets, Morals, and Practices of Trade: Jurisdictional Disputes in the U.S. Commerce in Cadavers. Administrative Science Quarterly, 55(4), 606638.

Arcand, A., Burt, M., \& Crawford, T. (2012). Fuel for thought: The economic benefits of oil sands investment for Canada's regions. The Conference Board of Canada. Retrieved from: http://www.conferenceboard.ca/e- library/abstract.aspx?did=5148 
Aritz, J., \& Walker, R. (2012). Introduction. In R. Walker \& J. Aritz, Discourse perspectives on organizational communication (pp 1-8). Madison, N.J.: Fairleigh Dickinson University Press.

Aronowitz, S. (1988). Science as power: Discourse and ideology in modern society. Minneapolis: University of Minnesota Press.

Astur Gold. (n.d.). Home. Retrieved from http://www.asturgold.com/s/Home.asp

Becklumb, P., \& Williams, T. G. (2012). Canada's changing federal environmental assessment process. Ottawa, ON: Library of Parliament.

Berger, P., \& Luckmann, T. (1967). The social construction of reality. Garden City, NY: Anchor Books.

Bergman, J.R., \& Meier, C. (2004). Electronic process data and analysis. In U. Flick, E. von Kardorff \& I. Steinke (Eds.), A companion to qualitative research (pp. 243247). Thousand Oaks, CA: Sage.

Blommaert, J., \& Bulcaen, C. (2000). Critical discourse analysis. Annual Review of Anthropology, 29(1), 447-466.

Bloor, M., \& Bloor, T. (2007). The practice of critical discourse analysis: An introduction. London: Hodder Arnold.

Boykoff, M.T. (2008). The cultural politics of climate change discourse in UK tabloids. Political Geography, 27(5), 549-569.

Breeze, R. (2012). Legitimation in corporate discourse: Oil corporations after Deepwater Horizon. Discourse \& Society: An International Journal for the Study of Discourse and Communication in Their Social, Political and Cultural Contexts, 23(1), 3-18. 
Breeze, R. (2013). Corporate discourse. London: Bloomsbury Academic.

Brown, H.D. (1980). Principles of language learning and teaching. Englewood Cliffs, N.J.: Prentice Hall.

Brownsey, K. (2005). Alberta's oil and gas industry in the era of the Kyoto Protocol. In G. B. Doern (Ed.), Canadian energy policy and the struggle for sustainable development (pp. 200-222). Toronto: University of Toronto Press.

Campanella, D. (2012). Misplaced generosity: Update 2012 - extraordinary profits in Alberta's oil and gas industry. Edmonton, AB: Parkland Institute.

Campbell, B. (2012). Managing oil wealth: The Alberta/Canada model vs. the Norwegian model. Canadian Centre for Policy Alternatives. Retrieved from www.policyalternatives.ca

Canadian Environmental Assessment Agency. (2006, September 29). Enbridge Gateway project - draft review panel agreement released for comment. Retrieved from http://www.ceaa-acee.gc.ca/050/document-eng.cfm?document=17245

Canadian Environmental Assessment Agency. (n.d.). Hearing order questions and answers. Retrieved from http://gatewaypanel.review-examen.gc.ca/clfnsi/fq/hrngrdrq-eng.html\#s1q2

Carvalho, A. (2007). Ideological cultures and media discourses on scientific knowledge: Re-reading news on climate change. Public Understanding of Science, 16(2), $223-243$.

Cerin, P. (2002). Communication in corporate environmental reports. Corporate Social Responsibility \& Environmental Management, 9(1), 46-65. 
Chen, S., \& Gunster, S. (2016). "Ethereal carbon": Legitimizing liquefied natural gas in British Columbia. Environmental Communication, 10(3), 305-321.

Chouliaraki, L., \& Fairclough, N. (1999). Discourse in late modernity: Rethinking critical discourse analysis. Edinburgh: Edinburgh University Press.

Clarke, T. (2008). Tar sands showdown: Canada and the new politics of oil in an age of climate change. Toronto: J. Lorimer \& Co.

Cmeciu, C. (2014). Discursive legitimation of profit and social benefit in annual reports. Romanian Journal of Journalism \& Communication, 9(1/2), 55-61.

Coupland, C. (2005). Corporate social responsibility as argument on the web. Journal of Business Ethics, 62(4), 355-366.

Creswell, J.W. (2014). Research design: Qualitative, quantitative, and mixed approaches (4th ed.). Thousand Oaks, CA: Sage.

Crotty, M. (1998). The foundations of social research: Meaning and perspective in the research process. London: Sage.

Davidson, D. J., \& Gismondi, M. (2011). Challenging legitimacy at the precipice of energy calamity. New York: Springer New York.

Denzin, N. (2004). Postmodernism and deconstructionism. In W. K. Carroll (Ed.), Critical strategies for social research (pp. 232-245). Toronto: Canadian Scholars' Press.

de Vries, G., Terwel, B.W., Ellemers, N., \& Daamen, D. (2015). Sustainability or profitability? How communicated motives for environmental policy affect public perceptions of corporate greenwashing. Corporate Social Responsibility and Environmental Management, 22(3), 142-154. 
Dörnyei, Z. (2007). Research methods in applied linguistics: Quantitative, qualitative, and mixed methodologies. Oxford: Oxford University Press.

Dobson, S., \& Asadollahi, A. (2014). Fossil fuel subsidies: An analysis of Federal financial support to Canada's oil sector. Calgary: Pembina Institute.

Doern, G. B. (2005). Political-economic context. In G. B. Doern (Ed.), Canadian energy policy and the struggle for sustainable development (pp. 3-50). Toronto: University of Toronto Press.

Dogwood Initiative. (2009, August 17). Letter. Retrieved from https://www.ceaaacee.gc.ca/050/documents/38188/38188E.pdf

Dunmire, P. (2005). Preempting the future: Rhetoric and ideology of the future in political discourse. Discourse \& Society, 16(4), 481-513.

Elsbach, K.D. (1994). Managing organizational legitimacy in the California cattle industry: The construction and effectiveness of verbal accounts. Administrative Science Quarterly, 39, 57-88.

Enbridge. (2005, April 14). Enbridge and PetroChina sign Gateway pipeline cooperation agreement. Retrieved from http://www.enbridge.com/MediaCentre/News.aspx?yearTab=en2005\&id=224841 $\underline{7}$

Enbridge. (2005, October 14). Kitimat, B.C., selected as end-site location for Enbridge's Gateway project. Retrieved from http://www.enbridge.com/MediaCentre/News.aspx?yearTab=en2005\&id=224837 $\underline{6}$ 
Enbridge Northern Gateway Project Joint Review Panel. (2013a). Environmental Assessment. Retrieved from http://gatewaypanel.review-examen.gc.ca/clfnsi/dcmnt/rcmndtnsrprt/rcmndtnsrprtvlm2chp8-eng.html

Enbridge Northern Gateway Project Joint Review Panel. (2013b). Potential conditions: Questions and answers. Retrieved from http://gatewaypanel.reviewexamen.gc.ca/clf-nsi/fq/cndtns-eng.html

Enbridge Northern Gateway Project Joint Review Panel. (2013c). Connections: Report of the Joint Review Panel for the Enbridge Northern Gateway Project (Vol 1). Retrieved from www.neb-one.gc.ca

Enbridge Northern Gateway Project Joint Review Panel. (2013d). Considerations: Report of the Joint Review Panel for the Enbridge Northern Gateway Project (Vol 2). Retrieved from www.neb-one.gc.ca

Esler, C. (2013). The operations of power: Federal government discourse and the Northern Gateway Pipeline (Master's thesis). Available from ProQuest Dissertations and Theses database.

Fairclough, N. (1989). Language and power. New York: Longman Publishing. Fairclough, N. (1992). Discourse and social change. Cambridge, UK: Polity Press. Fairclough, N. (1993). Critical discourse analysis and the marketization of public discourse: The universities. Discourse \& Society, 4(2), 133-186.

Fairclough, N. (1995a). Media discourse. London: Edward Arnold. Fairclough, N. (1995b). Critical discourse analysis: The critical study of language. New York: Longman Publishing. 
Fairclough, N. (1998). Political discourse in the media: An analytical framework. In A. Bell \& P. Garrett (Eds.), Approaches to media discourse (pp. 142-162). Oxford: Blackwell.

Fairclough, N. (2001). Language and power (2nd ed.). New York: Longman.

Fairclough, N., \& Wodak, R. (1997). Critical discourse analysis. In T. van Dijk (Ed.), Discourse as social interaction, discourse studies: A multidisciplinary introduction, Vol. 2 (pp. 258-284). London: Sage.

Fekete, J. (2012, August 7). Harper says science, not politics will decide Northern Gateway fate. Financial Post. Retrieved from www.business.financialpost.com

Fisheries and Oceans Canada.(2012). Response to the joint review panel's information request No. 1 to Fisheries and Oceans Canada. Retrieved from https://docs.nebone.gc.ca/l1eng/llisapi.dll/fetch/2000/90464/90552/384192/620327/624911/701102/822884/E 7-2-2 - Fisheries and Oceans Canada -

_Response_to_the_JRPs_IR_Request_No._1_to_Fisheries_and_Oceans_Canada_ -_A2T8V7.pdf?nodeid $=822885 \&$ vernum $=-2$

Fitzpatrick, M. (2012, January 26). Oilsands 'allies' and 'adversaries' named in federal documents. CBC News. Retrieved from http://www.cbc.ca/news/politics/oilsands$\underline{\text { allies-and-adversaries-named-in-federal-documents-1.1156539 }}$

Fowler, R., \& Kress, G. (1979). Critical Linguistics. In R. G. Fowler., G. R. Kress., A. A. Trew., \& R. I. Y. Hodge (Eds.), Language and control (pp. 185-213). London: Routledge \& Kegan Paul Ltd.

Fox, R., \& Fox, J. (2004). Organizational discourse. Westport: Praeger. 
Frynas, G. (2009). Beyond corporate social responsibility: Oil multinationals and social challenges. Cambridge: Cambridge University Press.

Fuoli, M. (2012). Assessing social responsibility: A quantitative analysis of Appraisal in BP's and IKEA's social reports. Discourse \& Communication, 6(1), 55-81.

Gateway hearing cancelled after protesters greet panel. (2012, April 2). CBC News.

Retrieved from http://www.cbc.ca/news/canada/british-columbia/gatewayhearing-cancelled-after-protesters-greet-panel-1.1289416

Gee, J.P. (1990). Social linguistics and literacies: Ideology in discourses. London: Taylor \& Francis.

Gee, J.P. (2005). An introduction to discourse analysis: Theory and method. New York: Routledge.

Gee, J.P. (2012). Discourse Versus discourse. In C.A. Chappelle (Ed.), The encyclopedia of applied linguistics (pp. 1-5). Retrieved from http://onlinelibrary.wiley.com.proxy.library.carleton.ca/doi/10.1002/97814051984 $\underline{\text { 31.wbeal0332/abstract }}$

Geppert, M. (2003). Sensemaking and politics in MNCs: A comparative analysis of vocabularies within the global manufacturing discourse in one industrial sector. Journal of Management Inquiry, 12(4), 312-329.

Ghobadian, A., Money, K., \& Hillenbrand, C. (2015). Corporate responsibility research: Past--present--future. Group \& Organization Management, 40(3), 271-294.

Given, L. (2008). Emergent Themes. J. N. Williams (Ed.), The SAGE encyclopedia of qualitative research methods. Retrieved from 
http://methods.sagepub.com/reference/sage-encyc-qualitative-researchmethods/n129.xml

Glasson, J., Therivel, R., \& Chadwick, A. (2013). Introduction to environmental impact assessment. London: Routledge.

Government of Canada. (2012) Economic action plan 2012, jobs growth and long-term prosperity. Retrieved from http://www.budget.gc.ca/2012/plan/pdf/Plan2012eng.pdf

Guimarães-Costa N., \& Pina e Cunha, M. (2008). The atrium effect of website openness on the communication of corporate social responsibility. Corporate Social Responsibility and Environmental Management, 15, 43-51.

Gunster, S., \& Saurette, P. (2014). Storylines in the sands: News, narrative, and ideology in the Calgary Herald. Canadian Journal of Communication, 39(3), 333.

Hahn, R., \& Lülfs, R. (2014). Legitimizing negative aspects in GRI-oriented sustainability reporting: A qualitative analysis of corporate disclosure strategies. The Journal of Business Ethics, 123, 401-420.

Halliday, M.A.K. (1985). An introduction to functional grammar. London: Arnold.

Halliday, M.A.K. (1993). The act of meaning. Language, communication and social meaning, 7-21.

Halliday, M.A.K. (2003). Introduction: On the "architecture" of human language. In J. Webster (Ed.), On language and linguistics (vol.3). London and New York: Continuum.

Hansen, A. (2015). Promising directions for environmental communication research. Environmental Communication, 9(3), 384-391. 
Hartelius, E.J., \& Browning, L.D. (2008). The application of rhetorical theory in managerial research: A literature review. Management Communication Quarterly, 22(1), 13-39.

Harvey, D. (2007). A brief history of neoliberalism. Oxford: Oxford University Press.

Heinze, N., \& Hu, Q. (2006). The evolution of corporate web presence: A longitudinal study of large American companies. International Journal of Information Management, 26, 313-325.

Heres, D. R., Jack, D., \& Salon, D. (2014). Do public transport investments promote urban economic development? Evidence from bus rapid transit in Bogotá, Colombia. Transportation, 41(1), 57-74.

Hodge, R., \& Kress, G. (1979). Language as ideology. London: Routledge.

Hodge, R., \& Kress, G. (1988). Social semiotics. Cambridge, UK: Polity Press.

Holden, M. (2013). Pipe or perish: Saving an oil industry at risk. Canada West Foundation. Retrieved from: http://cwf.ca/publications-1/pipe-or-perish

Holder, J. (2014, August 20). The Northern Gateway Pipeline is critical to Canada's economic future. The Huffington Post. Retrieved from http://www.huffingtonpost.ca/janet-holder/northern-gatewaypiepline b 5515630.html

Houston, S. (2013, January 30). Take national pipeline perspective. The Vancouver Sun. Retrieved from http://www.vancouversun.com/business/2035/take+national+pipeline+perspective /7889855/story.html 
Hume, M. (2013, April 3). Enbridge pipeline opponents say hearings unfair. The Globe and Mail. Retrieved from http://www.theglobeandmail.com/report-onbusiness/industry-news/energy-and-resources/enbridge-pipeline-opponents-sayhearings-unfair/article10702169/

Hunter, J. (2012, April 1). First nations school protests Northern Gateway pipeline. The Globe and Mail. Retrieved from http://www.theglobeandmail.com/news/britishcolumbia/first-nations-school-protests-northern-gateway-pipeline/article4097140/

Iedema, R., \& Wodak, R. (1999). Introduction: organizational discourses and practices. Discourse \& Society, 10(1), 5-19.

Insch, A. (2008). Online communication of corporate environmental citizenship: A study of New Zealand's electricity and gas retailers. Journal of Marketing Communications, 14(2), 139-153. http://doi.org/10.1080/13527260701858505

Jäger, S. (2001). Discourse and knowledge: Theoretical and methodological aspects of a critical discourse and dispositive analysis. In R. Wodak \& M. Meyer (Eds.), Methods of critical discourse analysis (pp. 32-62). London: Sage.

Jakopovich, D. (2009). Uniting to win: Labor-environmental alliances. Capitalism Nature Socialism, 20(2), 74-96.

Janks, H. (2005). Language and the design of texts. English Teaching, 4(3), 97-110.

Jasanoff, S. (2005). Judgement under siege: The three-body problem of expert legitimacy. In P. Weingart \& S. Maasen (Eds.), Democratization of expertise? Exploring novel forms of scientific advice in political decision-making (pp. 209224). Dordrecht, Netherlands: Springer. 
Jay, S., Jones, C., Slinn, P., \& Wood, C. (2007). Environmental impact assessment: Retrospect and prospect. Environmental impact assessment review, 27(4), 287300.

Jewitt, C. (2006). Technology, literacy and learning: A multimodal approach, London: Routledge.

Jones, R. H. (2009). Technology and sites of display. In C. Jewitt (Ed.), The Routledge handbook of multimodal analysis (pp. 114-126). New York: Routledge.

Joustenvirta, M. (2011). Setting boundaries for corporate social responsibility: FirmNGO relationship as discursive legitimation struggle. Journal of Business Ethics, $102,57-75$.

Judd, A. (2014, June 18). 4 opponents of Northern Gateway Pipeline arrested at protest at MP's office. Global News. Retrieved from http://globalnews.ca/news/1403151/opponents-of-northern-gateway-pipelineprotest-at-mps-office/

Karl, T. L. (1997). The paradox of plenty: Oil booms and petro-states. Berkeley: University of California Press.

Kent, P., \& Caron, G. (2012). [Letter to the Joint Review Panel]. Retrieved from https://docs.neb-one.gc.ca/ll-eng/llisapi.dll/fetch/2000/130635/835957/A2V5E2__Lettre_concerning_the_joint_review_of_the_Northern_Gateway_Pipeline_Proje ct.pdf?_gc_lang=en\&nodeid $=835958 \&$ vernum $=0$

Kimball, M., Chester, M., Gino, C., \& Reyna, J. (2013). Assessing the potential for reducing life-cycle environmental impacts through transit-oriented development 
infill along existing light rail in Phoenix. Journal of Planning Education and Research, 33(4), 395-410.

Kinsley, C. (2013, June 12). Quesnel needs oil as much as anywhere else. QuesnelCariboo Observer. Retrieved from http://greenspiritstrategies.com/quesnel-needsoil-as-much-as-anywhere-else/

Klein, N. (2014). This changes everything: Capitalism vs. the climate. Toronto: Knopf Canada.

Kolk, A. (2008). Sustainability, accountability and corporate governance: exploring multinationals' reporting practices. Business Strategy and the Environment, 17(1), $1-15$.

Kolk, A., Walhain, S., \& van de Wateringen, S. (2001). Environmental reporting by the Fortune Global 250: Exploring the influence of nationality and sector. World Development, 34(5), 789-801.

Kress, G. (2003). Literacy in the new media age. New York: Routledge.

Kress, G., \& van Leeuwen, T. (1996/2006). Reading images: The grammar of visual design. London: Routledge.

Kress, G., \& van Leeuwen, T. (2001). Multimodal discourse: The modes and media of contemporary communication. London: Routledge.

Landon, S., \& Smith, C. (2010). Energy prices and Alberta government revenue volatility. C.D. Howe Institute Commentary, 313, 1-25.

Lavoie, J. (2012, December 13). Spectators barred from Enbridge hearings in Victoria. Time Colonist. Retrieved from: 
http://www.timescolonist.com/news/local/spectators-barred-from-enbridgehearings-in-victoria-1.27695

Le Billon, P., \& Vandecasteyen, R. (2013). (Dis)connecting Alberta's Tar Sands and British Columbia's north coast. Studies in Political Economy, 91(0), 35-57.

Lemke, J.L. (2005). Textual politics: Discourse and social dynamics. London: Taylor \& Francis.

Lischinsky, A. (2015). What is the environment doing in my report? Analyzing the environment-as-stakeholder thesis through corpus linguistics. Environmental Communication, 9(4), 539-559.

Liu, S. (2015). Advertising greenness in China: A critical discourse analysis of the corporate online advertising discourse (Doctoral dissertation). Retrieved from Edinburgh Research Archive at https://www.era.lib.ed.ac.uk/handle/1842/11738

Livesey, S. (2001). Eco-identity as discursive struggle: Royal Dutch/Shell, Brent Spar, and Nigeria. The Journal of Business Communication, 38(1), 58-91.

Livesey, S. M. (2002). Global warming wars: Rhetorical and discourse analytic approaches to Exxonmobil's corporate public discourse. Journal of Business Communication, 39(1), 117-146.

Ljunggren, D. (2012, February 10). Harper vows to ensure Northern Gateway is built. Financial Post. Retrieved from http://business.financialpost.com/news/harpervows-to-ensure-northern-gateway-is-built

Maass, P. (2010). Crude world: The violent twilight of oil. New York: Vintage.

Machin, D., \& Mayr, A. (2012). How to do critical discourse analysis: A multimodal introduction. London: SAGE. 
Machin, D., \& van Leeuwen, T. (2007). Global media discourse: A critical introduction. New York: Routledge.

Mas, S., \& Payton, L. (2014, June 17). Northern Gateway pipeline approved with 209 conditions. CBC News. Retrieved from http://www.cbc.ca/news/politics/northerngateway-pipeline-approved-with-209-conditions-1.2678285

Matz, J., \& Renfrew, D. (2015). Selling "fracking": Energy in depth and the Marcellus shale. Environmental Communication, 9(3), 288-306.

Mautner, G. (2005). Time to get wired: Using web-based corpora in critical discourse analysis. Discourse \& Society, 16(6), 809-828.

Mayr, A. (2008). Introduction: Power, discourse and institutions. In A. Mayr (Ed.), Language and power: An introduction to institutional discourse (pp. 1-25). London, UK: Continuum.

McCarthy, S., Chase, S., \& Jang, B. (2014, June 17). Canadian government approves Enbridge's controversial Northern Gateway pipeline. The Globe and Mail. Retrieved from http://www.theglobeandmail.com/report-on-business/industrynews/energy-and-resources/northern-gateway-decision/article19180594/

McCreary, T. A., \& Milligan, R. A. (2014). Pipelines, permits, and protests: Carrier Sekani encounters with the Enbridge Northern Gateway Project. Cultural Geographies, 21(1), 115-129.

McKibben, B. (2012). Global warming's terrifying new math. Rolling Stone. Retrieved from http://www.rollingstone.com/politics/news/global-warmings-terrifying-newmath-20120719 
Moore, D. (2013, August 12). First nations representative abandons Northern Gateway review process. The Globe and Mail. Retrieved from http://www.theglobeandmail.com/news/british-columbia/first-nationsrepresentative-abandons-northern-gateway-review- process/article8169613/

Mortished, C. (2007). Shell rakes in profits from Canadian oil sands unit. The Times. Retrieved from http://www.thetimes.co.uk/tto/business/industries/naturalresources/article2180895 .ece

Munn, R. E. (1979). Environmental Impact Assessment: Principles and Procedures (2nd edition). New York: John Wiley \& Sons Ltd.

National Energy Board. (2014). [Decision statement issued to Northern Gateway Pipelines Inc.]. Retrieved from http://gatewaypanel.review-examen.gc.ca/clf$\underline{\text { nsi/dcmnt/dcsnsttmnt-eng.html }}$

National Energy Board, Canadian Environmental Assessment Board Canada. (n.d.) Enbridge Northern Gateway Project Joint Review Panel: The Project. Retrieved from http://gatewaypanel.review-examen.gc.ca/clf-nsi/bts/prjct-eng.html

Nikiforuk, A. (2010). Tar sands: Dirty oil and the future of a continent. Vancouver: Greystone Books.

Northern Gateway pipeline opponents get say at mega-hearing. (2015, October 1). CBC News. Retrieved from http://www.cbc.ca/news/canada/british-columbia/northerngateway-pipeline-hearing-1.3251780

Omand, G. (2015, October 8). Judges reserve decision on Northern Gateway pipeline approval. The Globe and Mail. Retrieved from 
http://www.theglobeandmail.com/news/british-columbia/northern-gateway-

naysayers-missed-chance-to-oppose-pipeline-industry-group/article26729594/

Patton, M.Q. (2002). Qualitative research and evaluation methods. Thousand Oaks, CA: Sage.

Pauwels, L. (2012). A multimodal framework for analyzing websites as cultural expressions. Journal of Computer-Mediated Communication, 17(3), 247-265.

Pennycook, A. (1994). Incommensurable discourses? Applied Linguistics, 15(2), 115138.

Pennycook, A. (2001). Critical applied linguistics: A critical introduction. London: Lawrence Erlbaum Associates.

Peyton, J., \& Franks, A. (2015). The new nature of things? Canada's conservative government and the design of the new environmental subject. Antipode, $O(00), 1-$ 21.

Phillips, B., \& McQuarrie, F. (2004). Beyond visual metaphor: A new typology of visual rhetoric in advertising. Marketing Theory, 4 (1/2): 113-136.

Phillips, N., Lawrence, T. B., \& Hardy, C. (2004). Discourse and institutions. The Academy of Management Review, 29(4), 635-652.

Pollach, I. (2005). Corporate self-presentation on the WWW: Strategies for enhancing usability, credibility and utility. Corporate Communications: An International Journal, 10(4), 285-301.

Pope, J., Bond, A., Morrison-Saunders, A. \& Retief, F. (2013). Advancing the theory and practice of impact assessment: Setting the research agenda. Environmental Impact assessment review, 41, 1-9. 
Proctor, J. (2016, June 30). Court overturns Northern Gateway pipeline approval. CBC News. Retrieved from http://www.cbc.ca/news/canada/british-columbia/northerngateway-pipeline-federal-court-of-appeal-1.3659561

Protesters arrested at pipeline hearing in Vancouver. (2013, January 15). CBC News. Retrieved from http://www.cbc.ca/news/canada/british-columbia/protestersarrested-at-pipeline-hearing-in-vancouver-1.1302329

Pull Together. (n.d.). Why. Retrieved from http://pull-together.ca/home/

Rally draws thousands to B.C. legislature to oppose Northern Gateway. (2012, October 22). The Globe and Mail. Retrieved from http://www.theglobeandmail.com/news/british-columbia/rally-draws-thousandsto-bc-legislature-to-oppose-northern-gateway/article4628738/

Raso, K., \& Neubauer, R. J. (2016). Managing dissent: Energy pipelines and "New Right” politics in Canada. Canadian Journal of Communication, 41(1).

Rich, J.L. (2016). Drilling is just the beginning: Romanticizing Rust Belt identities in the campaign for shale gas. Environmental Communication, 10(3), 292-304.

Richardson, L., \& Standing Committee on Natural Resources. (2007). The oil sands: Toward sustainable development: Report of the standing committee on natural resources. Retrieved from http://www.parl.gc.ca/HousePublications/Publication.aspx?DocId=2614277\&Lan guage $=$ E $\&$ Mode $=1 \&$ Parl $=39 \&$ Ses $=1 \&$ File $=27$

Ross, G. (2008). Introducing war: Visual analysis of online media discourse on forces and weapons of the Iraq conflict [Master's thesis]. Retrieved from ProQuest Dissertations and Theses database. 
Sallis, J. F., Frank, L. D., Saelens, B. E., \& Kraft, M. K. (2004). Active transportation and physical activity: Opportunities for collaboration on transportation and public health research. Transportation Research Part A: Policy and Practice, 38(4), 249-268.

Scherer, A. G., \& Palazzo, G. (2007). Toward a political conception of corporate responsibility: Business and society seen from a Habermasian perspective. Academy of Management Review, 32(4), 1096-1120.

Scherer, A. G., \& Palazzo, G. (2011). the new political role of business in a globalized world: A review of a new perspective on CSR and its implications for the firm, governance, and democracy. Journal of Management Studies, 48(4), 899-931.

Schlichting, I. (2013). Strategic framing of climate change by industry actors: A metaanalysis. Environmental Communication, 7(4), 493-511.

Smith, G., \& Desmond, J. (2015). Legal backgrounder: What are the Northern Gateway court challenges about? Retrieved from http://wcel.org/sites/default/files/2015-

$\underline{07-}$ 16\%20Backgrounder $\% 20$ on $\% 20$ Applicant $\% 20$ arguments $\% 20$ in $\% 20$ Enbridge $\% 2$ 0JR\%20(final).pdf

Sorenson, C. (2015, January 5). Stephen Harper: Oil's worst enemy. Macleans. Retrieved from http://www.macleans.ca/politics/ottawa/stephen-harper-oils-worst-enemy/

Stamou, A.G., \& Paraskevopolous, S. (2004). Images of nature by tourism and environmentalist discourses in visitor books: A critical discourse analysis of ecotourism. Discourse \& Society, 15(1), 105-129. 
Stefanick, L., \& Shrivastava, M. (2015). Alberta oil and the decline of democracy in Canada. Edmonton, Alberta: AU Press.

Steffek, J. (2009). Discursive legitimation in environmental governance. Forest Policy and Economics, 11(5-6), 313-318.

Stoymenoff, A. (2012, April 24). As Northern Gateway pipeline hearings return to Smithers, community rallies for tar sands protest. Vancouver Observer. Retrieved from http://www.vancouverobserver.com/sustainability/2012/04/24/northerngateway-pipeline-hearings-return-smithers-community-rallies-tar

Suchman, M. C. (1995). Managing legitimacy: Strategic and institutional approaches. The Academy of Management Review, 20(3), 571-610.

Taber, J. (2009, April 7). PM brands Canada an 'energy superpower'. The Globe and Mail. Retrieved from http://www.theglobeandmail.com/news/world/pm-brandscanada-an-energy-superpower/article1105875/

Teo, P. (2000). Racism in the news: A critical discourse analysis of news reporting in two Australian newspapers. Discourse \& Society, 11(1), 7-49.

The Canadian Chamber of Commerce. (n.d.) About us. Retrieved from http://www.chamber.ca/about-us/

The Canadian Chamber of Commerce (2014, June 6) Northern Gateway Pipeline: A project for Canada. Retrieved from http://www.chamber.ca/media/blog/140612northern-gateway-pipeline-a-project-for-Canada/

Thompson, G., \& Hunston, S. (2000). Evaluation: An introduction. In S. Hunston \& G. Thompson (Eds.), Evaluation in text (pp. 1-27). Oxford: Oxford University Press. 
Titscher, S., Meyer, M., Wodak, R., \& Vetter, E (2000). Methods of text and discourse analysis. (Bryan Jenner, Trans.). London: Sage.

Toolan, M. (1996). What is critical discourse analysis and why are people saying such terrible things about it? Language and Literature, 6(2), 83-103.

Topalovic, P., Carter, J., Topalovic, M., \& Krantzberg, G. (2012). Light Rail Transit in Hamilton: Health, environmental and economic impact analysis. Social Indicators Research, 108(2), 329-350.

Tutton, M. (2013, August 8). Harper: Energy East Pipeline would help build Canadian energy security. The Huffington Post. Retrieved from http://www.huffingtonpost.ca/2013/08/08/harper-east-pipelineenergy_n_3727056.html

Tyrwhitt-Drake, H. (1999). Resisting the discourse of critical discourse analysis: Reopening a Hong Kong case study. Journal of Pragmatics, 31(8), 1081-1088.

Uechi, J. (2012, April 8). Online petitions call for stop to Enbridge Northern Gateway pipeline project. Vancouver Observer. Retrieved from http://www.vancouverobserver.com/blogs/earthmatters/2012/04/08/onlinepetitions-call-stop-enbridge-northern-gateway-pipeline-project

Vaara, E. (2014). Struggles over legitimacy in the Eurozone crisis: Discursive legitimation strategies and their ideological underpinnings. Discourse \& Society, 25(4), 500-518.

Vaara, E., \& Tienar, J. (2008). A discursive perspective on legitimation strategies in multinational corporations. Academy of Management Review, 33(4), 985-993. 
Vanderklippe, N. (2012, January 27). Federal documents spark outcry by oil sands critics. The Globe and Mail. Retrieved from http://www.theglobeandmail.com/globeinvestor/federal-documents-spark-outcry-by-oil-sands-critics/article2316087/

van Dijk, T.A. (n.d.). Ideological discourse analysis. Retrieved from http://citeseerx.ist.psu.edu/viewdoc/download?doi=10.1.1.469.5195\&rep=rep1\&t ype $=$ pdf

van Dijk, T. A. (1985). Introduction: The role of discourse analysis in society. In T.A. van Dijk (Ed.), Handbook of discourse analysis: Discourse analysis in society (pp. 1-8). Orlando, FL: Academic Press Inc.

van Dijk, T.A. (1986) Racism in the Press. London: Arnold.

van Dijk, T.A. (1998). Ideology: A multidisciplinary approach. London: Sage.

van Dijk, T. A. (2000). Ideology. London: Sage.

van Dijk, T.A. (2001). Multidisciplinary CDA: A plea for diversity. In R. Wodak \& M. Meyer (Eds.), Methods of critical discourse analysis (pp. 95-120). London, UK: Sage Publications Ltd.

van Dijk, T. A. (2006). Ideology and discourse analysis. Journal of Political Ideologies, 11(2), 115-140.

van Leeuwen, T. (2005). Introducing social semiotics. London: Routledge.

van Leeuwen, T. (2008). Discourse and practice: New tools for critical discourse analysis. Oxford: Oxford University Press.

van Leeuwen, T., \& Kress, G. (2011). Discourse semiotics. In T.A. van Dijk (Ed.), Discourse studies: A multidisciplinary introduction, Vol. 2 (pp. 107-125). London: Sage.

Veltmeyer, H., \& Bowles, P. (2014). Extractivist resistance: The case of the Enbridge oil pipeline project in Northern British Columbia. The Extractive Industries and Society, 1(1), 59-68. 
Weber, J., \& Marley, K. A. (2012). In search of stakeholder salience exploring corporate social and sustainability reports. Business \& Society, 51(4), 626-649.

Weese, B. (2012, April 2). Canadian oil going to Asia, no matter what: Harper. Toronto Sun. Retrieved from www.torontosun.com

Whittington, L. (2012, August 3). Harper moves to streamline B.C. pipeline review process. The Toronto Star. Retrieved from http://www.thestar.com/news/canada/2012/08/03/harper_moves_to_streamline_b c_pipeline_review process.html

Widdowson, H.G. (1995). Discourse analysis: A critical view. Language and Literature, $4(3), 157-172$.

Winter, S. J., Saunders, C., \& Hart, P. (2003). Electronic window dressing: Impression management with websites. European Journal of Information Systems, 12, 309322.

Wodak, R. (2001a). What CDA is about: A summary of its history, important concepts and its developments. In R. Wodak \& M. Meyer (Eds.), Methods of critical discourse analysis (pp. 1-13). London: Sage.

Wodak, R. (2001b). The discourse-historical approach. In R. Wodak \& M. Meyer (Eds.), Methods of Critical Discourse Analysis (pp. 63-95). London: Sage.

Wodak, R. (2002). Aspects of critical discourse analysis. Retrieved from http://userpages.uni-koblenz.de/ diekmann/zfal/zfalarchiv/zfal36_1.pdf

Wodak, R. (2011). Critical linguistics and critical discourse analysis. In J. Zienkowski, J. Ostman \& J. Verschueren (Eds.), Discursive Pragmatics: A Handbook of Pragmatics (pp. 50-70). Amsterdam: John Benjamin Publishing Company. 
Wodak, R., \& Meyer, M. (2001). Critical discourse analysis: History, agenda, theory and methodology. In R. Wodak \& M. Meyer (Eds.), Methods of CDA (pp. 2-21). London: Sage.

Ziek, P. (2009). Making sense of CSR communication. Corporate Social Responsibility and Environmental Management, 16, 137-145. 